EUGÊNIO JOSÉ BORSATTI

ESTUDO DO SISTEMA DUTO-TROCADOR DE CALOR COMPACTO PARA VEÍCULOS DE COMPETIÇÃO

São Paulo

2010 
EUGÊNIO JOSÉ BORSATTI

\section{ESTUDO DO SISTEMA DUTO-TROCADOR DE CALOR COMPACTO PARA VEÍCULOS DE COMPETIÇÃO}

Dissertação apresentada à Escola

Politécnica da Universidade de São Paulo para obtenção do título de Mestre em Engenharia

Área de concentração:

Engenharia Mecânica de Energia e Fluidos

Orientador:

Prof. Dr. Antonio Luís de Campos Mariani

São Paulo 
Este exemplar foi revisado e alterado em relação à versão original, sob responsabilidade única do autor e com a anuência de seu orientador.

São Paulo, 15 de outubro 2010.

Assinatura do autor

Assinatura do orientador

FICHA CATALOGRÁFICA

Borsatti, Eugênio José

Estudo do sistema duto-trocador de calor compacto para veículos de competição / E.J. Borsatti. -- ed.rev. -- São Paulo, 2010.

$152 \mathrm{p}$.

Dissertação (Mestrado) - Escola Politécnica da Universidade de São Paulo. Departamento de Engenharia Mecânica.

1.Trocadores de calor 2.Aerodinâmica 3.Engenharia automotiva 4.Veículos de competição l.Universidade de São Paulo. Escola Politécnica. Departamento de Engenharia Mecânica II.t. 


\section{DEDICATÓRIA}

Aos meus pais, José e Tereza, pelo empenho e dedicação para meu crescimento.

Aos professores do Liceu de Artes e Ofícios de São Paulo, em especial ao Prof. Wilson Failla, pela excelente base para minha formação. 


\section{AGRADECIMENTOS}

A Deus, pela infinita bondade, por permitir meu desenvolvimento pessoal e intelectual, por apresentar constantemente caminhos e oportunidades.

Ao Prof. Dr. Antonio Luís de Campos Mariani, por suas valiosas orientações e contribuições, pelo incentivo constante, pelo exemplo de profissionalismo e dedicação e pela amizade sincera (e também pela inesquecível metáfora sobre o jantar após trinta dias no deserto...).

Ao Prof. Dr. Marcelo A. L. Alves e aos membros da equipe Poli Racing de 2010, pela oportunidade de trabalho em conjunto, pela colaboração com os testes e desenhos, pelas excelentes conversas sobre projeto de veículos e amizade. Em especial aos que colaboraram no ensaio experimental e preparação de desenhos: Alziro Neto, André Luiz (Alasca), Eduardo Gonzalo, Eduardo Quadros (John), Ivan Sanches, Lucas Steinle, Marcelo Prieto, Pedro Bussadore (Pi), Rafael Klumpp e Sérgio Hashiba.

Aos funcionários da Escola Politécnica, Douglas e Laércio, pelas diversas contribuições para a realização dos ensaios no laboratório.

Ao apoio oferecido pela empresa Multivac, com o fornecimento de dutos flexíveis e materiais para realização do ensaio experimental.

Aos funcionários da Biblioteca da Engenharia Mecânica, em especial à Fátima e Marina, pelas diversas colaborações ao longo do desenvolvimento desse trabalho.

Aos colegas da General Motors do Brasil, pela oportunidade de realizar esse estudo e pelas inestimáveis colaborações e direcionamentos. Particularmente aos amigos engenheiros Filipe F. Buscariolo, Luís Fernando Rallo, Milton Negrini, Nelson Quim, Rodolpho A. Campos, Rodrigo M. Freitas e aos gerentes Fabiana Mikami, Roberto P. 
Ramos e Sidney S. Ramos, pelas contribuições específicas e pela oportunidade de aprendizado em engenharia.

Aos amigos do Liceu de Artes e Ofícios de São Paulo, pelo aprendizado em conjunto, pelas incontáveis contribuições e indispensável amizade. Em especial ao "grande" Leandro E. Bosquim, pela ajuda durante o período do exame de qualificação.

Ao amigo Roberto Girolla, pelas valiosas conversas sobre os "objetos cintilantes", pelos artigos que muito me ajudaram e pelas orientações que foram essenciais para a continuidade e conclusão dessa dissertação e de outros projetos.

À querida Roberta, pelos cuidados, carinho, pelo exemplo de simplicidade, amor e dedicação em diversos momentos da elaboração desse trabalho. 


\section{RESUMO}

Esse estudo procura integrar as áreas de termodinâmica, transferência de calor e aerodinâmica no desenvolvimento de veículos de alto desempenho. É proposta uma ferramenta computacional que auxilie a análise de alternativas de trocadores de calor compactos, parte integrante do sistema de arrefecimento veicular. $\mathrm{O}$ aplicativo desenvolvido, denominado TROCALC, tem dois modos de uso: para colaborar no projeto de um trocador de calor ou para avaliar o desempenho de um trocador existente. Estruturado por um conjunto de equações e parâmetros com base na metodologia de Kays e London (1984), no primeiro modo esse aplicativo fornece alternativas de trocadores a partir dos dados de rejeição de calor por parte do motor e dos valores de vazão e temperatura dos fluidos envolvidos. Para o modo de avaliação de desempenho, além dos dados de entrada já mencionados, é necessário o detalhamento da geometria de superfície do trocador para calcular a quantidade de calor que o radiador é capaz de remover do sistema e comparar com o valor de fluxo de calor rejeitado pelo motor. É adotado um estudo de caso que considerou um veículo de competição da Fórmula SAE para investigar a eficácia do aplicativo TROCALC na análise de desempenho e na definição de novas alternativas para o trocador de calor dedicado àquele automóvel. Foram realizados ensaios em laboratório com a medição de valores para a rejeição de calor, vazão em massa de ar e perda de pressão no trocador existente. Os resultados validaram a ferramenta computacional e oferecem uma redução de $37 \%$ nas dimensões do trocador. Por fim é feita uma análise aerodinâmica para o conjunto duto-trocador de calor, que é uma solução típica utilizada em veículos de competição, integrando este conjunto à geometria da carenagem do veículo. Quatro alternativas, incluindo nova geometria para a carenagem do duto-trocador são investigadas do ponto de vista aerodinâmico com o auxílio de programa de dinâmica dos fluidos computacional (CFD). Nesta investigação, o objetivo é melhorar o comportamento de parâmetros relacionados ao escoamento de ar junto do sistema duto-trocador de calor, mantendo um bom comportamento para o arrasto total do veículo.

Palavras chave: Trocadores de calor. Aerodinâmica. Engenharia automotiva. Veículos de competição. 


\section{ABSTRACT}

This study looks for the integration of thermodynamics, heat transfer and aerodynamics in the high-performance vehicles development. A computational tool that facilitates the compact heat exchanges analysis, part of the vehicle cooling system, is proposed. The application denominated TROCALC has two different modes of use: one for compact heat exchanger design and another one to evaluate existent heat exchangers performance. This program, which is structured by a set of equations and parameters based on the Kays and London (1984) methodology, provides heat exchangers alternatives through the input of the engine heat rejection, fluids temperature and mass flow (air and coolant). The tool is also capable of providing a performance analysis of an existent compact heat exchanger. In this case, besides of the inputs already mentioned, it is necessary to inform the surface geometry data of the actual heat exchanger to calculate the heat rejection capacity and compare to the established value of the engine. The case study of the Formula SAE is proposed in order to investigate the efficiency of TROCALC in performance analysis and definition of new alternatives for the Formula SAE's dedicated heat exchanger. Laboratory tests were performed in order to achieve experimentally the heat rejection, mass flow (air side) and pressure drop values in the current heat exchanger. The results validated the computational tool and offered a reduction of $37 \%$ in the heat exchanger's dimensions. At last, aerodynamic analyses are performed for the duct-compact heat exchanger system, a typical solution adopted in race cars that is the integration of this set to the vehicle's bodywork. Four alternatives are researched from the aerodynamic perspective with the computational fluid dynamics program support (CFD), including a new geometry for the duct. In this research, the aim is the improvement of parameters' behavior related to the air flow around the duct-compact heat exchanger system, keeping a good behavior to the total drag of the vehicle.

Keywords: Heat exchangers. Aerodynamics. Automotive engineering. Race cars. 


\section{LISTA DE ILUSTRAÇÕES}

Figura 1 - Forças num objeto bidimensional submerso: (a) força de pressão, (b) força viscosa e (c) força resultante (arrasto e sustentação) (MUNSON; YOUNG; OKIISHI, 1997).

Figura 2 - Variação da relação de arrasto aerodinâmico e arrasto total (arrasto aerodinâmico e resistência ao rolamento) em função da velocidade (HUCHO et al., 1976)

Figura 3 - Representação esquemática de trocador de calor de escoamento cruzado mostrando a diferença de direção de vazão de fluido quente e frio (KAYS; LONDON, 1984).

Figura 4 - Representação esquemática do funcionamento de sistema de arrefecimento veicular, modificado de Kays e London (1984).

Figura 5 - Vista frontal do veículo Corvette C6 Z06 em testes em túnel de vento (FROLING; JUECHTER, 2006)

Figura 6 - Comparação de curvas de rejeição de calor dos motores disponíveis para o veículo Corvette C6 Z06 (FROLING; JUECHTER, 2006). "LS2" e "LS7" são as denominações utilizadas para os tipos de motores disponíveis para o veículo 44

Figura 7 - Geometria detalhada da parte frontal do veículo proposto para avaliação em CFD (GATTEI; ROSSI; CARDILE, 2008).

Figura 8 - Resultado da análise em CFD para a distribuição de velocidade do fluxo de ar na saída do radiador (GATTEI; ROSSI; CARDILE, 2008). 
Figura 9 - Comparação do erro relativo apresentado para o cálculo da temperatura de saída do líquido de arrefecimento em relação aos dados verificados experimentalmente (GATTEI; ROSSI; CARDILE, 2008).

Figura 10 - Aumento médio percentual do arrasto de arrefecimento medido em testes em túnel de vento com simulação de pista, em comparação com piso estacionário, para diferentes tipos de veículos (WICKERN et al., 2006). .50

Figura 11 - Exemplo de curvas de desempenho de motor (FUKUI et al., 2007) ......55

Figura 12- Modelo de veículo da Fórmula SAE e detalhe da entrada de ar para o radiador, antes da modificação proposta (CHRISTOFFERSEN; SÖDERBLOM; LÖFDAHL, 2008). 55

Figura 13 - Vistas superior dos três casos estudados: caso (1) apresenta o duto totalmente selado; caso (2) apresenta geometria semelhante ao primeiro porém não completamente selado; e caso (3) apresenta a configuração que favorece o aumento de pressão na entrada do radiador (CHRISTOFFERSEN; SÖDERBLOM; LÖFDAHL, 2008).

Figura 14 - Metodologia para projeto de trocador de calor (KAYS; LONDON, 1984)

Figura 15 - Efetividade de transferência de calor em função do número de unidades de transferência para trocadores de calor de escoamento cruzado com os dois fluidos não misturados (KAYS; LONDON, 1984) 62

Figura 16 - Transferência de calor e fator de atrito para um trocador de calor compacto com tubos e aletas circulares, superfície denominada CF-7.0-5/8J (KAYS; LONDON, 1984; INCROPERA; DEWITT, 1998).

Figura 17 - Imagem do aplicativo TROCALC que contém os dados de entrada para o cálculo de projeto de trocador de calor compacto. .71 
Figura 18 - Imagem do aplicativo TROCALC que contém os dados das propriedades fixas dos fluidos e material do radiador, para o cálculo de projeto de trocador de calor compacto.

Figura 19 - Imagem do aplicativo TROCALC que contém os dados de geometria do núcleo do trocador de calor e a tabela contendo o fator "j" de Colburn para transferência de calor e o fator de atrito para uma dada geometria em função do número de Reynolds. .74

Figura 20 - Gráfico que relaciona a efetividade de transferência de calor $(\varepsilon)$ com 0 número de unidades de transferência (NUT) e a razão entre as taxas de capacidade calorífica $\left(\mathrm{C}_{\min } / \mathrm{C}_{\max }\right)$, reproduzido conforme o trabalho de Kays e London (1984). ..76

Figura 21 - Superfície que relaciona a efetividade de transferência de calor $(\varepsilon)$ com o número de unidades de transferência (NUT) e a razão entre as taxas de capacidade calorífica $\left(\mathrm{C}_{\min } / \mathrm{C}_{\max }\right)$. 76

Figura 22 - Matriz para auxílio ao cálculo do número de unidades de transferência (NUT) com base nos dados de efetividade $(\varepsilon)$ e a razão entre as taxas de capacidade calorífica $\left(\mathrm{C}_{\min } / \mathrm{C}_{\max }\right)$. .77

Figura 23 - Imagem do aplicativo TROCALC que contém os cálculos e iterações para a área e a perda de pressão do fluxo de ar pelo radiador. 78

Figura 24 - Imagem da configuração do trocador de calor e a representação das dimensões principais. 80

Figura 25 - Imagem do aplicativo TROACALC que contém os cálculos finais para análise de desempenho de trocadores de calor.

Figura 26 - Veículo Fórmula SAE desenvolvido pela equipe Poli Racing. 84 
Figura 27 - Gráfico da relação de potência e rotações por minuto do motor Yamaha ${ }^{\circledR}$ de $400 \mathrm{~cm}^{3}$. A curva azul representa a condição original de funcionamento do motor; a vermelha representa a adequação do motor às restrições impostas pelas regras da Fórmula SAE. 90

Figura 28 - Imagem apresentando o suporte desenvolvido para a realização dos testes experimentais. .96

Figura 29 - Coifa desenvolvida para a realização dos testes experimentais. 97

Figura 30 - Imagem apresentando o desenvolvimento da selagem no contorno do radiador.

Figura 31 - (a) Suportes desenvolvidos para proporcionar a medição de temperatura e pressão; (b) tubo metálico flexível para junção do gerador de fluxo com os equipamentos desenvolvidos para medição. 99

Figura 32 - Imagem da instrumentação, do conjunto motor-ventilador e parte da tubulação pertencente ao aparato gerador de fluxo do Laboratório de Instrumentação em Mecânica dos Fluidos. 101

Figura 33 - Bancada interna do aparato experimental com gerador de fluxo de ar, extraído de Mariani (1995). 102

Figura 34 - Instrumentos de medição de temperatura do fluxo de ar no momento em que eram verificadas as temperaturas de entrada (LD) e saída (LE) de ar pelo radiador. 102

Figura 35 - Bancada externa disposta com os computadores interligados com os instrumentação para medições de temperatura e registro dos dados. 103

Figura 36 - Gráfico de Temperatura $\left({ }^{\circ} \mathrm{C}\right)$ x Tempo (s) para a condição de "marcha lenta". 107 
Figura 37 - Gráfico de Temperatura $\left({ }^{\circ} \mathrm{C}\right) \times$ Tempo (s) para a condição de primeira marcha a $20 \mathrm{~km} / \mathrm{h}$.

Figura 38 - Gráfico de Temperatura $\left({ }^{\circ} \mathrm{C}\right) \times$ Tempo (s) para a condição de segunda marcha a $40 \mathrm{~km} / \mathrm{h}$. 109

Figura 39 - Gráfico da relação de pressão diferencial em função da velocidade para as condições avaliadas experimentalmente, similar à adotada por Gattei, Rossi, Cardile (2008) e Quim (2007).

Figura 40 - Protótipo A: desenho do veículo Fórmula SAE com configuração original.

Figura 41 - Protótipo B: desenho do veículo Fórmula SAE com novos dutos, trocador de calor com dimensões reduzidas fixado na mesma posição do protótipo $A$. 116

Figura 42 - Protótipo C: desenho do veículo Fórmula SAE com duto similar ao protótipo $\mathrm{B}$, trocador de calor com novas dimensões e posicionamento perpendicular ao eixo longitudinal do veículo.

Figura 43 - Protótipo D: desenho do veículo Fórmula SAE com duto e trocador de calor com dimensões e posicionamento idênticos ao protótipo $\mathrm{C}$, mas com vedação no contorno do radiador.

Figura 44 - Vista lateral do duto que contém o trocador de calor instalado no protótipo A.

Figura 45 - Vista lateral do modelo proposto para o duto lateral das três propostas (protótipos B, C e D), considerando o conceito de duto divergente-convergente....118 Figura 46 - Distribuição de pressões sobre o modelo, representando o protótipo A. 
Figura 47 - Distribuição de pressões sobre o modelo, representando os protótipos B, C e D.

Figura 48 - Gráfico de distribuição de pressões na região frontal do trocador para o protótipo A. 124

Figura 49 - Gráfico de distribuição de pressões na região posterior do trocador para o protótipo A. 124

Figura 50 - Gráfico de distribuição de pressões na região frontal do trocador para o protótipo B. 125

Figura 51 - Gráfico de distribuição de pressões na região posterior do trocador para o protótipo B. 126

Figura 52 - Gráfico de distribuição de pressões na região frontal do trocador para o protótipo C. 126

Figura 53 - Gráfico de distribuição de pressões na região posterior do trocador para o protótipo C. 127

Figura 54 - Gráfico de distribuição de pressões na região frontal do trocador para o protótipo $\mathrm{D}$ 127

Figura 55 - Gráfico de distribuição de pressões na região posterior do trocador para o protótipo D. 128

Figura 56 - Vista superior da distribuição de vetores de velocidade na região próxima ao radiador para o protótipo $\mathrm{A}$. 129

Figura 57 - Vista superior da distribuição de vetores de velocidade na região próxima ao radiador para o protótipo $\mathrm{B}$. 130 
Figura 58 - Vista superior da distribuição de vetores de velocidade na região próxima ao radiador para o protótipo C.................................................................130

Figura 59 - Vista superior da distribuição de vetores de velocidade na região próxima ao radiador para o protótipo $\mathrm{D}$. 


\section{LISTA DE TABELAS}

Tabela 1 - Efetividade $(\varepsilon)$ em função da razão entre as taxas de capacidade térmica, Cmin/Cmax, e do número de unidades de transferência, NUT (KAYS; LONDON, 1984) para a condição de escoamento cruzado com os dois fluidos não misturados.

Tabela 2 - Quadro resumo para aplicação de método $\varepsilon$-NUT para as duas finalidades: análise de desempenho e projeto de trocador de calor; modificado de Kays e London (1984) 64

Tabela 3 - Quadro de apresentação dos eventos estáticos e dinâmicos da competição Fórmula SAE e as pontuações máximas possíveis para cada evento, conforme SAE (2009). 86

Tabela 4 - Balanço de energia em termos de perdas de calor por unidade de potência útil considerando alguns tipos de motores, conforme Plint e Martyr (1999).

Tabela 5 - Quadro da relação de marchas e as devidas rotações por minuto do motor considerando as velocidades específicas. 90

Tabela 6 - Apresentação de dados medidos para temperaturas de bulbo seco, TBS, bulbo úmido, TBU, e pressões para os ensaios realizados com veículo Fórmula SAE. 105

Tabela 7 - Apresentação de resultados de vazão, velocidade, massa específica e número de Reynolds para os ensaios realizados com veículo Fórmula SAE. 106

Tabela 8 - Registro das informações dos testes. 
Tabela 9 - Relação de pressão diferencial em função da velocidade para as condições avaliadas experimentalmente com veículo Fórmula SAE.

Tabela 10 - Áreas das seções transversais do duto que contém o trocador de calor nos protótipos $B, C$ e $D$ e razão entre as áreas.

Tabela 11 - Resumo dos dados de vazão em massa, área frontal projetada, força e coeficiente de arrasto para os quatro casos estudados. 121

Tabela 12 - Resumo dos dados calculados pela ferramenta computacional, dos testes experimentais e da simulação numérica com base no veículo Fórmula SAE da equipe Poli Racing. 139

Tabela 13 - Planilha de auxílio ao cálculo de troca de calor em testes de sistemas de arrefecimento veicular. 152 


\section{LISTA DE ABREVIATURAS E SIGLAS}

$\begin{array}{ll}\text { CAD } & \text { Computer Aided Design } \\ \text { CDS } & \text { Cooling system Dynamic Simulation } \\ \text { CFD } & \text { Computational Fluid Dynamics } \\ \text { DMLT } & \text { Diferença Média Logarítmica de Temperatura } \\ \text { EPUSP } & \text { Escola Politécnica da Universidade de São Paulo } \\ \text { FC } & \text { Ferramenta Computacional } \\ \text { ICS } & \text { Intelligent Cooling System } \\ \text { INMETRO } & \text { Instituto Nacional de Metrologia, Normalização e Qualidade } \\ & \text { Industrial } \\ \text { IPEM } & \text { Instituto de Pesos e Medidas } \\ \text { KERS } & \text { Kinetic Energy Recovery System } \\ \text { LMTD } & \text { Log Mean Temperature Difference } \\ \text { LTU } & \text { Lawrence Technological University } \\ \text { NTU } & \text { Number of Transfer Units } \\ \text { NUT } & \text { Número de Unidades de Transferência } \\ \text { SAE } & \text { Society of Automobile Engineers } \\ \text { SD } & \text { Specific Dissipation } \\ \text { SI } & \text { Sistema Internacional } \\ \text { TBS } & \text { Temperatura de bulbo seco } \\ \text { TBU } & \text { Temperatura de bulbo úmido }\end{array}$




\section{LISTA DE SÍMBOLOS}
A
Área total de transferência de calor $\left[\mathrm{m}^{2}\right]$
$A_{a}$
Área total das aletas $\left[\mathrm{m}^{2}\right]$
$A_{c}$
Área livre mínima para o escoamento entre as aletas do
trocador de calor $\left[\mathrm{m}^{2}\right]$
$A_{\text {fr }}$
Área frontal do trocador de calor $\left[\mathrm{m}^{2}\right]$
C
Calor específico [kJ/kg.k]
C
Taxa de capacidade térmica [W/K]
$C_{D}$
Coeficiente de arrasto aerodinâmico, adimensional
$\mathrm{CL}$
Coeficiente de sustentação aerodinâmica, adimensional
$C_{p}$
Calor específico a pressão constante [kJ/kg.K]
$\mathrm{D}$
Força de arrasto [N]
da
Diferencial de área $\left[\mathrm{m}^{2}\right]$
$d f_{x}$
Diferencial de força resultante na direção $x[\mathrm{~N}]$
$\mathrm{df}_{\mathrm{y}}$
Diferencial de força resultante na direção y $[\mathrm{N}]$
$d_{h}$
Diâmetro hidráulico da passagem para o escoamento [mm]
Fator de atrito ou coeficiente de perda distribuida, adimensional
$\mathrm{F}$
Fator de correção do método DMLT, adimensional
G
Velocidade mássica $\left[\mathrm{kg} / \mathrm{s} . \mathrm{m}^{2}\right]$
h
Coeficiente de transferência de calor por convecção $\left[\mathrm{W} / \mathrm{m}^{2} . \mathrm{K}\right]$
Entalpia por unidade de massa [J/kg]
L
Força de sustentação [N]
$\mathrm{P}$
Pressão [N/ $\left.\mathrm{m}^{2}\right]$
$\dot{m}$
Vazão em massa $\left[\mathrm{kg} / \mathrm{m}^{2}\right]$
q
Taxa de transferência de calor [W]
$\operatorname{Re}$
Número de Reynolds, adimensional
T
Temperatura $\left[{ }^{\circ} \mathrm{C}\right][\mathrm{K}]$
U
Coeficiente global de transferência de calor $\left[\mathrm{W} / \mathrm{m}^{2} . \mathrm{K}\right]$;
Velocidade $[\mathrm{m} / \mathrm{s}]$
$U_{\infty}$
Velocidade do ar ao longe $[\mathrm{m} / \mathrm{s}]$ 
Volume do trocador de calor $\left[\mathrm{m}^{3}\right]$

$v_{e}$ Volume específico do fluido $\left[\mathrm{m}^{3} / \mathrm{kg}\right.$ ]

$x, y$ Coordenadas cartesianas [m]

\section{LISTA DE SÍMBOLOS - LETRAS GREGAS}

$\varepsilon$

$\delta T$

$\sigma$

$\alpha$

$\tau_{p}$

$\theta$

$\rho$

$\eta_{f}$

$\eta_{0}$
Efetividade de um trocador de calor, adimensional

Diferencial de temperatura $\left[{ }^{\circ} \mathrm{C}\right][\mathrm{K}]$

Razão entre a área livre mínima para escoamento do ar através das aletas e a área frontal normal ao escoamento, adimensional Razão entre a área de transferência de calor e o volume do trocador de calor $\left[\mathrm{m}^{2} / \mathrm{m}^{3}\right.$ ] Tensão de cisalhamento $\left[\mathrm{N} / \mathrm{m}^{2}\right]$

Ângulo de referência ao longo de um corpo [rad] [ $\left.{ }^{\circ}\right]$

Massa específica $\left[\mathrm{kg} / \mathrm{m}^{3}\right]$

Eficiência da aleta, adimensional

Eficiência da superfície global, adimensional 


\section{LISTA DE ÍNDICES}

e

S

f

q

m

$\max$

$\min$
Entrada do trocador de calor

Saída do trocador de calor

Fluido frio

Fluido quente

Valor médio

Valor máximo

Valor mínimo 


\section{SUMÁRIO}

1. INTRODUÇÃO

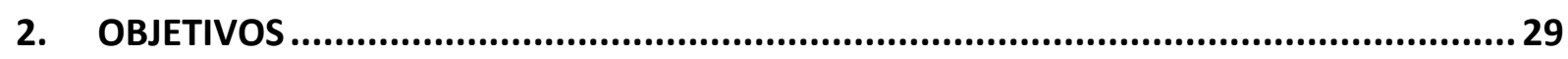

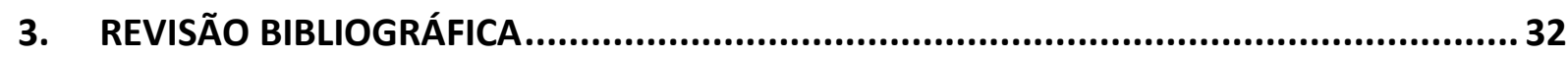

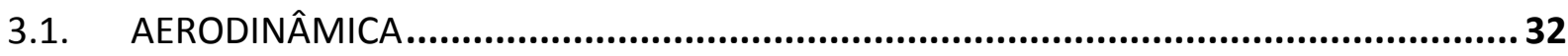

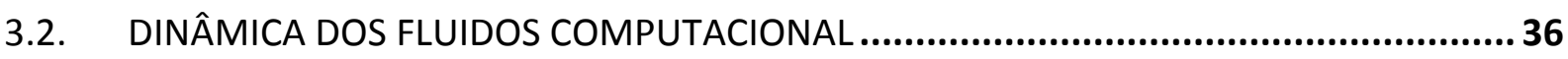

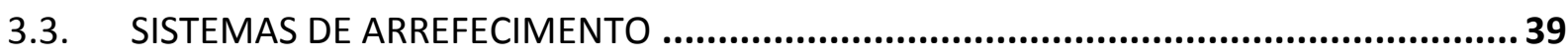

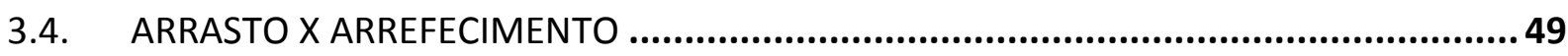

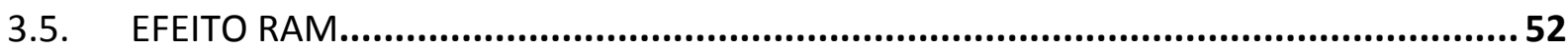

3.6. A COMPETIÇÃO FÓRMULA SAE …………………….........................................53

4. METODOLOGIA E MODELAGEM DE TROCADORES DE CALOR ……............................58

4.1. METODOLOGIA PARA DIMENSIONAMENTO E ANÁLISE DE DESEMPENHO DE UM

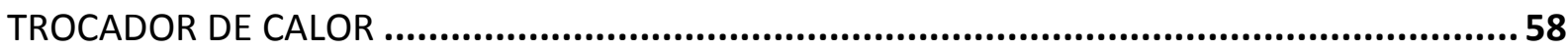

4.2. MÉTODOS PARA SOLUÇÃO DE PROBLEMAS RELACIONADOS A TROCADORES DE

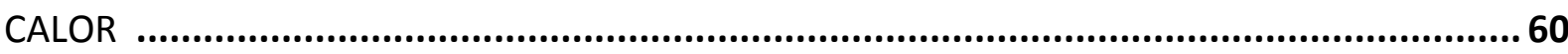

4.2.1. Método Efetividade-NUT ..................................................................................6

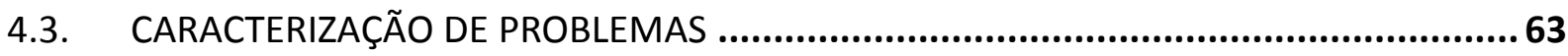

4.4. SELEÇÃO DE GEOMETRIA NO PROJETO DE TROCADOR DE CALOR COMPACTO ...........65

4.5. AVALIAÇÃO DE PERDA DE PRESSÃO ....................................................................67

5. DESENVOLVIMENTO DE FERRAMENTA COMPUTACIONAL PARA ANÁLISE DE

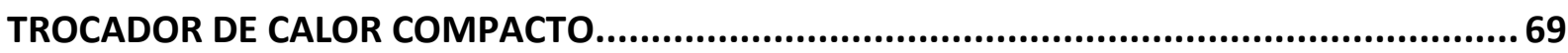

5.1. APLICATIVO PARA PROJETO DE TROCADOR DE CALOR COMPACTO ..........................70

5.1.1. Dados de entrada ........................................................................................... 71

5.1.2. Propriedades dos fluidos ........................................................................... 72 
5.1.3. Geometria do núcleo do trocador de calor ................................................. 73

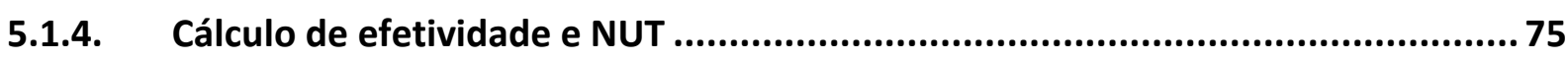

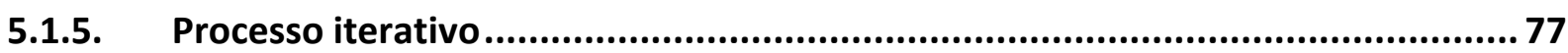

5.2. ÁNALISE DE DESEMPENHO DE TROCADORES DE CALOR COMPACTO ......................79

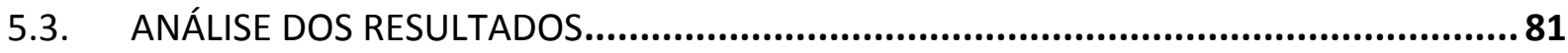

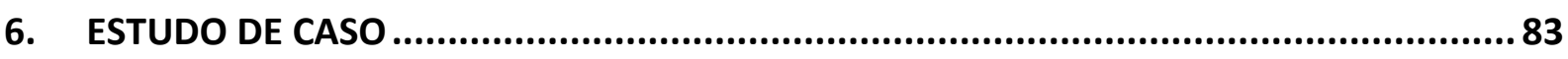

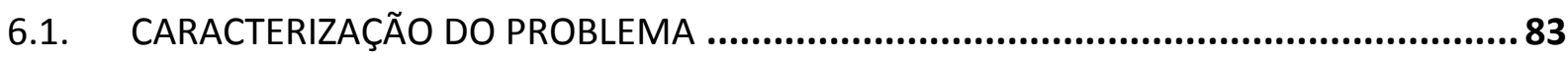

6.1.1. As regras da competição e o sistema de arrefecimento ..................................84

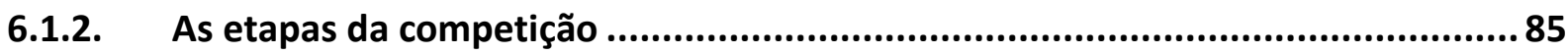

6.2. ANÁLISE DE DESEMPENHO DE TROCADOR DE CALOR COMPACTO ORIGINAL

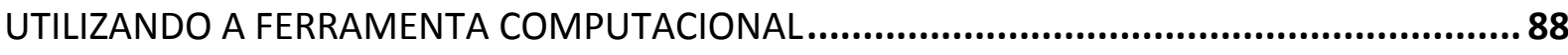

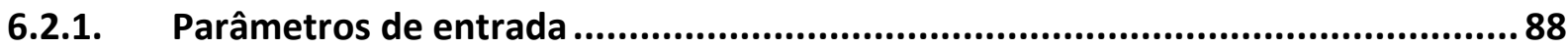

6.2.2. Apresentação e análise de resultados .................................................... 91

6.3. PROJETO DE NOVO TROCADOR DE CALOR COMPACTO UTILIZANDO FERRAMENTA

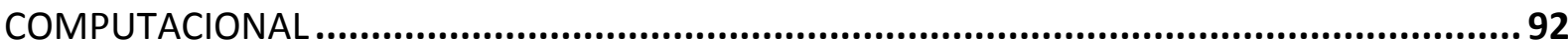

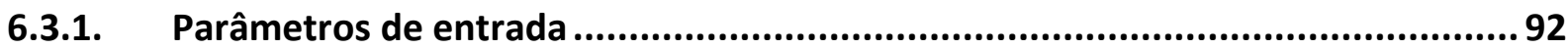

6.3.2. Apresentação e análise de resultados .........................................................93

6.4. ENSAIO EXPERIMENTAL DO TROCADOR DE CALOR ORIGINAL...............................95

6.4.1. Preparação de ensaios e fabricação de dispositivos..........................................96

6.4.2. Instrumentação e procedimento para aquisição de dados ................................99

6.4.3. Apresentação de dados medidos e resultados calculados ............................... 104

6.4.3.1. Medição de propriedades psicrométricas, perdas de pressão e vazão do ar . 105

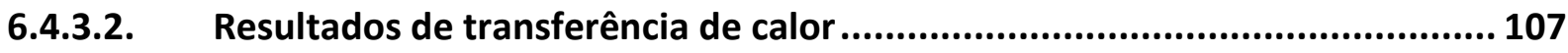

6.4.3.3. Considerações e análise dos resultados experimentais .............................. 111

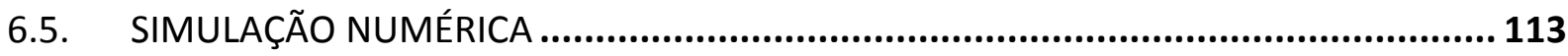


6.5.1. Alternativas para o sistema duto-trocador de calor

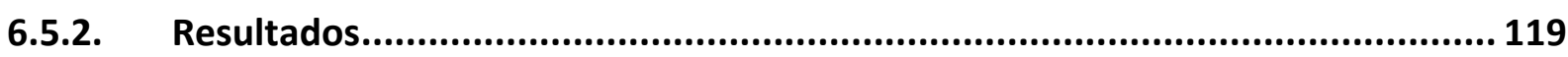

6.5.2.1. Força e coeficiente de arrasto e vazão em massa de ar .............................. 120

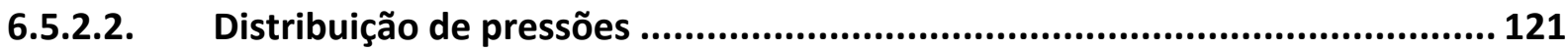

6.5.2.3. Visualização de escoamento de ar a partir do campo de velocidades ........... 129

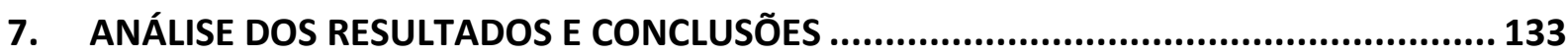

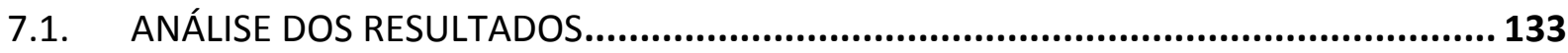

7.1.1. A ferramenta computacional TROCALC ..................................................... 134

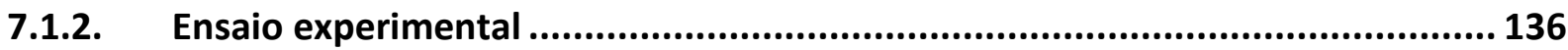

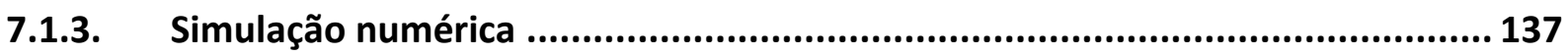

7.1.4. Comparação dos resultados ..................................................................... 138

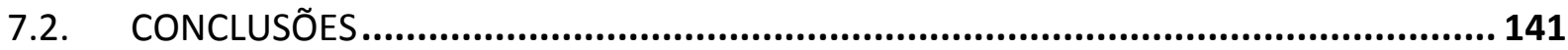

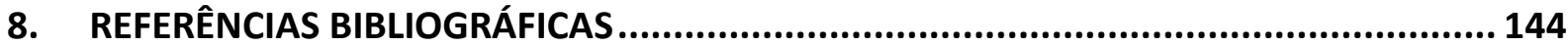

APÊNDICE A - Procedimento de Testes para Medição de Troca de Calor e de Perda de Pressão em Radiadores de Sistema de Arrefecimento Veicular. 


\section{INTRODUÇÃO}

Em determinadas competições de veículos ocorrem disputas por décimos e milésimos de segundos. Para muitas categorias, os projetos desses veículos atingiram um grande refino tecnológico, exigindo muitas vezes uma grande soma em investimentos por parte das equipes em busca de inovação e melhoria contínua de seus diversos subsistemas. Para ilustrar, podem-se citar alguns exemplos de subsistemas automotivos e soluções que obtiveram notável evolução, desenvolvidos e aplicados em veículos de competição, ao longo dos últimos 60 anos:

- Uso de materiais compostos de alta resistência na confecção de elementos de carroceria como a fibra de carbono;

- Aplicação de metais leves como o alumínio e titânio para aplicação em elementos do motor;

- Desenvolvimento de sistemas de recuperação de energia dissipada em frenagens para aumento de potência e diminuição do consumo de combustível (Kinetic Energy Recovery System - KERS);

- Suspensão ativa que faz uso de elementos pneumáticos e dispensa o uso de molas helicoidais;

- Sistema auxiliar de mapeamento de circuito para auxílio de seleção de marchas de transmissão semi-automática;

- Eletrônica embarcada auxiliando subsistemas e oferecendo ajustes durante as provas;

- Combustíveis de alta octanagem;

- Introdução de elementos aerodinâmicos como aerofólios e difusores que alteram consideravelmente a geometria dos veículos e aperfeiçoam a estabilidade em alta velocidade.

Em contrapartida a essa busca por qualidade e desempenho, geralmente as equipes e empresas envolvidas necessitam de reduções de custos que acabam por gerar uma escassez de recursos, seja material ou pessoal, para o desenvolvimento de 
projetos complexos, como são os de veículos de competição. Para o sucesso de uma equipe, faz-se necessária uma criteriosa administração desses recursos de forma que cada subsistema seja desenvolvido de forma plena e não comprometa sua confiabilidade e durabilidade.

Investir em eventos de competição representa não somente a exposição de uma marca mas também a oportunidade para aperfeiçoamento ou desenvolvimento de tecnologias e de pessoas. Muitos dos dispositivos e inovações desenvolvidos em pistas de corrida geralmente são aplicados posteriormente em veículos de passeio e de transporte.

A pesquisa e o desenvolvimento que em particular envolve a aerodinâmica e a termodinâmica são de elevada importância para a área automotiva, considerando-se principalmente as competições que envolvem carros e protótipos. Durante os últimos 30 anos, os aerodinamicistas tem tido forte influência no desenvolvimento de veículos comerciais, de passeio e de competição, objetivando menor arrasto, menor consumo de combustível, maior eficiência dinâmica (dirigibilidade) e maior fluxo de ar pelo sistema de arrefecimento. E, dependendo do projeto, pode-se incluir também a necessidade de desenvolver veículos com apelo visual diferenciado, dado o interesse comercial envolvido.

Para que o projeto ou estudo de soluções na área de aerodinâmica se desenvolva, são requeridas muitas horas de testes em túneis de vento com o intuito de avaliar e validar propostas para atualização de seus protótipos. Tais testes demandam modelos detalhados, análise criteriosa dos dados obtidos e a verificação do desempenho das propostas com testes de protótipos em pista, exigindo das equipes vultosas quantias de seu orçamento dedicado a essas atividades. Muitos esforços têm sido investidos com o objetivo de reduzir o orçamento de projetos, tais como a implementação de novas técnicas para projeto e validação com 0 uso de computadores ou com a utilização de componentes desenvolvidos em projetos anteriores. Com isso, é possível reduzir o número de protótipos a serem avaliados ou o número de eventos experimentais. 
Para veículos destinados a competições, assim como para veículos de passeio, as condições de trabalho do motor exigem um projeto eficiente e dedicado para o sistema de arrefecimento. Como parte de um projeto complexo, é função desse sistema garantir a faixa de temperatura necessária para o funcionamento adequado do motor, considerando também outras preocupações como, por exemplo, a influência aerodinâmica que os elementos desse sistema proporcionam ao veículo.

O escopo deste trabalho envolve estes dois aspectos de um projeto de um veículo de alto desempenho: o desenvolvimento do sistema de arrefecimento e seu impacto no desempenho aerodinâmico do veículo. A proposta está focada em desenvolver uma ferramenta para viabilizar alternativas de soluções para trocadores de calor do sistema de arrefecimento e a avaliação destas do ponto de vista da aerodinâmica do veículo. Para verificar de forma aplicada a funcionalidade desta ferramenta propôsse realizar um estudo de caso a partir de veículos da Fórmula SAE, competição promovida no Brasil e em outros países pela Sociedade dos Engenheiros da Mobilidade - SAE.

A SAE, originalmente identificada por Society of Automobile Engineers, organização sem fins lucrativos fundada em 1905 nos Estados Unidos, tem como um de seus objetivos a integração e divulgação de atividades relacionadas aos meios da mobilidade. Em mais de 100 anos de existência, a instituição é uma das principais referências para normas, padrões e publicações relativas ao setor automotivo e aeroespacial em todo o mundo. Dentre os membros fundadores da SAE destacamse líderes do meio automotivo e da então nascente indústria aeronáutica, como Henry Ford, Thomas Edson e Orville Wright.

Um dos eventos organizados por essa instituição é a Fórmula SAE, competição para estudantes de graduação e pós-graduação em engenharia que iniciou-se na América do Norte em 1981. O objetivo desse evento é de estimular os futuros engenheiros a planejar, projetar, construir e competir entre universidades com um veículo de competição. É um projeto complexo com problemas que envolvem a administração de recursos e os diversos ramos do conhecimento de engenharia, como por exemplo, estruturas, materiais, processos, simulações e planejamento de 
atividades. Os trabalhos envolvendo esses campos têm suma importância para a formação dos futuros engenheiros.

Os veículos da Fórmula SAE são equipados com motores de combustão interna disponíveis no mercado e os membros das equipes os preparam de acordo com as regras estipuladas pela instituição. Uma das alterações solicitadas pelas normas da competição é a limitação da seção transversal da tomada de ar instalada antes da câmara de combustão do motor. Os times geram alternativas de forma a compensarem a perda de potência gerada por essa restrição. Com as modificações apontadas, o sistema de arrefecimento que foi originalmente projetado para esse motor torna-se inadequado. Faz-se necessária então uma análise cuidadosa da rejeição de calor da nova configuração do motor e a implementação de um sistema de arrefecimento ajustado a essa nova característica. Esses fatos motivaram a utilização de modelos de veículos dessa competição como estudo de caso para o desenvolvimento da ferramenta computacional proposta, aplicada à solução de problemas relacionados com a aerodinâmica e a sistemas de arrefecimento de motores automotivos. 


\section{OBJETIVOS}

O presente trabalho, que se propõe estudar o sistema de arrefecimento de um veículo, dirige seu foco para os seguintes componentes deste sistema: o trocador de calor e o duto formado por uma carenagem que contém o radiador.

As metas são estudar métodos e modelos que relacionam as variáveis envolvidas no processo de transferência de calor, de modo a viabilizar meios e ferramentas computacionais e experimentais para projetar ou analisar desempenho de trocadores de calor correlacionando as variáveis selecionadas.

Esta pesquisa também pretende avaliar o comportamento aerodinâmico do conjunto duto-trocador de calor para diferentes geometrias e configurações procurando conhecer como são estabelecidos os campos de velocidade e de pressão do lado do ar.

Assim podem ser explicitados os seguintes objetivos centrais para este estudo:

- Estudar os métodos que permitem relacionar a taxa de transferência de calor aos parâmetros associados à geometria, fluidos e materiais utilizados em trocadores de calor compactos;

- Desenvolver uma ferramenta computacional na forma de um aplicativo que utilize um método dentre os estudados e que possa ser utilizada para projeto e para avaliação de desempenho de trocadores de calor;

- Adotar um estudo de caso para analise de desempenho e para projeto de trocador de calor de um veículo de competição Fórmula SAE. São consideradas as condições particulares relacionadas às atividades do protótipo em suas diversas provas da competição, em que é possível a aplicação dos conceitos estudados e fazer o uso da ferramenta computacional desenvolvida; 
- Realizar o estudo aerodinâmico para o conjunto duto-trocador de calor compacto, permitindo a comparação de alternativas para configurações geométricas a partir dos resultados obtidos através de simulações numéricas;

Como objetivos secundários para esse trabalho estão relacionadas as seguintes atividades:

- Realizar testes da ferramenta computacional denominada TROCALC (Trocadores de Calor Compactos) aplicando-a ao trocador de calor selecionado como estudo de caso;

- Planejar e realizar ensaio experimental do trocador de calor montado em veículo, estabelecer as condições de teste, fabricar dispositivos e organizar procedimentos e instrumentação;

- Realizar o tratamento de dados dos ensaios para obtenção de resultados com incertezas e possibilitando a comparação com aqueles obtidos a partir do aplicativo TROCALC;

- Preparar protótipos tridimensionais para o sistema duto-trocador de calor acoplado ao veículo;

- Realizar simulações numéricas para o escoamento de ar para diferentes propostas alternativas de arranjos e geometrias do conjunto duto-trocador de calor compacto;

- Discutir os resultados obtidos no estudo de caso para as três investigações: ferramenta computacional TROCALC, ensaio experimental e simulações numéricas;

- Adequar bancos de dados empíricos que relacionam diferentes geometrias para uso em um aplicativo computacional. Converter as relações publicadas 
por Kays e London (1984) em curvas com equações definidas, facilitando sua utilização por um programa de computador;

- Estabelecimento de metodologia experimental para ensaio estático de trocador de calor instalado em veículo. 


\section{REVISÃO BIBLIOGRÁFICA}

\subsection{AERODINÂMICA}

As inovações pesquisadas durante muitos anos em pista de testes, túneis de vento, e em corridas de carros são incorporados anualmente aos novos lançamentos da indústria automobilística, ocasião em que o mercado consumidor de larga escala tem acesso aos resultados, como por exemplo, às formas arredondadas dos automóveis que, ao mesmo tempo em que proporcionam um design mais agradável, permitem um melhor desempenho aerodinâmico (MENOTTI; BARREIRO, 1999).

As características aerodinâmicas de um veículo têm influência em muitos aspectos de sua operação. Essas áreas de influência envolvem desempenho, segurança, refinamento e confiabilidade e pode ser convenientemente organizado através dos seguintes itens:

- Desempenho e economia;

- Estabilidade;

- Visibilidade, do ponto de vista do usuário;

- Conforto dos passageiros (ventilação e nível de ruído);

- Refrigeração de componentes (trocadores de calor, sistema de marchas e freios).

A interação entre a aerodinâmica e o sistema de arrefecimento de um veículo de competição ocorre de modo expressivo, e no presente estudo é considerada e analisada. 
Um programa de desenvolvimento requer uma gama de técnicas e ferramentas especializadas em testes aerodinâmicos. Embora algum trabalho possa ser cumprido em campo de provas, a necessidade de se realizar ensaios em condições controladas e repetitivas determina o uso de um laboratório apropriado ( $\mathrm{HUCHO}$, 1987; CARR, 1995).

As forças de sustentação e arrasto em veículos de superfície (como carros, caminhões e bicicletas) têm se tornado cada vez mais importantes devido à possibilidade de obter um menor consumo de combustível e melhorar as características de mobilidade com a evolução do projeto destes veículos (MUNSON; YOUNG; OKIISHI, 1997).

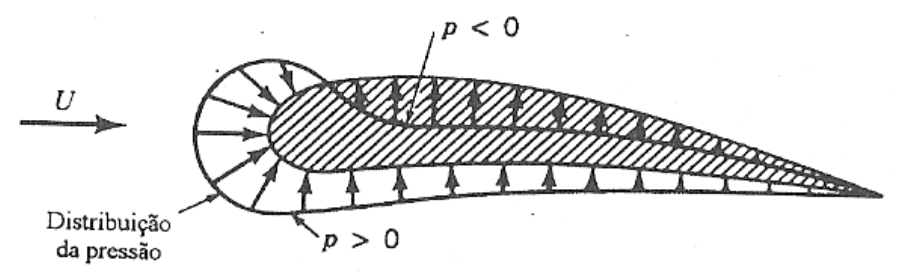

(a)

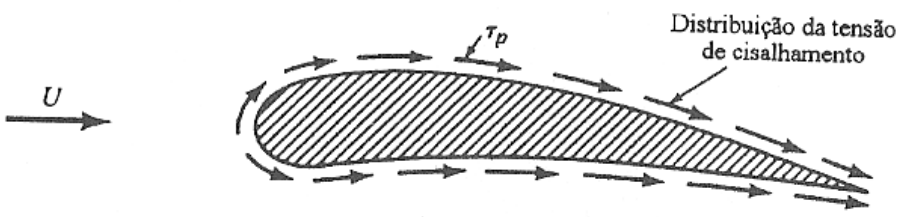

(b)

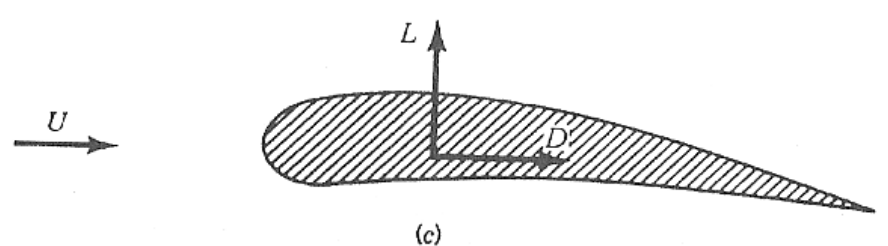

(c)

Figura 1 - Forças num objeto bidimensional submerso: (a) força de pressão, (b) força viscosa e (c) força resultante (arrasto e sustentação) (MUNSON; YOUNG; OKIISHI, 1997).

Forças aerodinâmicas podem ser mensuradas fazendo-se uso de método computacional ou experimental. Experimentos são geralmente conduzidos em túneis 
de vento com o auxílio de sistema de balanças com o intuito de se obter tais medidas. Contudo, métodos computacionais podem calcular os coeficientes aerodinâmicos através de avaliações dos modelos matemáticos com boa confiabilidade de resultados. Geralmente as medidas de pressão, velocidade e temperatura são informações que os programas computacionais têm capacidade de gerar nas diversas regiões do modelo avaliado (BAYRAKTAR; BAYRAKTAR, 2006). Conhecer o comportamento dos campos de velocidade e pressão nas regiões próximas aos trocadores de calor, nos dutos que conduzem o ar, pode auxiliar a melhorar o projeto desses sistemas.

Hucho (1998) menciona que em 1920, a média do coeficiente de arrasto dos veículos era de 0,7 enquanto que, para os atuais veículos de produção, esse número foi reduzido para menos que 0,3 . Essa melhoria aconteceu principalmente após a crise do petróleo da década de 70 . Inicialmente, os engenheiros aproveitavam conceitos navais e aeronáuticos para aplicação das formas aerodinâmicas em veículos. Porém, devido à grande proximidade do solo, tais conceitos não foram de grande sucesso. Após os anos 70 , muitos desses conceitos foram adequadamente desenvolvidos e gradativamente foram obtidos menores coeficientes de arrasto.

Em sua dissertação, Quim (2007) apresenta que a redução de arrasto representa a maior contribuição para a economia de combustível. Há referência a um estudo realizado por Emmelmann e Berneburg (1990) que indica que o arrasto aerodinâmico contribui com $40 \%$ das perdas relacionadas ao consumo. É apontada também a evolução do veículo Opel Vectra, que apresentou uma redução progressiva do coeficiente de arrasto de 26\% durante o período de 1979 a 1988. Outro exemplo é o veículo Opel Kadett, que apresentava $C_{D}$ de 0,51 no modelo de 1975 e passou a 0,30 no modelo de 1985 , o que significa uma diferença de pouco mais de $40 \%$.

Estudos recentes com veículos em túnel de vento, investigações numéricas e a combinação desses estudos têm demonstrado que os efeitos de pequenas mudanças nos parâmetros de um carro de corrida podem apresentar efeitos significantes em aerodinâmica. No estudo de Hurst apud Jasinski e Selig (1998) 
mostra que a mudança de 1 grau no ângulo de câmber da roda de um veículo de competição pode alterar a força de sustentação negativa (downforce) em mais de $2 \%$. Esses estudos mostram a importância da correta modelagem desses veículos em túneis de vento e através de métodos computacionais (JASINSKI; SELIG, 1998).

Conforme apresentado por Hucho et al. (1976), a relação entre arrasto aerodinâmico e a resistência total externa ao movimento de um veículo, que considera resistência de rolagem e aerodinâmica, é mostrada na Figura 2. Acima da velocidade de 40 milhas por hora (aproximadamente $65 \mathrm{~km} / \mathrm{h}$ ), a proporção que representa o arrasto aerodinâmico é de mais de 50\%. Dependendo do coeficiente de arrasto e da massa, o arrasto aerodinâmico contabiliza 80 ou $90 \%$ para velocidades mais altas.

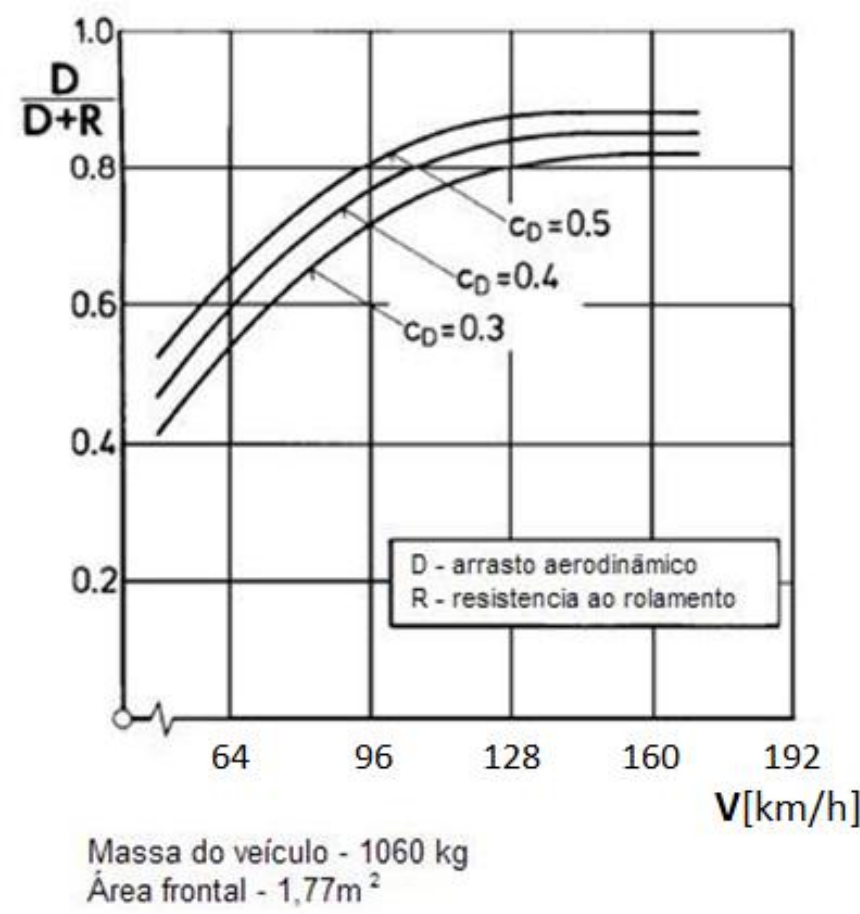

Figura 2 - Variação da relação de arrasto aerodinâmico e arrasto total (arrasto aerodinâmico e resistência ao rolamento) em função da velocidade (HUCHO et al., 1976)

As componentes das forças aerodinâmicas em um veículo são geradas por diversas fontes. O corpo de um veículo de passeio propriamente dito pode, em certas 
ocasiões, ser aproximado a um corpo rombudo que gera uma grande resistência com o ar. Porém alguns componentes tais como espelhos retrovisores, pneus, sistemas de freio e de arrefecimento, devido à geometria ou à particularidade de funcionamento, contribuem consideravelmente para 0 aumento do arrasto aerodinâmico. Em função desses elementos, podem-se dividir as causas da força de arrasto em dois grupos: a contribuição que provém de elementos externos, como espelhos e pneus, e o outro grupo em que é causada por componentes internos, tais como sistema de arrefecimento e freios (BAYRAKTAR; BAYRAKTAR, 2006). Através do estudo do grau de influência individual dos componentes na resistência aerodinâmica do veículo, pode-se modificar a sua geometria otimizando assim a sua eficiência (MENOTTI; BARREIRO, 1999).

Muitas vezes há propostas de otimizar-se a configuração geométrica de um veículo, modificar as tomadas de ar para possibilitar um menor arrasto aerodinâmico. Contudo esse tipo de solução pode provocar uma redução no processo de troca de calor dos sistemas de arrefecimento. A busca do equilíbrio entre ganhos e perdas na interação aerodinâmica e sistemas de refrigeração que contam com o ar ambiente é um grande desafio para o projeto de ambas as áreas. O presente trabalho pretende contribuir neste campo.

\subsection{DINÂMICA DOS FLUIDOS COMPUTACIONAL}

Até recentemente, o túnel de vento era a ferramenta fundamental para avaliação de aerodinâmica de veículos. Entretanto, os desenvolvimentos mais recentes em hardware de computadores permitiram 0 desenvolvimento de ferramentas computacionais para simulações que foram incluídas no processo de desenvolvimento aerodinâmico veicular. Com a disponibilidade desses recursos, essas avaliações preliminares dos projetos tornaram-se mais rápidas e conseqüentemente o uso de CFD (Computational Fluid Dynamics) cresceu de forma considerável (BAYRAKTAR e BAYRAKTAR, 2006). 
Dinâmica dos fluidos computacional ou CFD é a análise de sistemas envolvendo movimentação de fluidos, transferência de calor e outros fenômenos associados tais como reações químicas, através de simulação por computador. Essa técnica é poderosa e abrange em larga escala diversas áreas de aplicações, industriais e não industriais. Desde os anos 60 a indústria aeroespacial tem integrado técnicas de CFD junto ao projeto, pesquisa e desenvolvimento de aeronaves e motores a jato. Mais recentemente esses métodos têm sido aplicados em projetos de motores de combustão interna e câmaras de combustão de turbinas a gás. Além disso, os fabricantes de veículos têm utilizado tais técnicas de modo rotineiro com o intuito de prever forças de arrasto e o fluxo de ar no compartimento do motor e no interior do veículo (VERSTEEG e MALALASEKERA, 2007).

Os códigos de CFD estão estruturados com algoritmos numéricos que podem resolver problemas de mecânica dos fluidos. Em razão de oferecer um melhor acesso para solução de problemas, os pacotes de códigos comerciais apresentam uma sofisticada interface para que o usuário possa incluir os parâmetros dos problemas e examinar posteriormente os resultados (VERSTEEG e MALALASEKERA, 2007).

Tais pacotes possuem estruturas de programas semelhantes: pré-processamento, processamento propriamente dito e pós-processamento. Para processamento, existem linhas distintas de técnicas de solução numérica dentre elas a de diferenças finitas. Os principais códigos comerciais de CFD, tais como CFX/ANSYS ${ }^{\circledR}$, FLUENT $^{\circledR}$ e STAR-CD ${ }^{\circledR}$, utilizam o método dos volumes finitos desenvolvido com base na formulação das diferenças finitas (VERSTEEG e MALALASEKERA, 2007). O algoritmo numérico segue basicamente os seguintes passos:

- Integração das equações governantes do fluxo em função do volume de controle do domínio;

- Discretização ou conversão das equações integrais resultantes em um sistemas de equações algébricas;

- Solução das equações algébricas através de método iterativo. 
Conforme Buscariolo (2009), as ferramentas tradicionais de CFD são baseadas nas equações completas de Navier-Stokes. Tais equações são diferenciais de segunda ordem parciais, não lineares, que descrevem o comportamento do escoamento. Dentre as técnicas disponíveis para solução das equações de Navier Stokes, Buscariolo (2009) destaca o método RANS (Reynolds-average Navier Stokes) utilizado pelo programa FLUENT ${ }^{\circledR}$. Em Hucho (1987), esse método trata da solução das equações de continuidade e do modelo de turbulência utilizando técnicas dos volumes ou elementos finitos. O realismo da simulação de fluxo pelo método RANS é altamente dependente do modelo de turbulência utilizado.

Conforme expõe Davidson (2003), a maioria dos fluxos em movimento que encontramos diariamente são turbulentos. Exemplos típicos dessa condição podem ser encontrados na movimentação do ar em torno de carros, aviões e edifícios. A camada limite e as esteiras formadas em torno e a jusante desses corpos rombudos são turbulentas. Em análises de combustão interna, tais como em motores à pistão e em turbinas à gás, o fluxo é altamente turbulento. Consequentemente, ao realizar cálculos computacionais relacionados com dinâmica dos fluidos, geralmente abordase casos turbulentos.

A transição de um escoamento laminar para um turbulento ocorre para número de Reynolds elevado e disparado por instabilidades fluidodinâmicas. Essa situação transitória é de alta complexidade para modelagem e não existe uma teoria que modele essa fase de maneira satisfatória. Tais problemas geralmente possuem um conjunto de expressões de incógnitas que é maior que o número de equações disponíveis, sendo necessário o uso de hipóteses para obtenção de equações adicionais ou de critérios para simplificação A maioria dos códigos comerciais de CFD ignora essa fase, classificando os escoamentos em laminar ou turbulento plenamente desenvolvido (BUSCARIOLO, 2009). Nos trabalhos de Hucho (1987) e Buscariolo (2009), conclui-se que os tipos de escoamento encontrados em problemas reais de Engenharia são, em geral, considerados turbulentos, inclusive o escoamento de ar no entorno de veículos.

Como a capacidade de processamento dos computadores tem crescido rapidamente nos últimos anos, uma grande quantidade de análises de fluxos, através da solução 
da formulação de Navier-Stokes, tem sido direcionada por meio da Dinâmica dos Fluidos Computacional. O CFD pode ser uma ferramenta muito útil por indicar o prognóstico do desempenho aerodinâmico veicular de forma relativamente rápida e de baixo custo nos primeiros estágios do ciclo de projeto. Em relação a sistemas de arrefecimento, cálculos do fluxo de ar através do radiador tanto quanto a capabilidade de transferência de calor de um determinado projeto podem ser estimados antes da fabricação de protótipos (NG et al., 2002, BAYRAKTAR; BAYRAKTAR, 2006). Porém vale ressaltar que atualmente não há um código de CFD conhecido que seja apto a apresentar resultados sem a incidência de erros ou distorções. Por esse motivo, a validação experimental é necessária para a confirmação de que o fluxo está sendo modelado corretamente (NG et al., 2002).

\subsection{SISTEMAS DE ARREFECIMENTO}

O processo de troca de calor entre dois fluidos que estão em diferentes temperaturas e se encontram separados por uma parede sólida ocorre em muitas aplicações na Engenharia. O equipamento utilizado para implementar essa troca é conhecido por trocador de calor e exemplos específicos de sua utilização podem ser encontrados no aquecimento e no condicionamento de ar, na produção de energia, na recuperação de calor e em processos químicos (INCROPERA; DEWITT, 1998; MELLO, 1998).

Os trocadores de calor são tipicamente classificados em função da configuração de escoamento e do tipo de construção. Os tipos de trocadores disponíveis conforme as definições de Incropera e DeWitt (1998) são: 
- Trocadores concêntricos (paralelo e contracorrente)

- Trocadores de escoamento cruzado (com um fluido não misturado ou dois fluidos não misturados)

- Trocadores tipo casco e tubo

- Trocadores compactos

Em um trocador de calor de escoamento cruzado, um fluido escoa perpendicularmente ao outro, conforme é apresentado na Figura 3.

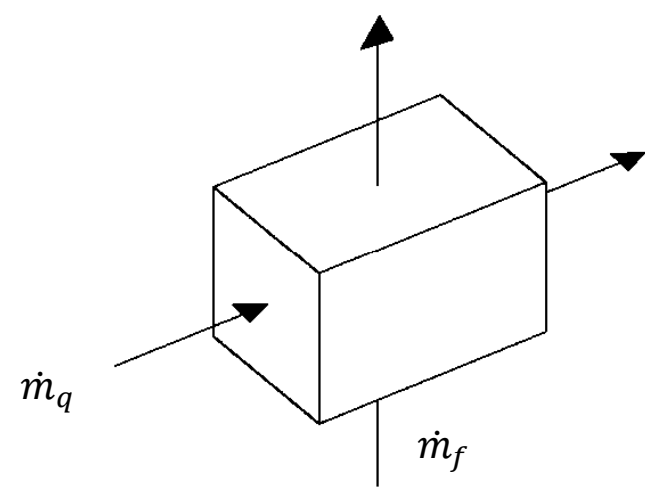

Figura 3 - Representação esquemática de trocador de calor de escoamento cruzado mostrando a diferença de direção de vazão de fluido quente e frio (KAYS; LONDON, 1984).

O escoamento dito não misturado é interpretado como se o mesmo fosse dividido em um grande número de tubos para passagem pelo trocador, de forma a não existirem componentes de velocidade que não seja na direção perpendicular ao plano do trocador. Isso ocorre devido à geometria do trocador que possibilita um fluxo ordenado (KAYS; LONDON, 1984).

Trocadores de calor ditos compactos são utilizados para atingir altas áreas de transferência de calor por unidade de volume $\left(\geq 700 \mathrm{~m}^{2} / \mathrm{m}^{3}\right)$. São caracterizados por uma densa matriz de tubos ou placas aletadas e são tipicamente usados quando pelo menos um dos fluidos é um gás, que é caracterizado por um pequeno coeficiente de transferência de calor (INCROPERA; DEWITT, 1998; MELLO, 1998). 
A transferência de calor que ocorre no sistema de arrefecimento do motor de um veículo, foco do presente estudo, é apresentada esquematicamente a seguir conforme a publicação de Kays e London (1984), na Figura 4.

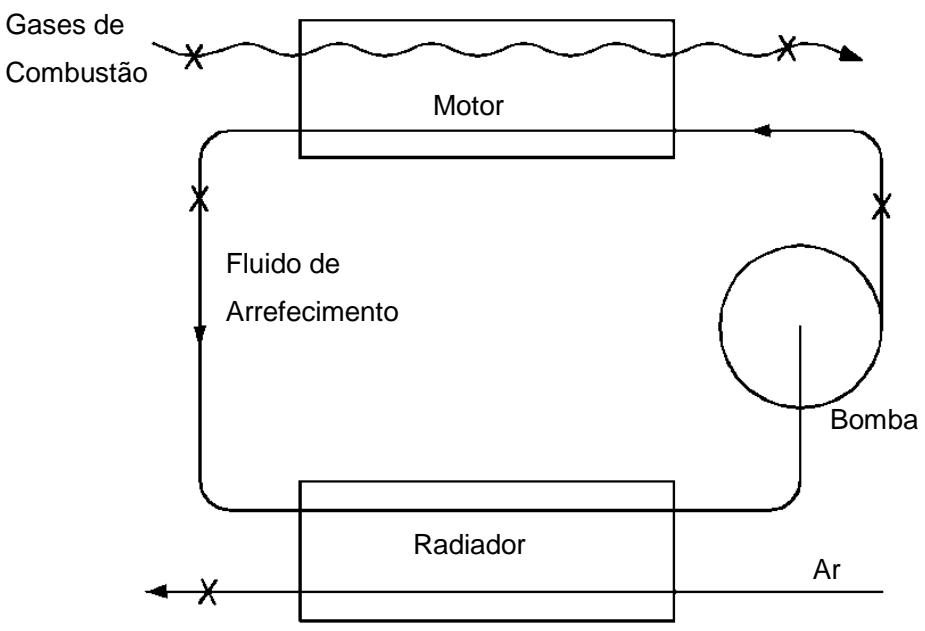

Figura 4 - Representação esquemática do funcionamento de sistema de arrefecimento veicular, modificado de Kays e London (1984).

A função principal de um sistema de arrefecimento é certificar que os componentes do motor sejam adequadamente resfriados sob todas as condições operacionais do veículo. Quando o motor superaquece, numa condição em que o sistema de arrefecimento falha ou não está adequadamente dimensionado, pode ocorrer o travamento dos pistões do motor devido à ineficácia do filme de óleo que os separa do bloco do motor (QUIM, 2007).

Sistemas de arrefecimento mais modernos são compostos basicamente de trocadores de calor (usualmente denominados radiadores), ventiladores elétricos, mangueiras, líquido de arrefecimento, bomba e válvula termostática. O líquido mantém-se em contato com o bloco do motor até o momento que uma dada temperatura limite é atingida. Essa temperatura é identificada pela válvula que libera o liquido para passagem pelo radiador. Com o movimento do veículo, o ar atravessa o radiador e efetua-se a transferência de calor. Caso o veículo esteja parado ou em 
baixa velocidade, de forma que a vazão de ar seja insuficiente para a transferência de calor, o sistema aciona o ventilador que fica acoplado junto ao radiador e o ar é então forçado a atravessá-lo (QUIM, 2007).

Requisitos de baixo arrasto aerodinâmico, alta potência de motores e estilo são temas que frequentemente estão em conflito por fabricantes de veículos, no que se refere ao projeto de sistema de arrefecimento (NG et al., 2002).

O sistema de arrefecimento tem influência sobre outros subsistemas, e vice-versa, e é fundamental a integração dos componentes semelhantes para uma condição ótima de trabalho para veículos de qualquer natureza. Costa e Pinto (2002) pesquisaram a respeito do gerenciamento do fluxo de ar por sob veículos automotores (caminhões) em conjunto com o desenvolvimento de isoladores de ruído. Tal estudo visa à integração dos subsistemas com o intuito de eliminar retrabalhos posteriores, fazendo uso de análises experimentais e computacionais (CFD). Segundo os autores, a definição do conjunto de isoladores de ruído tradicionalmente não considera os impactos térmicos da região do compartimento do motor. Com tal proposta, foi possível uma considerável redução do custo de fabricação por veículo devido ao uso de isoladores menores e em menor quantidade, a um sistema de arrefecimento reduzido, com ventiladores de menor potência e radiadores menores e à diminuição de testes em laboratório e em pista. Todo esse projeto foi concluído em apenas dez meses.

O estudo desenvolvido por Charyulu et al. (1999) objetiva avaliar o desempenho de um radiador existente sob determinadas condições de operação. O radiador é um trocador de calor compacto de escoamento cruzado com fluidos não misturados, que possui 644 tubos distribuídos em 6 fileiras e 346 aletas contínuas e está aplicado a um motor movido a Diesel de 12 cilindros e 368 kW de potência (493,49HP) que, segundo o autor, demanda dissipar $147,06 \mathrm{~kW}$ de calor. Com base na formulação de Kays e London (1984), foi desenvolvido um programa em FORTRAN ${ }^{\circledR}$ para implementar a proposta. O programa apresenta sub-rotinas para avaliação das propriedades térmicas do ar e liquido de arrefecimento baseado em temperaturas de operação através das entradas, de vazão dos fluidos, materiais e características geométricas do radiador. Em seus comentários conclusivos, o autor aponta que o 
trocador de calor com tubos em latão e aletas em cobre apresenta super dimensionamento de 30\%, sendo capaz de dissipar 191,56 kW perante os $147,06 \mathrm{~kW}$ requeridos.

O estudo apresentado por Froling e Juechter (2006) apresenta de forma sucinta o desenvolvimento aerodinâmico do veículo Chevrolet Corvette C6 Z06 de 2006. Segundo os autores, o foco do trabalho foi aumentar sua eficiência aerodinâmica enquanto que no modelo básico, desenvolvido anteriormente, havia sido a redução de arrasto. Com isso, uma série de dispositivos aerodinâmicos foi aplicada ao modelo. Dentre os diversos elementos propostos está uma nova grade dianteira, que provê uma maior área para entrada de ar, e extratores laterais maiores para auxiliar na remoção do excesso de calor gerado pelo motor e na diminuição da pressão no interior do cofre do motor.

Segundo os autores Froling e Juechter (2006), um dos objetivos propostos para esse desenvolvimento foi "atender condições agressivas para fluxo de ar para arrefecimento". Foram investidas mais de 240 horas em túnel de vento para o desenvolvimento aerodinâmico desse veículo, que também recebeu significantes contribuições do departamento responsável pela análise de dinâmica dos fluidos computacional e da experiência prévia dos membros do time em competições. Com a informação de que o motor (denominado LS7) do novo veículo rejeitaria 47,5 kW de calor adicional, em comparação ao modelo anterior (LS2), a proposta de aumentar verticalmente a abertura para a grade dianteira em $25 \mathrm{~mm}$ proporcionou uma vazão de ar maior para atender a necessidade de arrefecimento (Figuras 5 e 6). O desenho da estrutura entrelaçada da grade foi desenvolvida e melhorada em testes em túnel de vento para minimizar a perda de pressão e passou a fornecer um adicional de $1 \mathrm{~m} / \mathrm{min}$ de ar para o interior do cofre do motor a $80 \mathrm{~km} / \mathrm{h}$, em comparação com a grade desenvolvida anteriormente. 


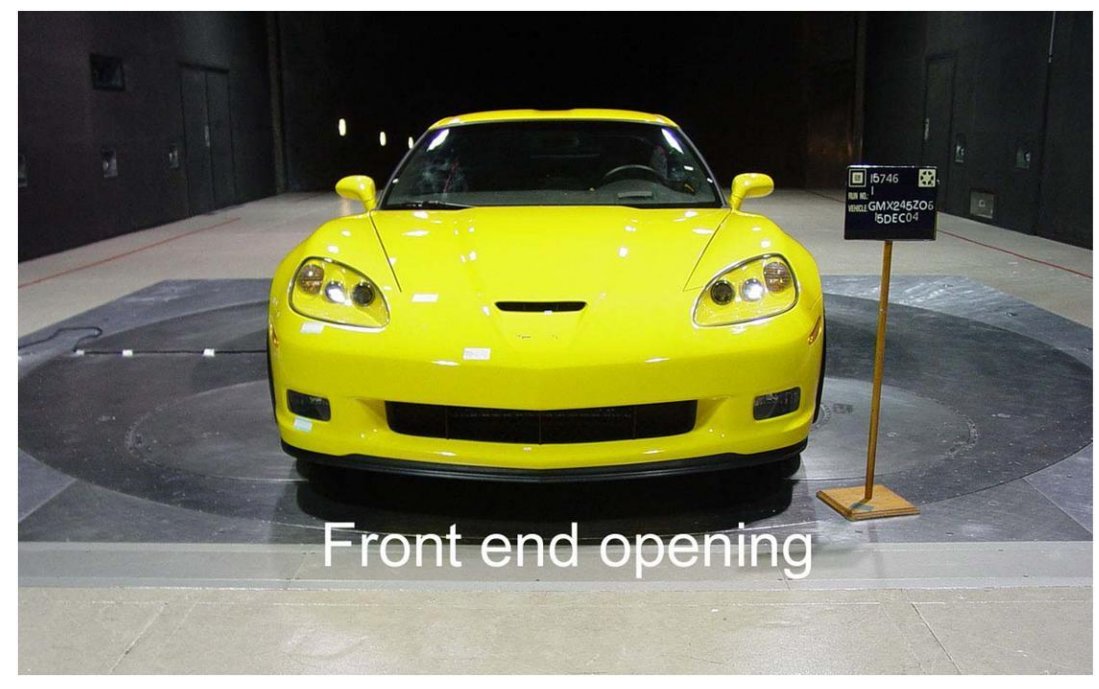

Figura 5 - Vista frontal do veículo Corvette C6 Z06 em testes em túnel de vento (FROLING; JUECHTER, 2006)

\section{Comparação de Rejeição de Calor entre Motores Corvette}

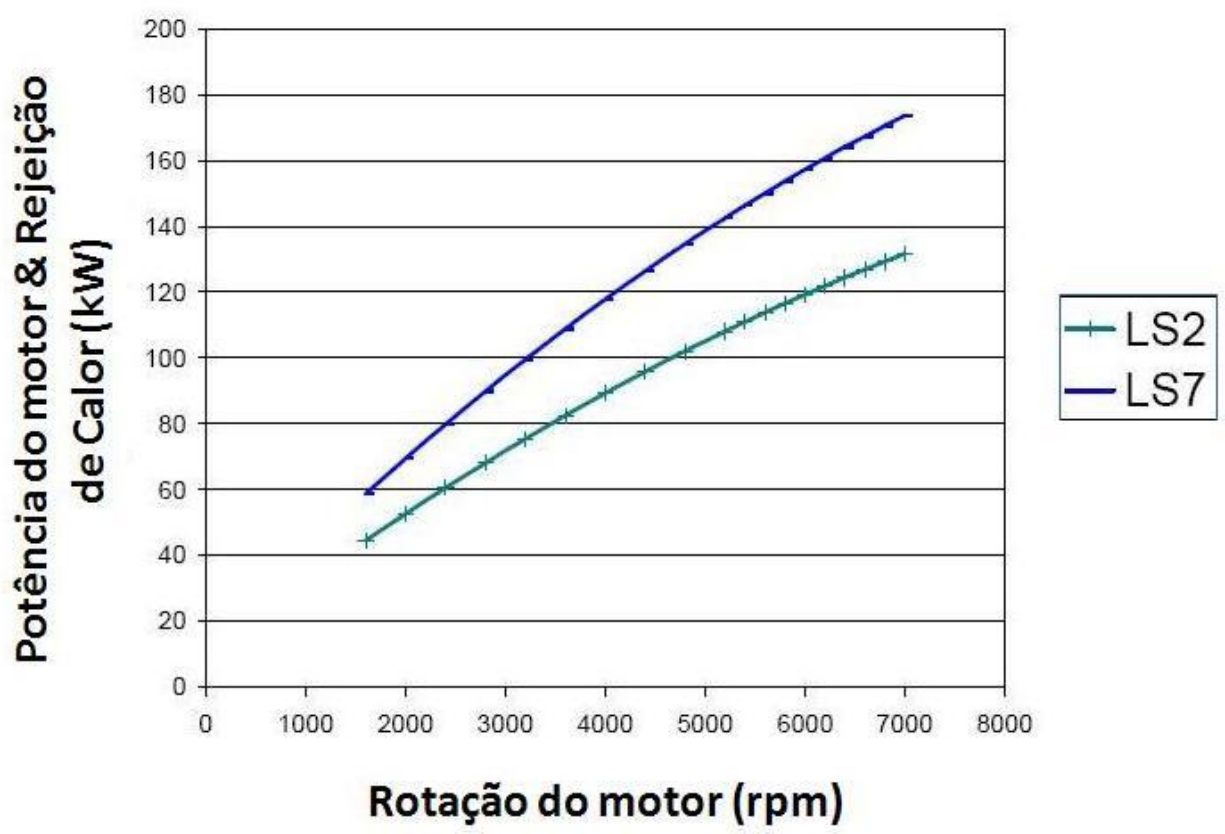

Figura 6 - Comparação de curvas de rejeição de calor dos motores disponíveis para o veículo Corvette C6 Z06 (FROLING; JUECHTER, 2006). "LS2" e "LS7" são as denominações utilizadas para os tipos de motores disponíveis para o veículo. 
A Dinâmica dos Fluidos Computacional (CFD) foi utilizada no início do desenvolvimento do projeto de Froling e Juechter (2006), antes mesmo do estudo em túnel de vento do protótipo em escala em argila sintética (clay) com o escopo de computar o fluxo de ar na parte dianteira e identificar áreas de alta pressão e de separação de fluxo na superfície do veículo.

Koch e Haubner (2000) expõem que as reduções de emissão de gases poluentes e do consumo de combustível são os principais objetivos para o desenvolvimento de motores. Ambos são altamente influenciados pela temperatura dos fluidos e materiais que compõem os motores, principalmente nas condições de baixa velocidade em que é reduzida a capacidade de arrefecimento. Os autores apresentam dados referentes à pesquisa de utilização dos veículos na Alemanha em que $75 \%$ dos trajetos são menores que $10 \mathrm{~km}$, demonstrando a importância em estudar o comportamento do motor e do sistema de arrefecimento nessas condições. É então proposta uma estratégia de controle para o gerenciamento inteligente de temperatura de líquido de arrefecimento, mostrando seus benefícios. Os resultados demonstram que, através da análise do comportamento térmico de motores e com a implementação de um sistema inteligente de arrefecimento (ICS, sigla do termo em inglês Intelligent Cooling System), é possível reduzir o tempo de aquecimento do motor e conseqüentemente reduzir significantemente o consumo de combustível e o nível de emissões.

Gattei, Rossi, Cardile (2008) descrevem o desenvolvimento e aplicação de uma ferramenta para simulação de sistemas de arrefecimento veicular baseada em modelagem matemática. A modelagem, desenvolvida através de uma técnica computacional de baixo custo, é fundamentada em um circuito unidimensional que possibilita a análise de sistemas de arrefecimento de maior complexidade. Essa ferramenta abrange cálculos de fluxo e temperatura dos fluidos para cada componente do sistema.

Segundo Gattei, Rossi, Cardile (2008), o sistema de arrefecimento é atualmente representado por um complexo circuito com diversos componentes. Devido à maior complexidade desses sistemas, a otimização com base experimental tem se tornado 
mais difícil, exigindo dispendiosos recursos como testes em túneis de vento climatizados em conjunto com testes em pista.

O programa computacional, chamado de CDS (abreviatura para Cooling system Dynamic Simulation), realiza as análises dinâmicas e térmicas do sistema de arrefecimento. A proposta dessa ferramenta é prever a taxa de fluxo em massa dos fluidos e a variação de pressão em cada componente do sistema de arrefecimento. Os dados de entrada para a análise térmica são derivados da solução do circuito para o líquido de arrefecimento. Com o intuito de calcular as temperaturas de entrada e saída para cada elemento desse circuito, é necessário o balanço de energia entre 0 calor gerado pelo motor e o dissipado pelo radiador, desconsiderando possíveis perdas por radiação e convecção nas adjacências dos componentes do motor. Conforme exposto por Gattei, Rossi, Cardile (2008), a rejeição de calor no radiador pode ser calculada pelo CDS por meio de dois modelos paramétricos, chamados de "conjunto" e "distribuído", e o campo de velocidades pode ser determinado por análise em CFD. Os códigos computacionais utilizados para essas modelagens são MATLAB $^{\circledR}$ e FLUENT ${ }^{\circledR}$.

Para a modelagem térmica, com base na teoria de redes, Gattei, Rossi, Cardile (2008) propõem uma correlação com circuitos elétricos, em que os componentes do sistema de arrefecimento são representados por resistências elétricas com curvas características. Os componentes do circuito são basicamente: a bomba do líquido de arrefecimento, as fontes de calor (motor e aquecedor) e o trocador de calor (radiador). Para a modelagem térmica, faz-se uso de uma análise de transferência de calor unidimensional. O balanço é determinado por quatro fatores principais: força motriz, desempenho de rejeição de carga térmica, característica do fluxo de ar e desempenho do trocador de calor. Esse mecanismo de balanço de energia encontra o equilíbrio quando o desempenho de perda de carga térmica é igual ao desempenho do trocador de calor para uma dada condição de solicitação do motor (carga e velocidade). Para estimar a temperatura do líquido de arrefecimento na entrada e saída de cada componente do sistema é realizado um processo iterativo. A condição inicial é a rejeição de calor do motor para o liquido de arrefecimento e a taxa de fluxo em massa do líquido em cada componente. Através do balanço de entalpia para cada parte do circuito, obtêm-se as referidas temperaturas. 
Para compor os cálculos iniciais do programa, Gattei, Rossi, Cardile (2008) fazem uso de três metodologias para obter e comparar o coeficiente de transferência de calor $\boldsymbol{h}$ : SD (sigla para Specific Dissipation), Diferença Média Logarítmica de Temperatura (DMLT), e Efetividade-NUT ( $\varepsilon$-NUT). Por definição, SD é a razão entre a taxa de transferência de calor $\boldsymbol{q}$ pela diferença máxima de temperatura no trocador de calor $\left(\boldsymbol{T}_{q e}-\boldsymbol{T}_{\boldsymbol{f s}}\right)$. Essas metodologias podem ser interpretadas como uma definição macroscópica do calor trocado no radiador. O programa CDS é então alimentado com esses dados para compor os cálculos dos dois modelos paramétricos, distribuído e conjunto. Para o primeiro modelo, realiza-se uma subdivisão do radiador em um número específico de células e a equação da conservação de energia é então solucionada para cada célula, de forma a calcular os efeitos locais de transferência de calor. Para o modelo paramétrico conjunto, toma-se o cálculo do coeficiente global de transferência de calor $\boldsymbol{U}$ e o radiador é analisado de forma única, desprezando-se as possíveis perdas de energia cinética e potencial e de troca de calor com outros componentes. A equação da conservação de energia é reduzida ao balanço de entalpia, uma vez que não há trabalho externo sendo realizado.

Para validar o programa, Gattei, Rossi, Cardile (2008) realizaram testes em bancada e testes em túnel de vento climatizado com o veículo Maserati Quattroporte. Os resultados apresentam uma boa correlação dos dados experimentais com os métodos LMTD e $\varepsilon$-NUT. Uma vantagem dessas duas metodologias em relação à SD é a consideração do tipo de trocador de calor para o cálculo do coeficiente de transferência de calor.

Para a correlação dinâmica, a malha geométrica desenvolvida para o veículo foi avaliado em CFD com algumas considerações importantes. Nessa simulação, não foi considerada a equação de conservação de entalpia. Dessa forma, os fenômenos térmicos e fluidodinâmicos foram tratados de forma independente. Outro dado importante para essa analise é que o ar foi considerado como fluido incompressível, com o objetivo de se obter um menor tempo de processamento. O número de Reynolds para essa avaliação foi de $13,8 \times 10^{6}$, com temperatura ambiente de $20{ }^{\circ} \mathrm{C}$ 
e o modelo de turbulência utilizado foi o $\mathrm{k}-\varepsilon$. A malha gerada considerou 6,93 milhões de elementos tetraédricos, conforme Figuras 7 e 8.

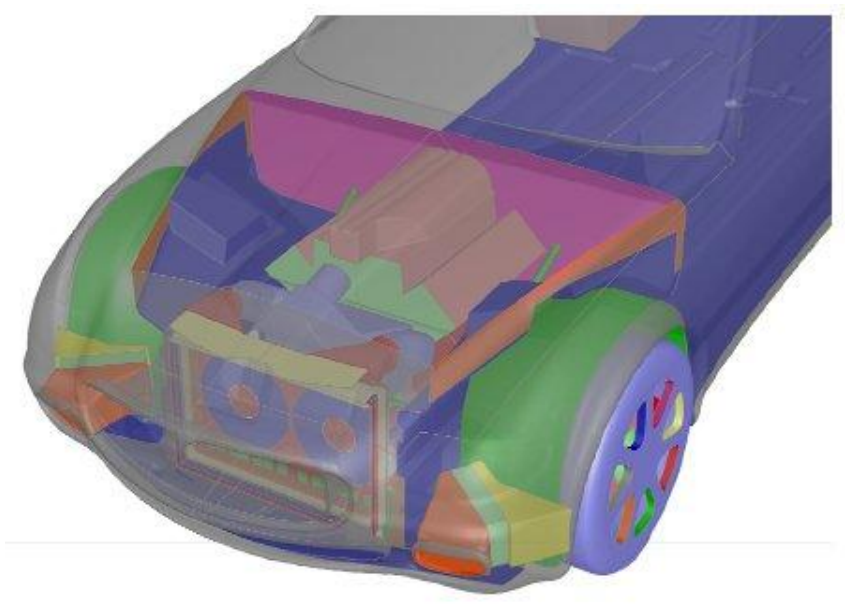

Figura 7 - Geometria detalhada da parte frontal do veículo proposto para avaliação em CFD (GATTEI; ROSSI; CARDILE, 2008).

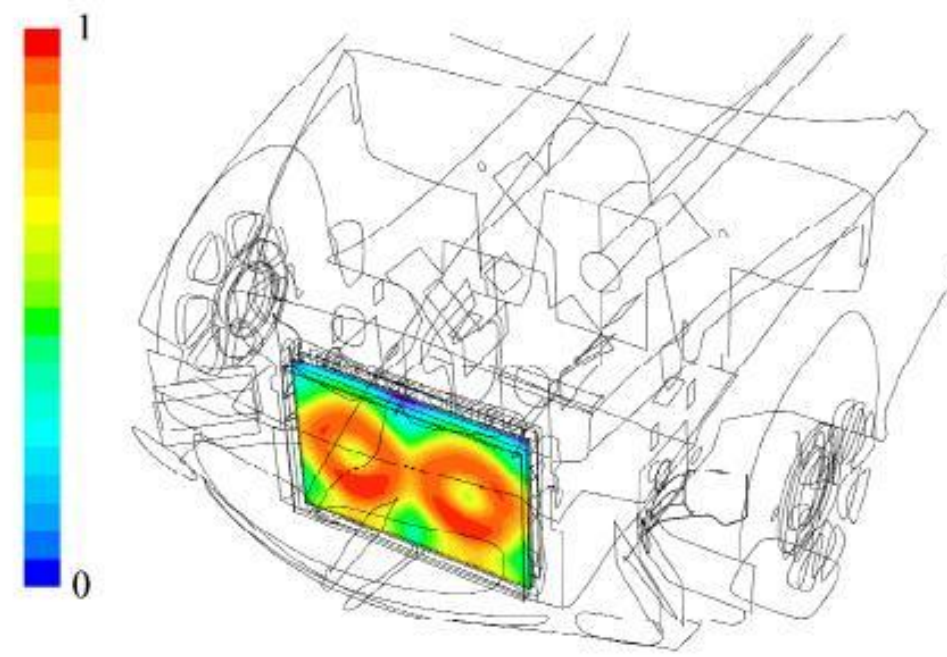

Figura 8 - Resultado da análise em CFD para a distribuição de velocidade do fluxo de ar na saída do radiador (GATTEI; ROSSI; CARDILE, 2008). 


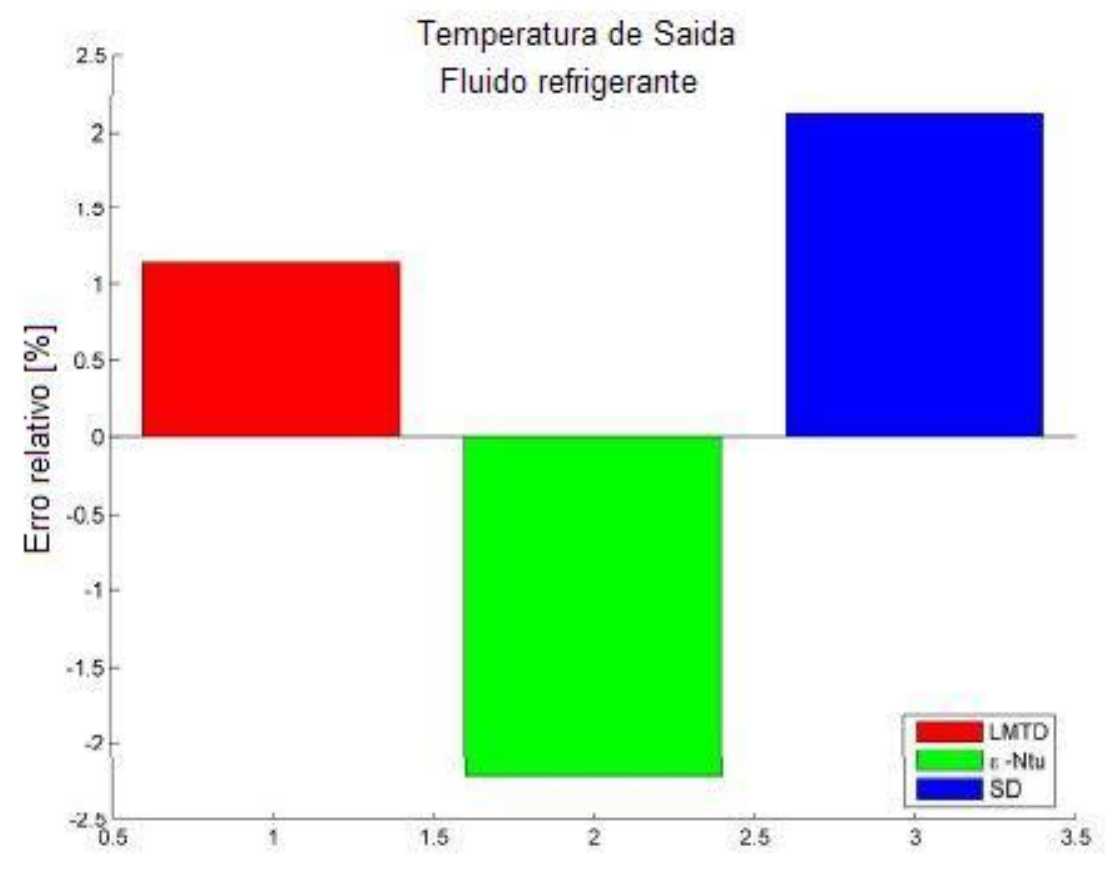

Figura 9 - Comparação do erro relativo apresentado para o cálculo da temperatura de saída do líquido de arrefecimento em relação aos dados verificados experimentalmente (GATTEI; ROSSI; CARDILE, 2008).

Em seus resultados, Gattei, Rossi, Cardile (2008) apresentam que, para o caso do veículo Maserati Quattroporte, o modelo paramétrico distribuído com a metodologia LMTD apresentou os melhores resultados, com base nas comparações com testes experimentais, conforme exemplo da Figura 9.

\subsection{ARRASTO X ARREFECIMENTO}

O arrasto é uma força resultante na direção da velocidade porém em sentido oposto ao movimento do veículo. Essa força de oposição impacta diretamente na potência disponível para acelerar o veículo à máxima velocidade como também para o consumo de combustível. À medida que a velocidade aumenta, maior é o efeito da força de arrasto (JAWAD; LONGNECKER; TIMMER, 2001). 
O arrasto adicional devido ao fluxo através do sistema de arrefecimento tem sido o foco dos aerodinamicistas desde as primeiras pesquisas nesta área. A publicação de Wickern et al. (2006) apresenta uma fonte de interferência positiva entre o fluxo de ar em torno de um veículo com o fluxo direcionado ao arrefecimento. Essa interferência está associada à rotação das rodas e o foco dos autores é apresentar a importância do movimento das rodas em testes em túnel de vento para redução de arrasto de arrefecimento (cooling drag) e o efeito característico de simulação de pista. Os autores concluíram que a interferência é menor quando se faz uso correto da simulação de pista em túnel de vento, se comparado com os resultados dos testes com rodas estacionarias. A generalidade dessa tendência é evidenciada experimentalmente através dos resultados dos testes com trinta modelos de veículos de diferentes tipos (Figura 10).

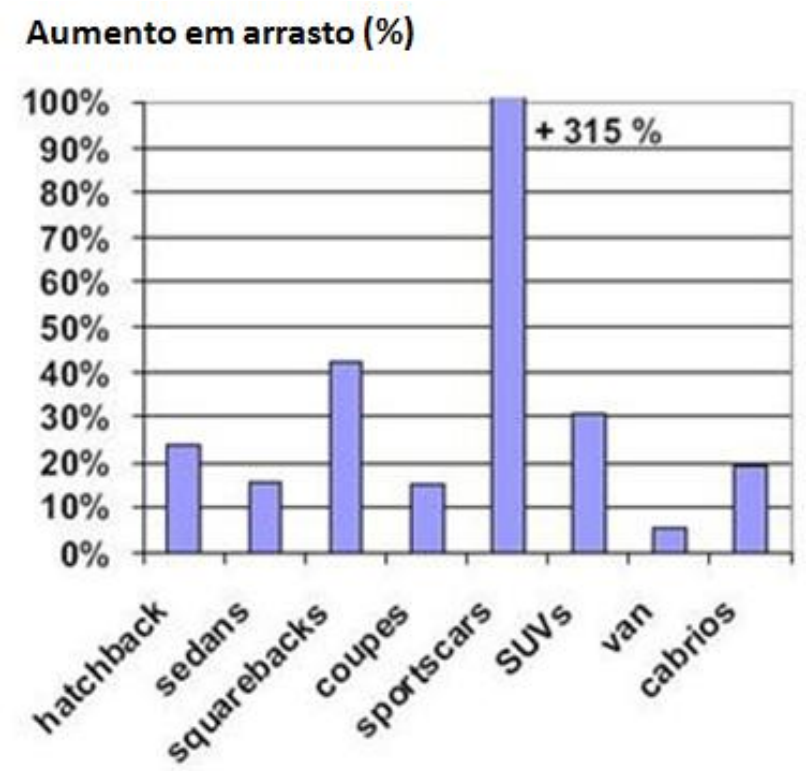

Figura 10 - Aumento médio percentual do arrasto de arrefecimento medido em testes em túnel de vento com simulação de pista, em comparação com piso estacionário, para diferentes tipos de veículos (WICKERN et al., 2006) 
Com a constante demanda dos fabricantes de veículos em reduzir o tempo de desenvolvimento, melhorar desempenho, atender as exigências legais de ruído e emissões de poluentes e com o advento do ar condicionado veicular há a necessidade de avaliações e melhorias no desempenho do sistema de arrefecimento na fase de projeto. Com base nessa premissa, White et al. (1998) descrevem a estrutura principal de um programa computacional que permite otimizar o desempenho do sistema de arrefecimento ainda numa fase conceitual ou anterior ao período permissível às mudanças de grande impacto no veículo, como por exemplo, modificações radicais no estilo da carroceria ou uma alteração de motor.

Os autores numeram três propostas para projetar o sistema de arrefecimento:

a. Procedimento iterativo baseado em ensaios experimentais e desenvolvimento de componentes;

b. Análise aerodinâmica completa do veículo, que leva em conta o fluxo externo, interno (cofre do motor) e dos componentes do sistema de arrefecimento;

c. Modelo composto utilizando dados de testes, análise dos componentes e algoritmos para definir modos de interação.

Segundo os autores, a primeira opção seria cara e não poderia ser implementada na fase preliminar de projeto por requerer testes físicos de componentes e, frequentemente, testes nessas condições produzem dados que não são aproveitados para futuros veículos ou problemas relacionados. As limitações desse tipo de desenvolvimento "corta e cola" tem levado os fabricantes e seus fornecedores a buscarem melhores alternativas.

A segunda opção requer uso de dinâmica dos fluidos computacional que, para uma análise completa do veículo, exige a geração de malhas com milhões de células que por sua vez necessita de computadores potentes, disponíveis em locais específicos como fabricantes e empresas de projeto que mantém tais recursos para uso diversificado. 
É proposto então o desenvolvimento de modelo composto de dados de testes, análise de componentes e a conexão com algoritmos, que seria a proposta a ser seguida por diversas empresas, com as vantagens de uso de dados transferíveis de componentes e não necessitar de hardware computacional sofisticado, como na segunda opção. A filosofia seria criar um programa computacional de simples uso, que tenha disponível uma base de dados com diversos tipos de motores, transmissões, componentes e condições de testes ou que fosse possível o usuário introduzir dados próprios.

O estudo apresenta uma comparação de valores sintetizados para a perda de pressão para $\mathrm{o}$ ar através do sistema de arrefecimento com valores medidos em testes com boa concordância, atestando a confiabilidade ao método.

\subsection{EFEITO RAM}

Conforme os trabalhos de Hucho (1998) e Quim (2007), o escoamento de ar relacionado à diferença de pressão presente, por exemplo, na entrada de ar dianteira de um veículo (alta pressão) e posterior ao protetor de cárter (baixa pressão) é conhecido por efeito "ram". Quando o efeito "ram" não se estabelece ou não é suficiente para o arrefecimento, faz-se necessário o uso dos ventiladores presentes junto ao radiador. Jawad e Longnecker (2001) propõem uma avaliação dos efeitos da aerodinâmica, interna e externamente, em veículos da Formula SAE construídos pelos alunos da Lawrence Technological University (LTU) em 1999 e 2000. No que tange a análise interna está uma avaliação relacionada ao efeito "ram" presente no compartimento do radiador do veículo. Para fazer o melhor uso desse efeito, os autores propõem para novos projetos um longo difusor a montante do radiador e um bocal a jusante do mesmo. A forma do difusor proporciona uma gradual redução de velocidade de forma que a pressão aumente enquanto que o bocal tende a gerar o efeito contrário, proporcionando o retorno do ar ao ambiente em velocidade próxima à do veículo. 


\subsection{A COMPETIÇÃO FÓRMULA SAE}

A SAE (Society of Automobile Engineers) possui como lema "desenvolver, criar e divulgar estudos na área da mobilidade". Com o intuito de estimular a criatividade e o aprendizado dos alunos de engenharia, a SAE organiza competições entre as universidades como o Mini Baja, o AeroDesign e o Fórmula SAE.

A Fórmula SAE é uma competição acadêmica dedicada ao projeto e fabricação de carros de competição do tipo fórmula, característico por suas rodas e pneus descobertos. Mais de 200 universidades e faculdades participam dessa categoria com eventos de competição que acontecem em diversos países (Estados Unidos, Reino Unido, Alemanha, Brasil, Itália, Japão e Austrália). O evento é caracterizado pela ampla gama de inovações utilizadas nos veículos e por proporcionar o desenvolvimento de diversas habilidades dos estudantes, através do projeto e manufatura de um veículo real de competição. Os estudantes são responsáveis pelos projetos de chassis, suspensão, componentes elétricos, sistema de combustível e de arrefecimento e diversos outros. Um ponto interessante é a aquisição de habilidades de integração de projetos de engenharia com a apresentação de gestão de custos e recursos (CLAYWELL; HORKHEIMER, 2006; FUKUI et al., 2007).

As regras estabelecidas para a competição apresentam algumas restrições técnicas, com exceção às áreas relacionadas à segurança. Apesar de existirem diversos meios de exploração do sistema de propulsão e seus componentes, a grande maioria dos times utiliza motores originalmente aspirados de quatro cilindros provenientes de motocicletas disponíveis no mercado. A regra determina que a escolha dos times limita-se a qualquer motor de quatro tempos com capacidade máxima de 610 cilindradas $\left(\mathrm{cm}^{3}\right)$ porém com número de cilindros ilimitado. Também é exigida uma restrição dimensional quanto à dimensão da entrada de ar para a câmara de combustão de $20 \mathrm{~mm}$ considerando o uso de combustíveis de 94 a 100 octanas ou $19 \mathrm{~mm}$ no caso de etanol E-85. Diante disso, a forma, configuração, o tamanho e acondicionamento dos componentes do motor, como é o caso da tomada 
de ar, variam para cada equipe, de maneira que não se permite comparações diretas das soluções entre os times (CLAYWELL; HORKHEIMER, 2006). Esses veículos movimentam-se em uma faixa de velocidade compreendida entre zero e $115 \mathrm{~km} / \mathrm{h}$ (JAWAD; LONGNECKER; TIMMER, 2001).

São desenvolvidas e apresentadas para os juízes do evento soluções de engenharia com o intuito de compensar a perda de potência sofrida pelo motor devido às adaptações ao veículo, assim como as limitações impostas pelas regras da competição. Apenas para ilustrar, abaixo algumas das alterações praticadas pelas equipes:

- Redução de massa do veículo através da remoção ou substituição de componentes por outros de massa específica menor;

- Ajuste do centro de gravidade do veículo através de modificação ou rearranjo dos diversos componentes;

- Introdução de turbocompressores ou alimentadores de ar (supercharger).

O desenvolvimento descrito no trabalho de Fukui et al. (2007) apresenta as modificações em um motor de quatro tempos, de $650 \mathrm{~cm}^{3}$ e dois cilindros em "V" para adequação às regras para a primeira prova de Fórmula SAE no Japão. Dentre as modificações apresentadas, está a implementação de um novo sistema de admissão de combustível por injeção eletrônica em substituição ao sistema de carburador original, com o intuito de obter aumento de torque e potência. Com o auxílio de um dinamômetro, é apresentado como resultado um aumento de $19 \%$ em torque e $21 \%$ em potência para uma determinada faixa de rotação do motor, conforme mostrado na Figura 11. Os autores apresentam ainda potenciais áreas para outras melhorias em torque e potência, porém não é mencionada nenhuma intenção de estudo relacionada ao sistema de arrefecimento. 


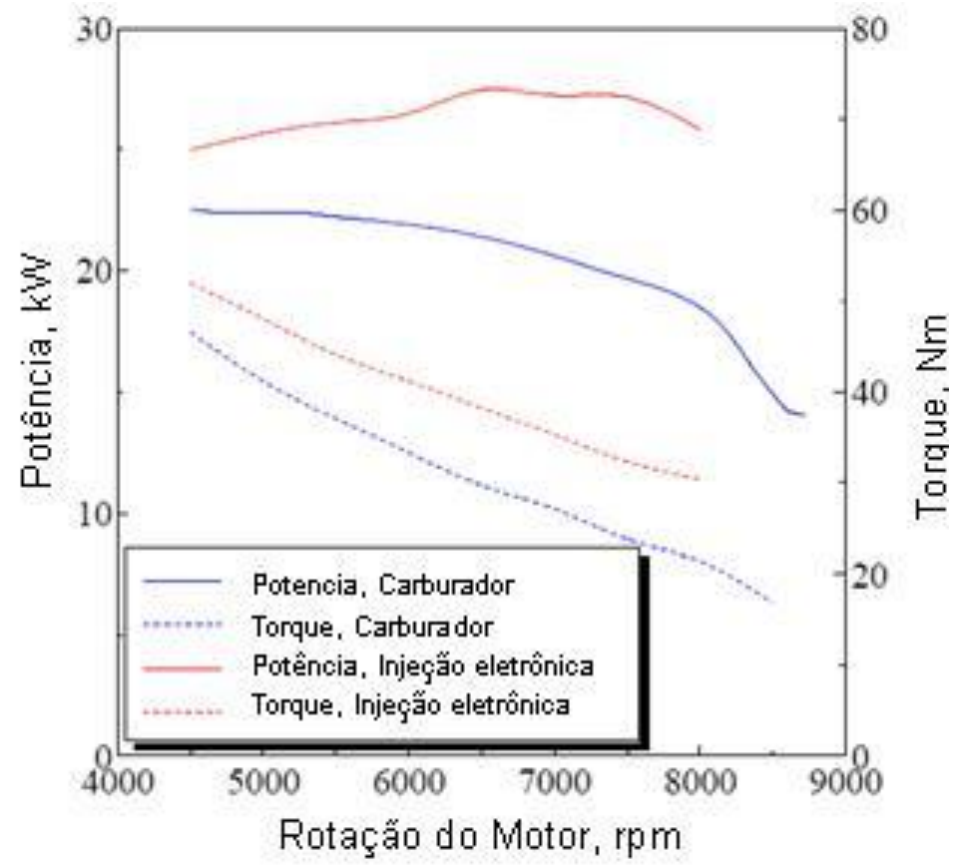

Figura 11 - Exemplo de curvas de desempenho de motor (FUKUI et al., 2007)

Christoffersen et al. (2008) propõem um estudo exclusivamente em dinâmica dos fluidos computacional com o objetivo de melhorar o fluxo de arrefecimento em veículos da Formula SAE sem alterar radicalmente a geometria do veículo (que possui o desenho baseado na Lotus Type 49 de 1967), com o propósito de otimizar o sistema de arrefecimento e, consequentemente, diminuir a massa e o arrasto aerodinâmico do veículo (Figura 12).
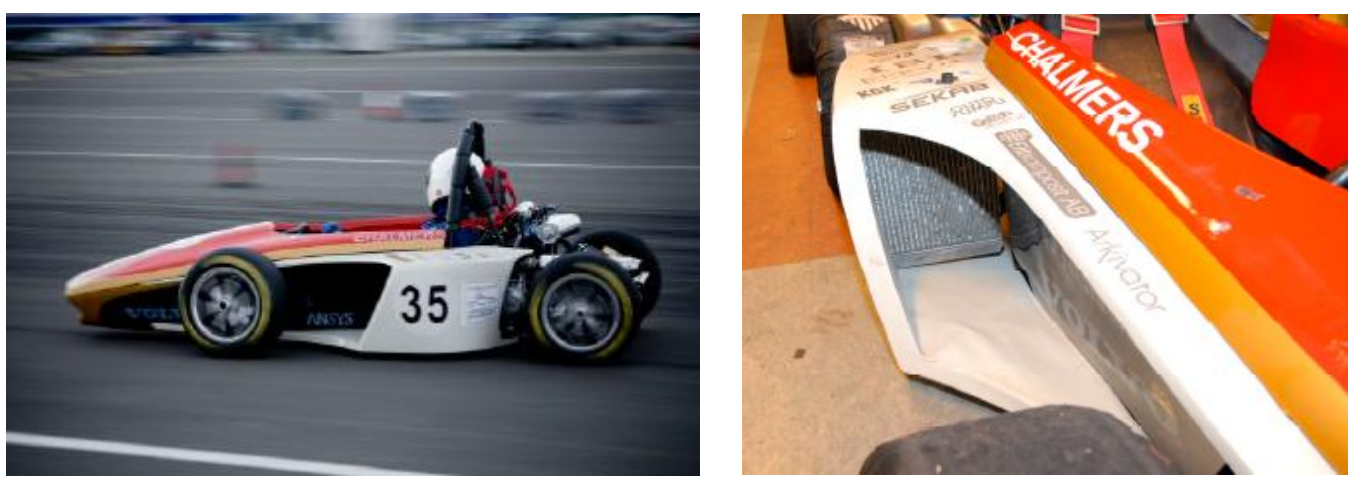

Figura 12- Modelo de veículo da Fórmula SAE e detalhe da entrada de ar para o radiador, antes da modificação proposta (CHRISTOFFERSEN; SÖDERBLOM; LÖFDAHL, 2008) 


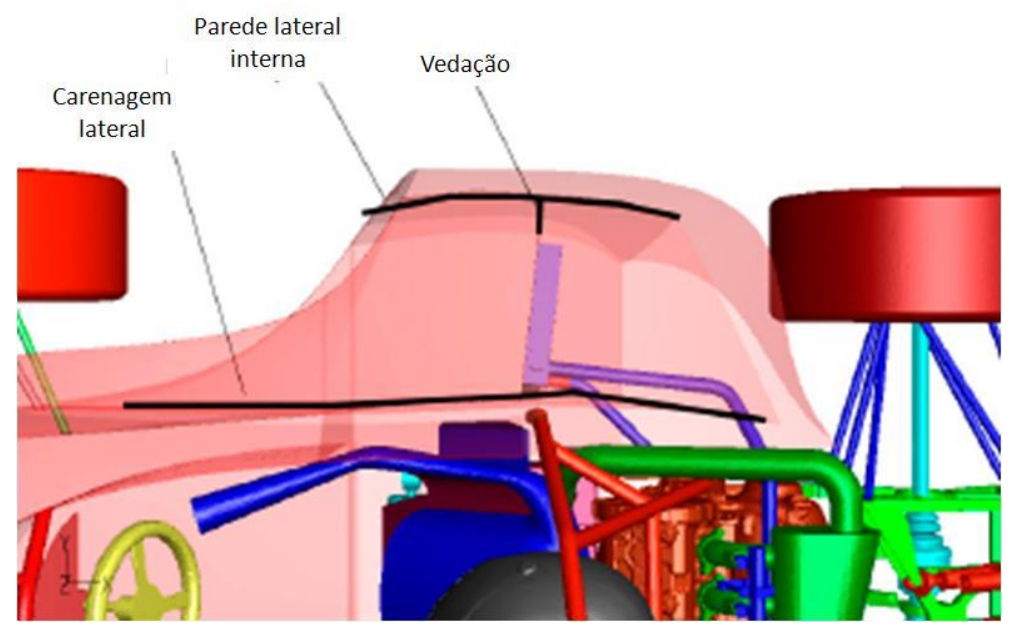

(1)

Parede lateral interna

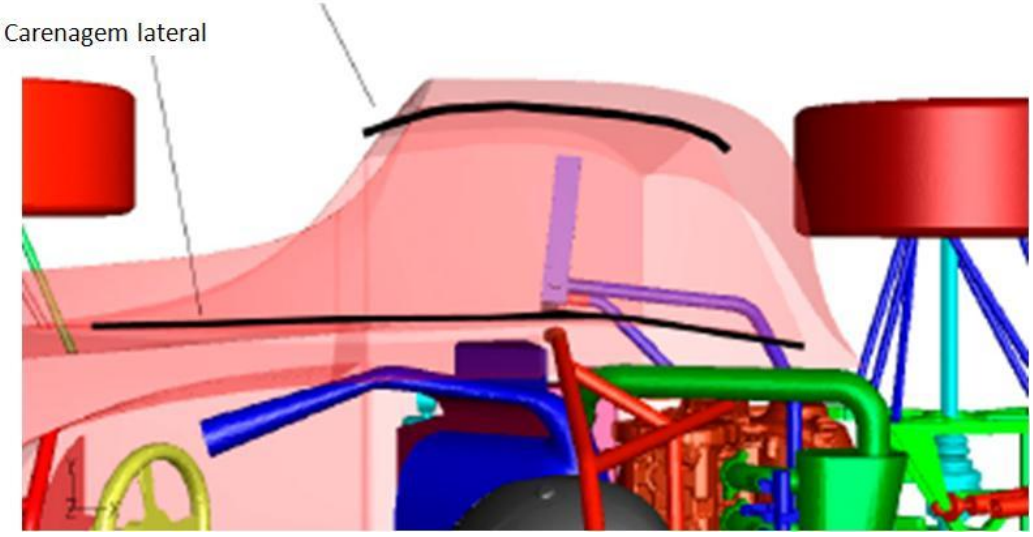

(2)

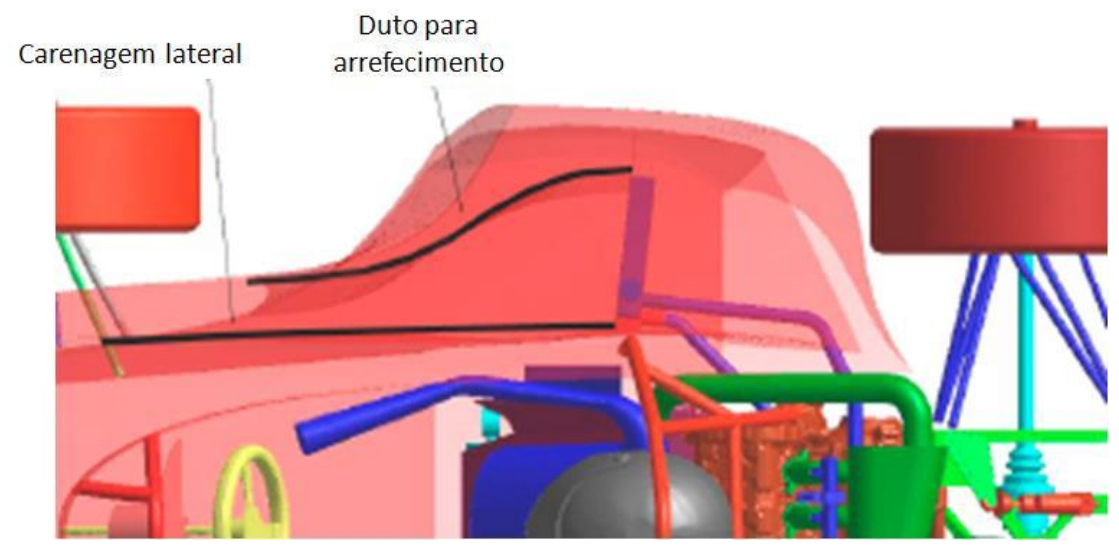

(3)

Figura 13 - Vistas superior dos três casos estudados: caso (1) apresenta o duto totalmente selado; caso (2) apresenta geometria semelhante ao primeiro porém não completamente selado; e caso (3) apresenta a configuração que favorece 0 aumento de pressão na entrada do radiador (CHRISTOFFERSEN; SÖDERBLOM; LÖFDAHL, 2008). 
O veículo da Figura 12 possui motor de $600 \mathrm{~cm}^{3}$ com sistema adicional de alimentação de ar para o motor (supercharger). Os autores relatam que logo após os primeiros testes com o veículo construído para a competição do ano de 2007, percebeu-se a necessidade de melhorar o sistema de arrefecimento devido ocorrências de superaquecimento do motor. $O$ time passou a buscar as causas e as soluções para esses problemas e após ter dimensionado um sistema de arrefecimento adequado, o próximo passo do desenvolvimento seria propor melhorias para a área de aerodinâmica, de forma a melhorar a vazão de ar para o duto do radiador. Foi proposta então a avaliação de três novos dutos de entrada para o ar, conforme Figura 13.

Nos resultados de Christoffersen et al. (2008) verifica-se que, preservando o desenho do veículo, foi possível um ganho de $154 \%$ na vazão em massa de ar através do radiador devido ao uso de uma nova configuração na tomada de ar com o uso de difusor (caso 3 da Figura 13). Também foi relatado que o uso de vedações entre o trocador de calor e a carenagem do veículo nem sempre melhora a vazão em massa de ar através do radiador (caso 1 da Figura 13). Em uma das propostas que é totalmente selada para forçar a passagem do ar através do radiador, foi observada uma diminuição de vazão em massa de ar através do radiador, um aumento do arrasto aerodinâmico e a presença de recirculação de ar.

Conforme Quim (2007) menciona em seu trabalho, ao desenvolver o projeto de um novo veículo sem a utilização de plataformas pré-existentes (de componentes conhecidos), somente o valor de vazão de ar obtido em simulação não é suficiente para predizer a eficiência de um sistema de arrefecimento. Em ocasião como essa, se faz necessário o conhecimento da capacidade de transferência de calor do trocador de calor com o ar externo. 


\section{METODOLOGIA E MODELAGEM DE TROCADORES DE CALOR}

Neste capítulo está apresentada a metodologia utilizada para o dimensionamento e análise de soluções para trocadores de calor com a aplicação de conceitos obtidos no processo de revisão bibliográfica. Está detalhado o método de cálculo utilizado para desenvolver alternativas para projeto e modelagem de trocador de calor compacto com aplicação veicular. Tais métodos são utilizados na ferramenta computacional TROCALC.

\subsection{METODOLOGIA PARA DIMENSIONAMENTO E ANÁLISE DE DESEMPENHO DE UM TROCADOR DE CALOR}

Conforme proposto por Kays e London (1984), a metodologia para a realização de um projeto de trocador de calor ideal é complexa, não somente pela aritmética envolvida mas pela grande quantidade de hipóteses qualitativas que devem ser adotadas. Um procedimento de projeto proposto pelos autores é ilustrado pelo esquema apresentado na Figura 14.

Os dados de entrada para o método de projeto do trocador de calor incluem três conjuntos de dados: especificações do problema, as características da superfície para transferência de calor e informações relacionadas às propriedades físicas dos fluidos e materiais.

As características de superfície estão relacionadas ao tipo de trocador de calor a ser utilizado, e podem ser selecionadas alternativas a partir de estudos especializados que produziram bancos de dados, como aqueles apresentados na própria publicação de Kays e London (1984). 
As propriedades físicas referem-se às propriedades termodinâmicas dos fluidos envolvidos, que no caso veicular podem ser ar e solução de líquido de arrefecimento, e materiais a serem utilizados pelo trocador. O alumínio, por exemplo, é amplamente utilizado pela indústria automobilística.

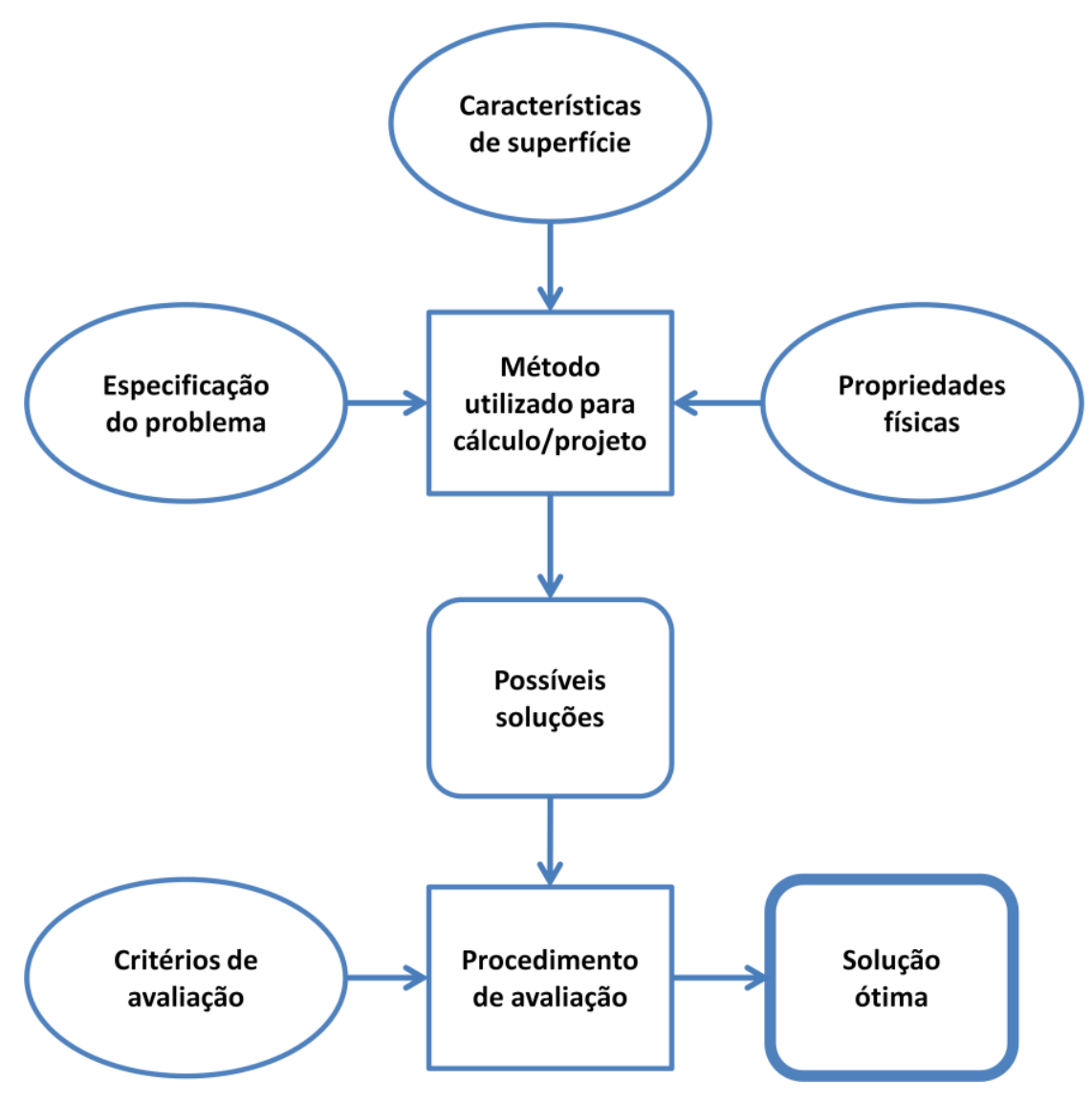

Figura 14 - Metodologia para projeto de trocador de calor (KAYS; LONDON, 1984)

Os métodos de cálculo das trocas térmicas avaliados e que podem ser empregados nesse tipo de projeto são:

- Método que adota a Diferença Média Logarítmica de Temperatura, chamada de DMLT ou, da abreviação do inglês, de LMTD (Log Mean Temperature Difference); 
- Método da Efetividade-NUT, que relaciona parâmetros adimensionais relacionados à efetividade e capacidade de transferência de calor, $\varepsilon$ e NUT (número de unidades de transferência) respectivamente.

Dependendo da quantidade e qualidade dos dados de entrada disponíveis, diversas alternativas de soluções podem ser sugeridas. Os critérios podem ser de naturezas distintas, qualitativas ou quantitativas, tais como custos, massa, limitações geométricas, prazos, regulamentações e outros.

\subsection{MÉTODOS PARA SOLUÇÃO DE PROBLEMAS RELACIONADOS A TROCADORES DE CALOR}

Para desenvolver a ferramenta de cálculo de trocadores de calor, foram estudadas as característica dos dois métodos apontados para dimensionar o trocador de calor. O método $\varepsilon$-NUT mostrou-se mais adequado para o desenvolvimento do presente trabalho. Esse método é adotado no trabalho de Kays e London (1984), a principal referência para esse estudo, e é o método mais citado nos trabalhos estudados durante o processo de revisão bibliográfica. Possui modelagem apropriada para implementação em programa computacional e possui a flexibilidade de ser utilizado não somente para o projeto como também para análise de desempenho de trocadores de calor existentes.

\subsubsection{Método Efetividade-NUT}

Conforme mencionado nos trabalhos de Incropera e DeWitt (1998) e Kays e London (1984), o método DMLT é de fácil utilização quando as temperaturas dos fluidos na entrada são conhecidas e as temperaturas de saída são especificadas ou 
determinadas por expressões específicas do método. Se somente as temperaturas de entrada são conhecidas, o método DMLT exige um processo iterativo e é preferível utilizar o método conhecido pela relação Efetividade-NUT ( $\varepsilon-N U T)$.

Em um trocador de calor, a efetividade de transferência de calor $\varepsilon$ é definida pela razão entre a transferência de calor real e a máxima transferência de calor possível, conforme a equação abaixo:

$$
\varepsilon \equiv \frac{q}{q_{\max }}=\frac{C_{q}\left(T_{q, e}-T_{q, s}\right)}{C_{\min }\left(T_{q, e}-T_{f, e}\right)}=\frac{C_{f}\left(T_{f, s}-T_{f, e}\right)}{C_{\min }\left(T_{q, e}-T_{f, e}\right)}
$$

O termo $\boldsymbol{C}$ representa a taxa de capacidade térmica e pode ser expresso pela relação $C=\dot{m} c_{p}$. O índice "min" indica a menor taxa entre os valores de $\boldsymbol{C}_{\boldsymbol{f}}$ e $\boldsymbol{C}_{\boldsymbol{q}}$.

O parâmetro adimensional NUT (Número de Unidades de Transferência) é amplamente utilizado para análise de trocadores de calor, definido por:

$$
N U T=\frac{U A}{C_{\min }}
$$

A equação para a relação $\varepsilon$-NUT desenvolvida para escoamento cruzado e ambos os fluidos não misturados em único passe é representado pela equação 4.3:

$$
\varepsilon=1-\exp \left[\left(\frac{C_{\min }}{C_{\max }}\right)^{-1}(N U T)^{0,22}\left\{\exp \left[-\frac{C_{\min }}{C_{\max }}(N U T)^{0,78}\right]-1\right\}\right]
$$

Para cálculos de projeto de trocadores de calor, é conveniente trabalhar com a relação $\varepsilon$-NUT na seguinte forma:

$$
N U T=f\left(\varepsilon, \frac{C_{\min }}{C_{\max }}, \text { característica do escoamento }\right)
$$

Porém, segundo Incropera e DeWitt (1998), a relação 4.4 não é possível a partir da manipulação da equação 4.3. Especificamente para o tipo de trocador de calor em 
questão, escoamento cruzado com fluidos não misturados e um único passe, Kays e London (1984) fornecem o seguinte gráfico com a relação de $\varepsilon$ em função de NUT:

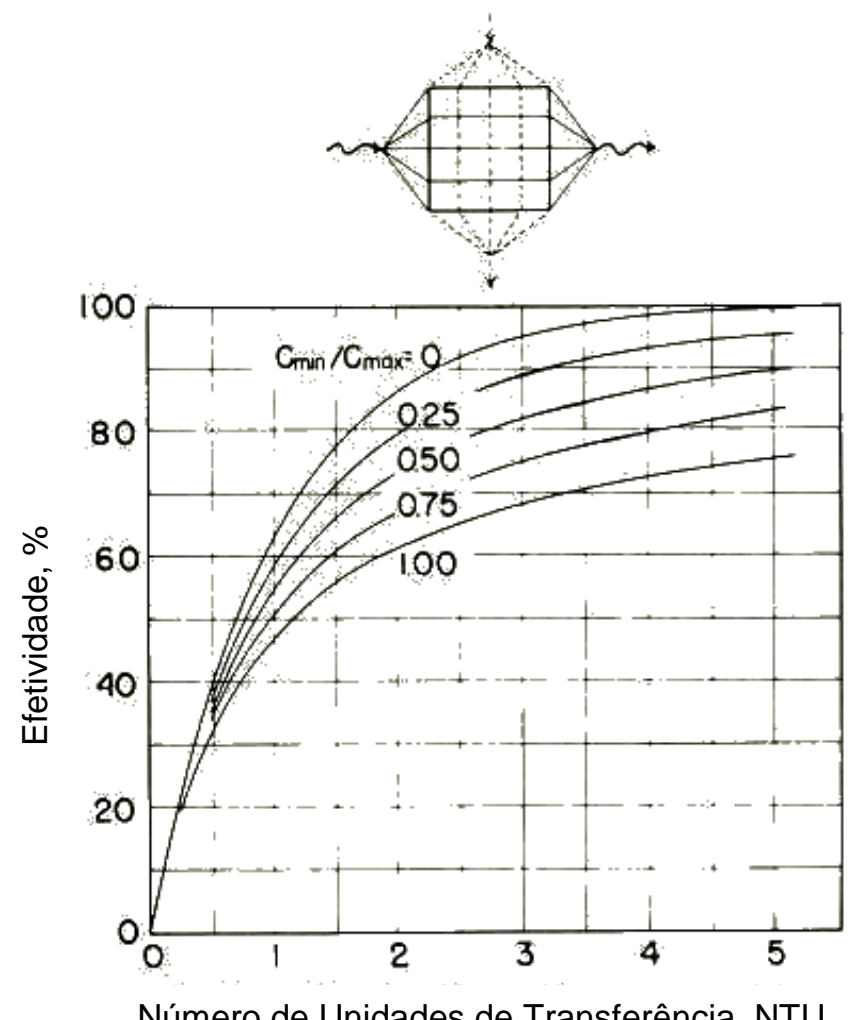

Número de Unidades de Transferência, NTU

Figura 15 - Efetividade de transferência de calor em função do número de unidades de transferência para trocadores de calor de escoamento cruzado com os dois fluidos não misturados (KAYS;

LONDON, 1984)

Conforme mencionado pelos autores Kays e London (1984), através do gráfico da Figura 15 percebe-se que quanto menor o valor de NUT, menor será a efetividade do trocador. Já com o aumento de NUT, nota-se uma aproximação assintótica para o limite imposto pela característica do fluxo e por considerações termodinâmicas. Isso significa que para a condição $\mathrm{C}_{\min } / \mathrm{C}_{\max } \rightarrow 0$ a efetividade é independente da característica do escoamento e a equação (4.5) é válida para qualquer tipo de trocador de calor.

$$
\varepsilon=1-\exp [-N U T]
$$


A mesma referência (KAYS; LONDON, 1984) fornece uma tabela com os valores da relação de $\varepsilon$ em função de NUT, conforme a seguir:

Tabela 1 - Efetividade $(\varepsilon)$ em função da razão entre as taxas de capacidade térmica, $\mathrm{Cmin} / \mathrm{Cmax}$, e do número de unidades de transferência, NUT (KAYS; LONDON, 1984) para a condição de escoamento cruzado com os dois fluidos não misturados.

\begin{tabular}{lcccccc} 
NUT & \multicolumn{5}{c}{$\boldsymbol{\varepsilon}$ em função de Cmin/Cmax } \\
\cline { 2 - 6 } 0,00 & 0,00 & 0,25 & 0,50 & 0,75 & 1,00 \\
\hline 0,25 & 0,000 & 0,000 & 0,000 & 0,000 & 0,000 \\
0,50 & 0,221 & 0,215 & 0,209 & 0,204 & 0,199 \\
0,75 & 0,393 & 0,375 & 0,358 & 0,341 & 0,326 \\
1,00 & 0,528 & 0,495 & 0,466 & 0,439 & 0,413 \\
1,25 & 0,632 & 0,588 & 0,547 & 0,510 & 0,476 \\
1,50 & 0,714 & 0,660 & 0,610 & 0,565 & 0,523 \\
1,75 & 0,777 & 0,716 & 0,660 & 0,608 & 0,560 \\
2,00 & 0,826 & 0,761 & 0,700 & 0,642 & 0,590 \\
2,50 & 0,865 & 0,797 & 0,732 & 0,671 & 0,614 \\
3,00 & 0,918 & 0,851 & 0,783 & 0,716 & 0,652 \\
3,50 & 0,950 & 0,888 & 0,819 & 0,749 & 0,681 \\
4,00 & 0,970 & 0,915 & 0,848 & 0,776 & 0,704 \\
4,50 & 0,982 & 0,934 & 0,869 & 0,797 & 0,722 \\
5,00 & 0,989 & 0,948 & 0,887 & 0,814 & 0,737 \\
6,00 & 0,993 & 0,959 & 0,901 & 0,829 & 0,751 \\
7,00 & 0,997 & 0,974 & 0,924 & 0,853 & 0,772 \\
& 0,999 & 0,983 & 0,940 & 0,871 & 0,789
\end{tabular}

\subsection{CARACTERIZAÇÃO DE PROBLEMAS}

Para problemas que envolvem trocadores de calor compacto, de análise de desempenho e cálculo de projeto, é possível determinar as características termofísicas dos fluidos correspondentes tais como calor específico à pressão constante $\left(\boldsymbol{c}_{\boldsymbol{p}}\right)$, condutividade térmica $(\boldsymbol{k})$, volume específico $(\boldsymbol{v})$, número de Prandtl $(\boldsymbol{P r})$ e viscosidade dinâmica $(\boldsymbol{\mu})$ através dos valores de temperatura dos fluidos e das 
especificações de materiais. Para os dois tipos de problema, o método $\boldsymbol{\varepsilon}$-NUT pode ser empregado de forma satisfatória. Como o objetivo do presente trabalho são trocadores de calor com aplicação veicular, considera-se somente o arranjo dos fluxos cruzados com ambos os fluidos não misturados.

Para problemas de análise de desempenho, em que o tipo e as dimensões do trocador são conhecidos, o objetivo é determinar a taxa de transferência de calor e as temperaturas de saída dos fluidos para vazões e temperaturas de entrada especificadas.

Para problemas de projeto de trocadores de calor, uma dada taxa de transferência de calor é desejada e as temperaturas de entrada e as vazões dos fluidos são conhecidas ou estimadas. Nesse caso, há a possibilidade de iterações.

Conforme Kays e London (1984), o seguinte quadro resumo para o método $\varepsilon$-NUT pode ser obtido, conforme os tipos de problema:

Tabela 2 - Quadro resumo para aplicação de método $\varepsilon$-NUT para as duas finalidades: análise de desempenho e projeto de trocador de calor; modificado de Kays e London (1984)

\begin{tabular}{|c|c|}
\hline Análise de desempenho & Projeto \\
\hline $\begin{array}{l}\text { 1. Calcular "NUT" das vazões, temperaturas e } \\
\text { área dadas; } \\
\text { 2. Calcular a relação " } \mathrm{C}_{\min } / \mathrm{C}_{\max } \text { "; } \\
\text { 3. Utilizar o gráfico " } \varepsilon-N U T " \text { para o tipo de fluxo } \\
\text { cruzado e fluidos não misturados e obter " } \varepsilon " ; \\
\text { 4. Calcular "q" através da equação } \\
\qquad q=\varepsilon C_{\min }\left(T_{q e}-T_{f s}\right)\end{array}$ & $\begin{array}{l}\text { 1. Calcular " } \varepsilon \text { " através das temperaturas dadas; } \\
\text { 2. Calcular a relação " } \mathrm{C}_{\min } / \mathrm{C}_{\max } \text { "; } \\
\text { 3. Utilizar o gráfico " } \varepsilon \text {-NUT" para o tipo de fluxo } \\
\text { cruzado e fluidos não misturados e obter "NUT"; } \\
\text { 4. Calcular "A" através da equação: } \\
\qquad A=\text { NUT }\left(C_{\min } / U\right)\end{array}$ \\
\hline
\end{tabular}




\subsection{SELEÇÃO DE GEOMETRIA NO PROJETO DE TROCADOR DE CALOR COMPACTO}

As características de transferência de calor e do escoamento para trocadores de calor compactos foram determinadas para configurações geométricas e são usualmente apresentadas em forma de gráficos e tabelas de dados, como o exemplo da Figura 16. Os dados para cada configuração de trocador de calor compacto de interesse para esse estudo estão disponíveis em Kays e London (1984) e em Incropera e DeWitt (1998).

As diferenças básicas estão no dimensionamento dos tubos e no arranjo das aletas. Resultados da transferência de calor são correlacionados em termos adimensionais em gráficos que relacionam o fator "j" de Colburn e Reynolds, conforme segue:

$$
\begin{gathered}
j_{c}=S t P r^{2 / 3} \\
S t=h / G c_{p} \\
R e=G D_{h} / \mu
\end{gathered}
$$




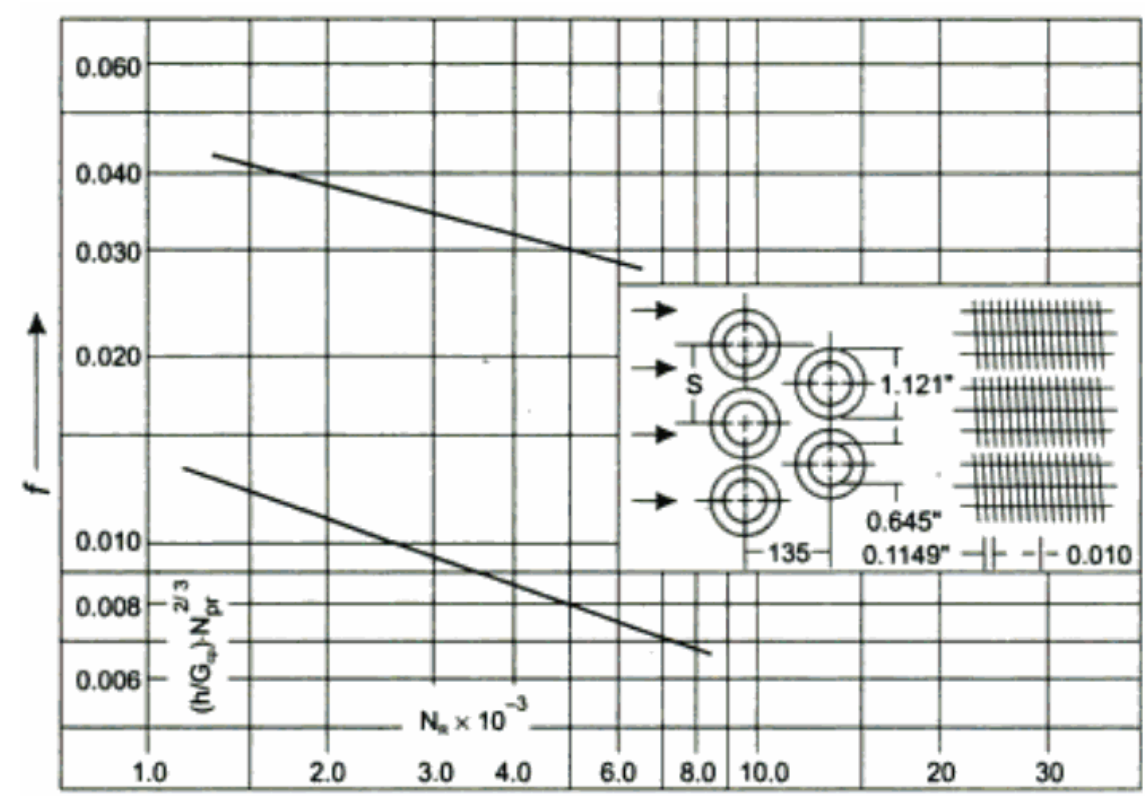

Diâmetro externo dois tubos, $D_{e}=16,4 \mathrm{~mm}$

Número de aletas $=275$ por metro

Diâmetro hidráulico da passagem de escoamento, $D_{h}=6,68 \mathrm{~mm}$

Espessura das aletas $t=0,254 \mathrm{~mm}$

Área de escoamento livre/ área frontal, $\sigma=0,449$

Área de transferência de calor/ volume total, $\alpha=269 \mathrm{~m}^{2} / \mathrm{m}^{3}$

Área das aletas/ área total, $A_{\alpha} / \mathrm{A}=0,830$

Nota: A área mínima para o escoamento livre encontra-se nos espaços normais ao escoamento.

Figura 16 - Transferência de calor e fator de atrito para um trocador de calor compacto com tubos e aletas circulares, superfície denominada CF-7.0-5/8J (KAYS; LONDON, 1984; INCROPERA; DEWITT, 1998).

Tanto o número de Stanton quanto o número de Reynolds aparecem em função da velocidade mássica máxima definida por $\mathrm{G}$, conforme segue:

$$
G=\rho U_{\text {max }}=\frac{\rho U A_{f r}}{A_{c}}=\frac{\dot{m}}{A_{c}}=\frac{\dot{m}}{\sigma A_{f r}}
$$

Considerando o cálculo de projeto de trocadores de calor, o valor de $\boldsymbol{\alpha}$ apresentado pelo gráfico da Figura 16 é utilizado para determinar o volume requerido do trocador de calor após a determinação da área total necessária para a transferência de calor. 
De forma inversa, para cálculos de desempenho, o valor de $\boldsymbol{\alpha}$ seria utilizado para determinar a área a partir do conhecimento do volume do trocador de calor existente.

Os gráficos obtidos na literatura pesquisada estão disponíveis na forma de banco de dados e de equações ajustadas para que possam ser utilizadas pela ferramenta computacional.

\subsection{AVALIAÇÃO DE PERDA DE PRESSÃO}

Conforme Kays e London (1984), no projeto de trocadores de calor em que um dos fluidos é um gás, é importante o conhecimento da característica relacionada ao atrito na superfície de transferência de calor. Como gases são fluidos de baixa densidade, o efeito do atrito viscoso em função da vazão é ampliado consideravelmente. Em um projeto de trocador de calor, o conhecimento da influência do atrito é tão importante quanto à característica de transferência de calor de uma determinada superfície. A característica relacionada ao atrito viscoso é representada pelo fator adimensional $\boldsymbol{f}$ em função do número de Reynolds, conforme apresentado no exemplo da Figura 16.

Para avaliação da perda de pressão em relação ao ar, considerando o escoamento normal a um conjunto de tubos, tem-se desenvolvida a seguinte fórmula:

$$
\Delta P=\frac{G^{2} v_{e}}{2}\left[\left(1+\sigma^{2}\right)\left(\frac{v_{s}}{v_{e}}-1\right)+f \frac{A}{A_{c}} \frac{v_{m}}{v_{e}}\right]
$$

A primeira parcela do lado direito da equação, dentro dos colchetes, considera os efeitos de aceleração ou desaceleração do fluido ao passar pelo trocador; a segunda parcela está relacionada com as perdas por atrito.

Para uma dada dimensão de um trocador de calor, a relação entre as áreas pode ser relacionada através da seguinte expressão: 


$$
\frac{A}{A_{c}}=\frac{\alpha v}{\sigma A_{f r}}
$$

No caso de radiadores veiculares, as propriedades geométricas do veículo podem influenciar diretamente na qualidade do fluxo e consequentemente nos valores de perda de carga no radiador. Outro fator importante está na distribuição de pressão ao longo da superfície do radiador, que depende diretamente da disposição do radiador em relação ao fluxo livre e podem ocorrer distribuições não uniformes. 


\section{DESENVOLVIMENTO DE FERRAMENTA COMPUTACIONAL PARA ANÁLISE DE TROCADOR DE CALOR COMPACTO}

Nesse capítulo é apresentada a ferramenta computacional desenvolvida para realizar o cálculo exigido em um projeto e para fazer a análise de desempenho de trocadores de calor compactos. O desenvolvimento dessa ferramenta tem como principal referência o trabalho de Kays e London (1984), amplamente citado pelas publicações que tratam de trocadores de calor e pode ser reconhecida pela contribuição que oferece para a Engenharia.

Em um projeto de trocador de calor para veículos de competição, são necessárias duas abordagens principais para o desenvolvimento de uma solução ótima. Uma está relacionada ao problema térmico e outra ao problema fluidodinâmico. $\mathrm{Na}$ primeira abordagem, basicamente, é necessário saber qual a área ou o volume necessário para que o trocador de calor realize o trabalho de arrefecimento de forma satisfatória. Através dos dados de entrada que são temperatura dos fluidos, rejeição térmica do motor e perda de pressão do fluido de arrefecimento, é possível calcular as dimensões do trocador de calor. Esses dados de entrada podem ser obtidos através de estimativas ou experimentalmente.

A segunda abordagem está relacionada à dinâmica dos fluidos e é complementar à abordagem térmica. O trocador de calor, ou usualmente denominado radiador, é um dos subsistemas de um veículo e parte do problema está em sua integração junto ao mesmo. Essa integração necessita de critérios para completar-se de forma plena. No caso de um veículo de alto desempenho, o baixo arrasto aerodinâmico é um dos principais fatores de projeto. Ao se definir a geometria do trocador de calor, é necessária a análise do comportamento desse dispositivo em conjunto com outros componentes, tais como carenagens, reservatórios e os dutos do liquido de arrefecimento. Dependendo da competição, algumas regras podem limitar a geometria do veículo e eventualmente alguma dimensão do radiador. 
O programa foi desenvolvido utilizando o aplicativo Microsoft Excel ${ }^{\circledR}$ e sua utilização não necessita de computadores de alto desempenho. Nesse programa foram implementadas as equações, tabelas e gráficos que compõem o trabalho de Kays e London (1984) a serem utilizados para solução de problemas do ponto de vista térmico.

A partir do momento em que se obtém os resultados dimensionais do trocador de calor, pode-se iniciar os desenhos de propostas detalhadas do sistema de arrefecimento integrado ao veículo, que podem ser executados com programas de CAD (Computer Aided Design). Tais modelos são a base para a geração de malhas de elementos finitos e necessários para o desenvolvimento de análises do comportamento do ar, com uso de programas de dinâmica dos fluidos computacional (CFD).

\subsection{APLICATIVO PARA PROJETO DE TROCADOR DE CALOR COMPACTO}

Nesse item é apresentado o aplicativo que foi desenvolvido para projeto de trocador de calor compacto, denominado TROCALC, em formato de planilha que está dividida em cinco partes principais: dados de entrada, dados de propriedades dos fluidos, geometria do núcleo do trocador de calor, cálculo de $\varepsilon$-NUT e processo iterativo. Como regra geral, as células a serem preenchidas pelo usuário são indicadas na cor verde e as unidades devem respeitar o Sistema Internacional (SI), sendo informadas ao lado dos valores a serem preenchidos, como também nos campos de resultados. Estas características podem ser vistas nas figuras 17 e 18.

Mesmo que utilize grande quantidade de informações, a interface do aplicativo TROCALC é simples e direta. Possui conteúdo auto-explicativo de modo a auxiliar o usuário na entrada de dados e análise de resultados. Todos os valores para parâmetros envolvidos e resultados de cálculos disponibilizados são para a 
verificação do usuário, com o objetivo de facilitar a interpretação dos resultados e a identificação de possíveis erros no preenchimento. São utilizadas variáveis conforme o trabalho de Kays e London (1984)

\subsubsection{Dados de entrada}

Essa parte do aplicativo apresenta as células a serem preenchidas com os valores de vazão e temperatura de entrada e saída dos fluidos e pressão atmosférica local na entrada do radiador. É também solicitada uma estimativa de perda de pressão para o ar, relacionada à resistência ao fluxo imposta pelo núcleo do radiador em estudo.

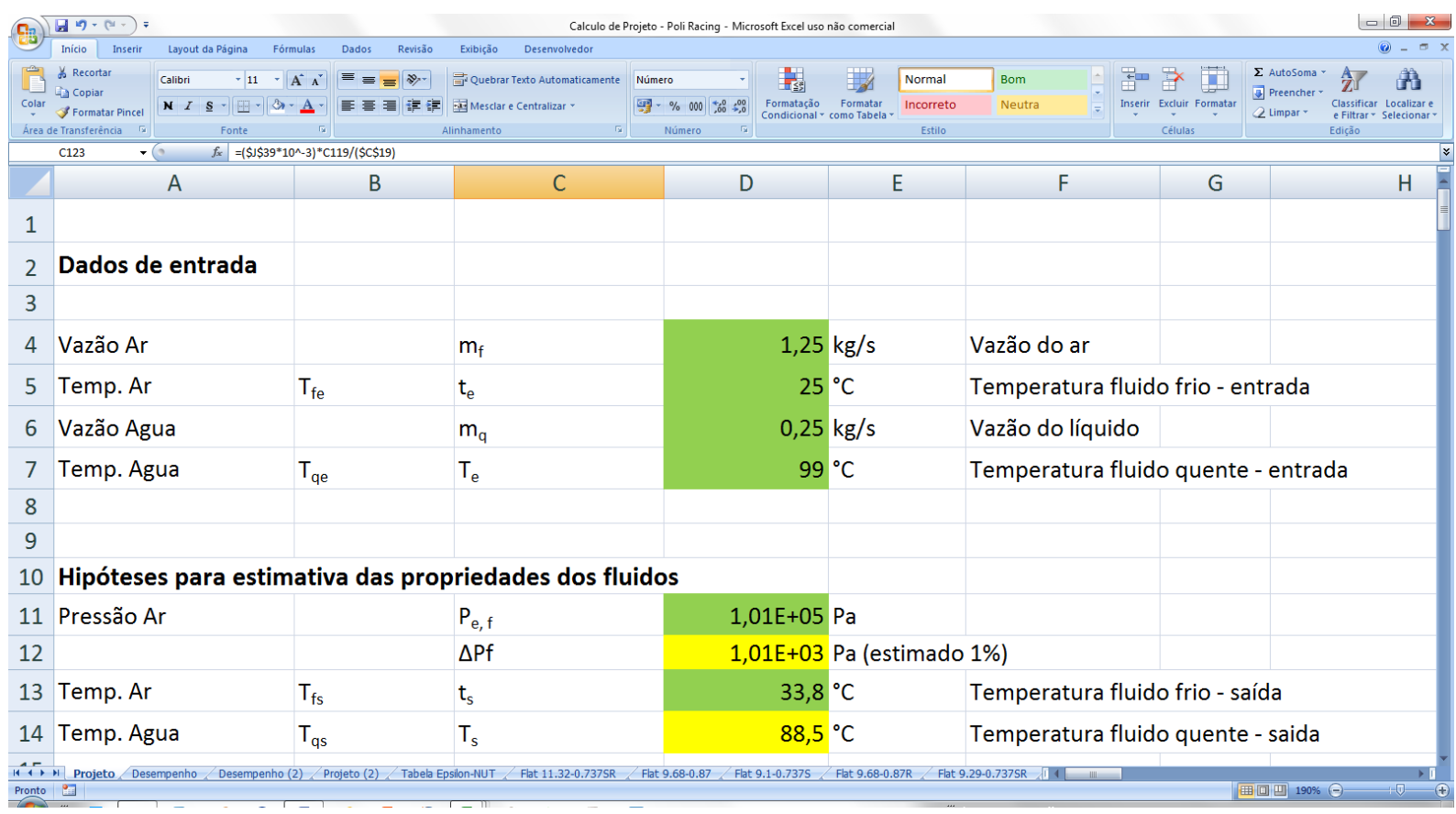

Figura 17 - Imagem do aplicativo TROCALC que contém os dados de entrada para o cálculo de projeto de trocador de calor compacto. 
Os dados de entrada podem ser obtidos pelo usuário através de diversas fontes, tais como dados de cálculos anteriores, valores estimados ou extraído de testes de bancada, dinamômetro ou em pista com o veículo.

\subsubsection{Propriedades dos fluidos}

Os dados de propriedade dos fluidos devem ser adotados consideradas as condições de temperatura e de pressão destes. São eles: massa específica, volume específico, viscosidade dinâmica, condutividade térmica, calor específico e constante gravitacional. É também necessário o preenchimento da célula relacionada à condutividade térmica do material que compõe o trocador de calor.

Esses dados são requeridos para ambos os fluidos e da mesma forma como a seção anterior, a origem proveniente desses dados irão garantir a qualidade dos resultados. Informações como o tipo de uso que é esperado para o veículo e a faixa de rotação que o motor deve trabalhar são dados fundamentais para uma clara identificação do problema. 


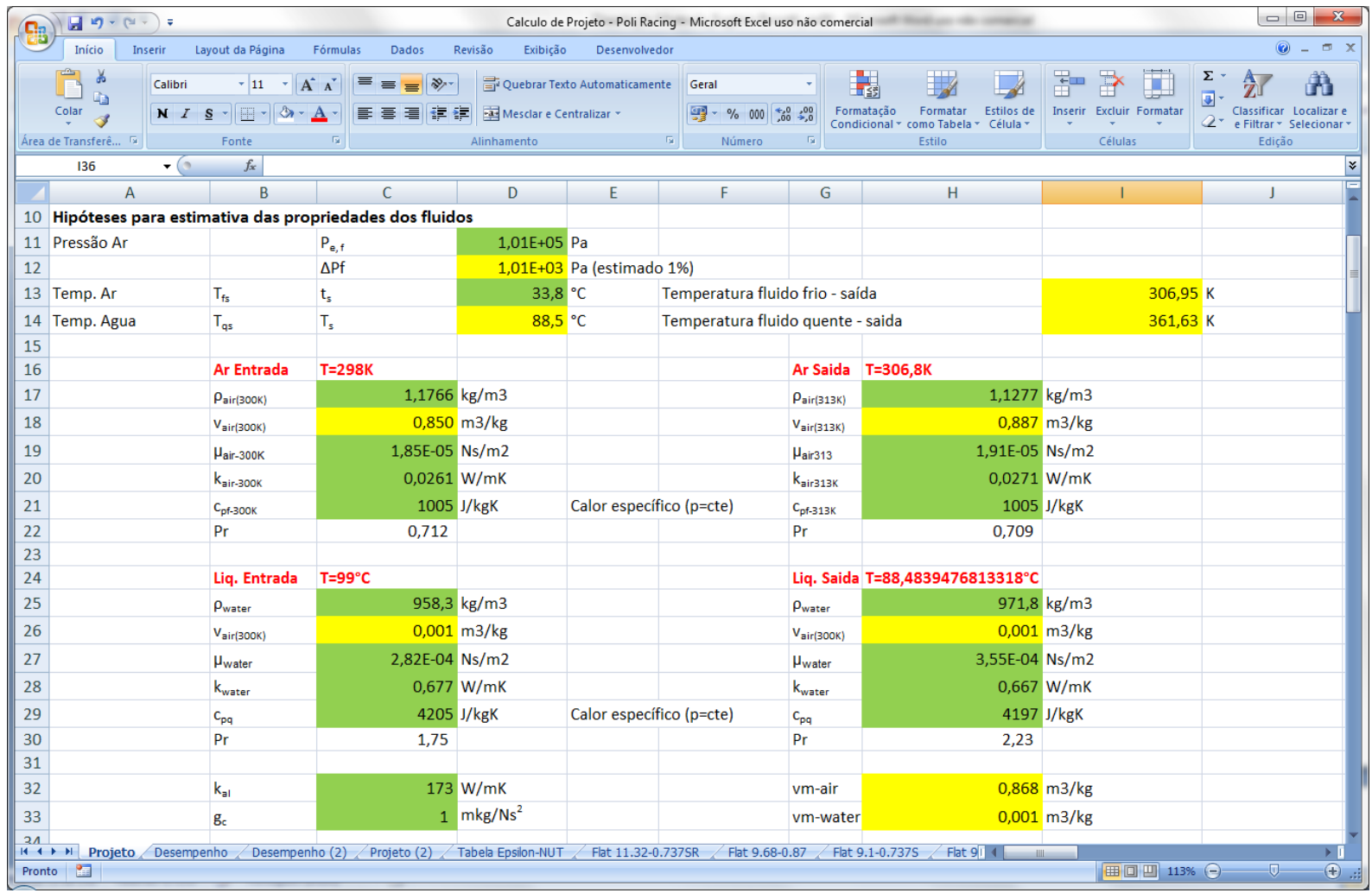

Figura 18 - Imagem do aplicativo TROCALC que contém os dados das propriedades fixas dos fluidos e material do radiador, para o cálculo de projeto de trocador de calor compacto.

\subsubsection{Geometria do núcleo do trocador de calor}

Essa parte do aplicativo contém os dados de geometria do núcleo do trocador de calor, que é composto basicamente por tubos e aletas. As informações sobre o arranjo de tubos (se alinhados ou escalonados), o tipo de aleta (se plana ou ondulada), diâmetro dos tubos, espessura de aleta, diâmetro hidráulico, razão entre a área de transferência de calor e volume do trocador de calor são dados fornecidos por Kays e London (1984) para os diversos tipos de geometria.

Também compõe essa parte da planilha uma lista de dados relacionados ao fator de transferência de calor $\left(\mathrm{StPr}^{2 / 3}\right)$, conhecido também como fator "j" de Colburn, e ao fator de atrito (f) específico para a geometria de núcleo escolhida, em função do 
número de Reynolds (Re). A Figura 19 ilustra a disposição dessas informações na ferramenta TROCALC.

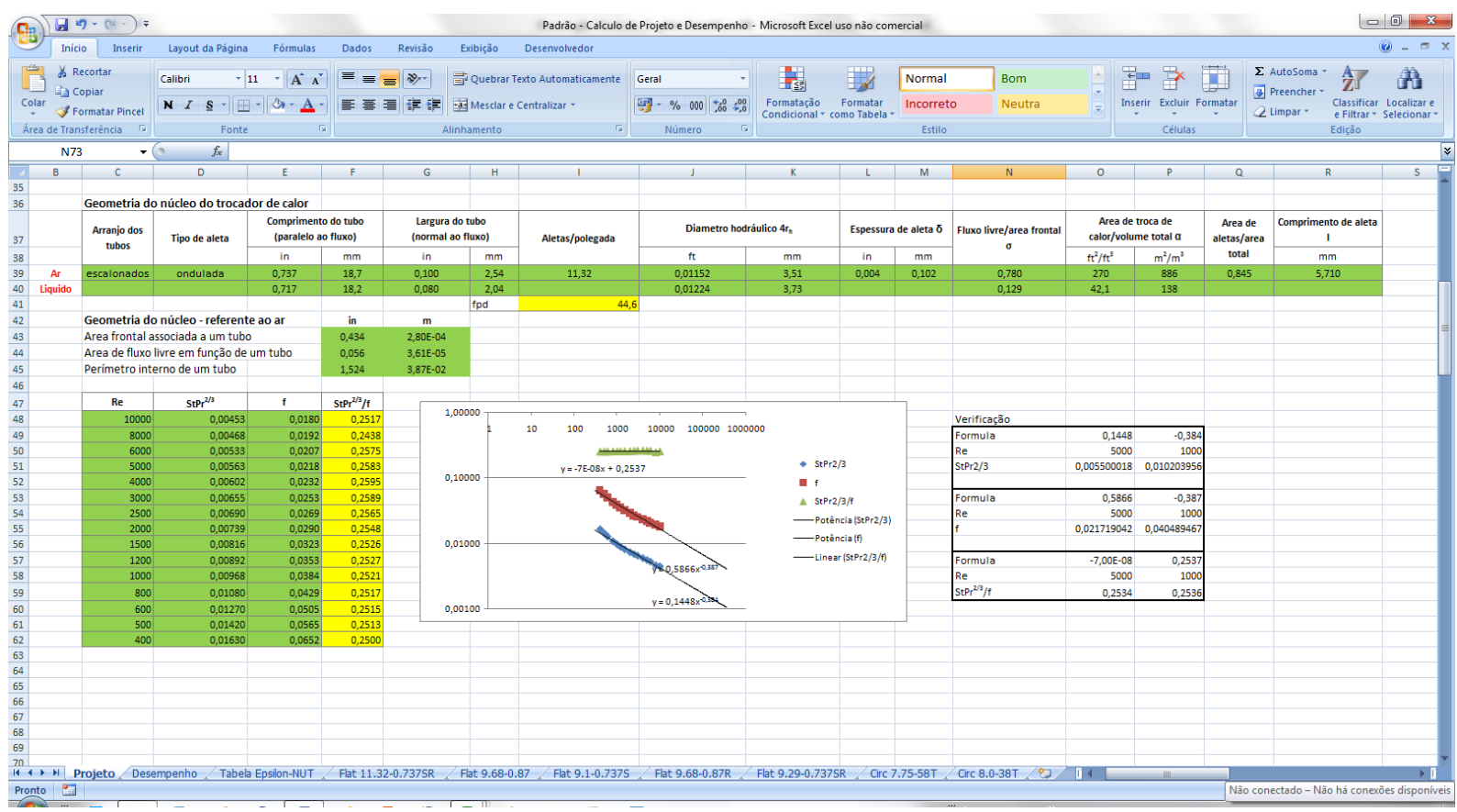

Figura 19 - Imagem do aplicativo TROCALC que contém os dados de geometria do núcleo do trocador de calor e a tabela contendo o fator "j" de Colburn para transferência de calor e o fator de atrito para uma dada geometria em função do número de Reynolds.

Todas as geometrias possíveis de serem implementadas em aplicações veiculares e disponíveis no trabalho de Kays e London (1984) foram adicionados a essa ferramenta. Sabe-se porém que há uma limitação para esses dados e, ao longo do tempo, novas geometrias podem ser estudadas e implementadas em projetos de radiadores de veículos. Com isso, o aplicativo possui a flexibilidade para que sejam inseridos novos dados geométricos e o usuário deve se atentar para o preenchimento completo dos dados requeridos, dentro das unidades estabelecidas, e respeitar a disposição dos mesmos na planilha a fim de evitar erros. 


\subsubsection{Cálculo de efetividade e NUT}

Após as seções de inserção de dados, o aplicativo TROCALC apresenta os primeiros cálculos que estão relacionados à metodologia escolhida ( $\varepsilon$-NUT) para compor a análise de troca de calor. Kays e London (1984) apresentam gráficos que relacionam a efetividade $(\varepsilon)$ em função do número de unidades de transferência (NUT) para valores de razão entre as taxas de capacidade calorífica $\left(\mathrm{C}_{\min } / \mathrm{C}_{\max }\right)$, conforme já apresentado pela Figura 15. Apresenta também uma tabela com os valores extraídos do gráfico mencionado (Tabela 1).

Utilizando os pontos informados na tabela, foi possível reproduzir o gráfico específico para a condição de trocadores de calor com ambos os fluidos não misturados, conforme é apresentado pela Figura 20 que segue, utilizando os recursos do programa Microsoft Excel ${ }^{\circledR}$. Além dos pontos, foram geradas as devidas curvas de tendência com o intuito de reproduzir as linhas do gráfico da Figura 15. As curvas adotadas estão relacionadas às equações polinomiais de $5^{\circ}$ grau, que apresentaram o melhor ajuste perante os dados informados pelos autores.

A partir das equações e do gráfico apresentados, foi possível expandir esses dados para uma superfície considerando a variação de valores de 0,00 a 1,00 para a relação $C_{\min } / C_{\max }$, conforme é apresentada pela Figura 21 .

Um algoritmo foi desenvolvido para selecionar valores da planilha que relacionam os três dados mencionados $\left(\varepsilon\right.$, NUT e $\left.\mathrm{C}_{\min } / \mathrm{C}_{\max }\right)$. Obtendo os valores de $\mathrm{C}_{\min } / \mathrm{C}_{\max }$ e da efetividade $\varepsilon$, a própria planilha realiza a escolha dos dados para cálculo do número de unidades de transferência (NUT). A importância de ter o gráfico e a superfície é um recurso útil para que o usuário dessa ferramenta possa confrontar os resultados calculados com os gráficos, caso encontre alguma inconsistência dos valores. Uma imagem desse algoritmo implementado na ferramenta computacional de cálculo pode ser vista na Figura 22. 
عx NUT

Fluidos não misturados

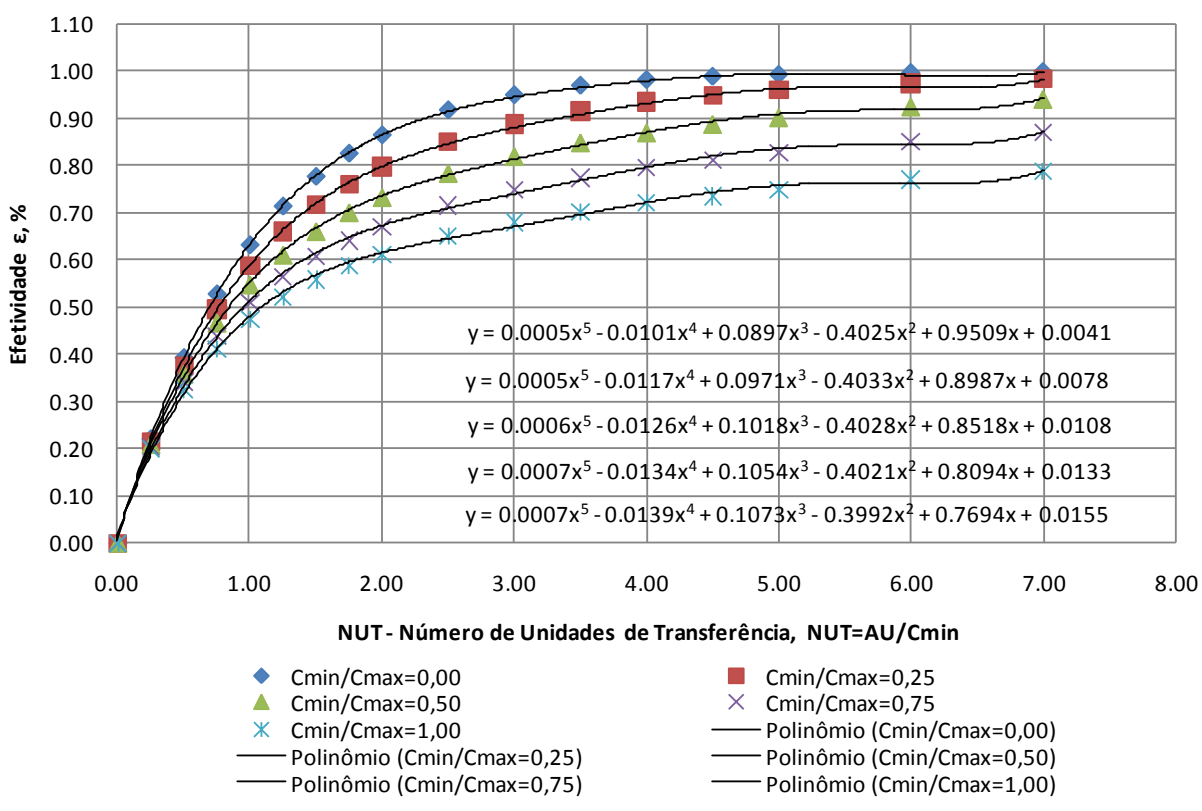

Figura 20 - Gráfico que relaciona a efetividade de transferência de calor $(\varepsilon)$ com o número de unidades de transferência (NUT) e a razão entre as taxas de capacidade calorífica $\left(\mathrm{C}_{\min } / \mathrm{C}_{\max }\right)$, reproduzido conforme o trabalho de Kays e London (1984).

$\varepsilon \times$ NUT

Fluidos não misturados

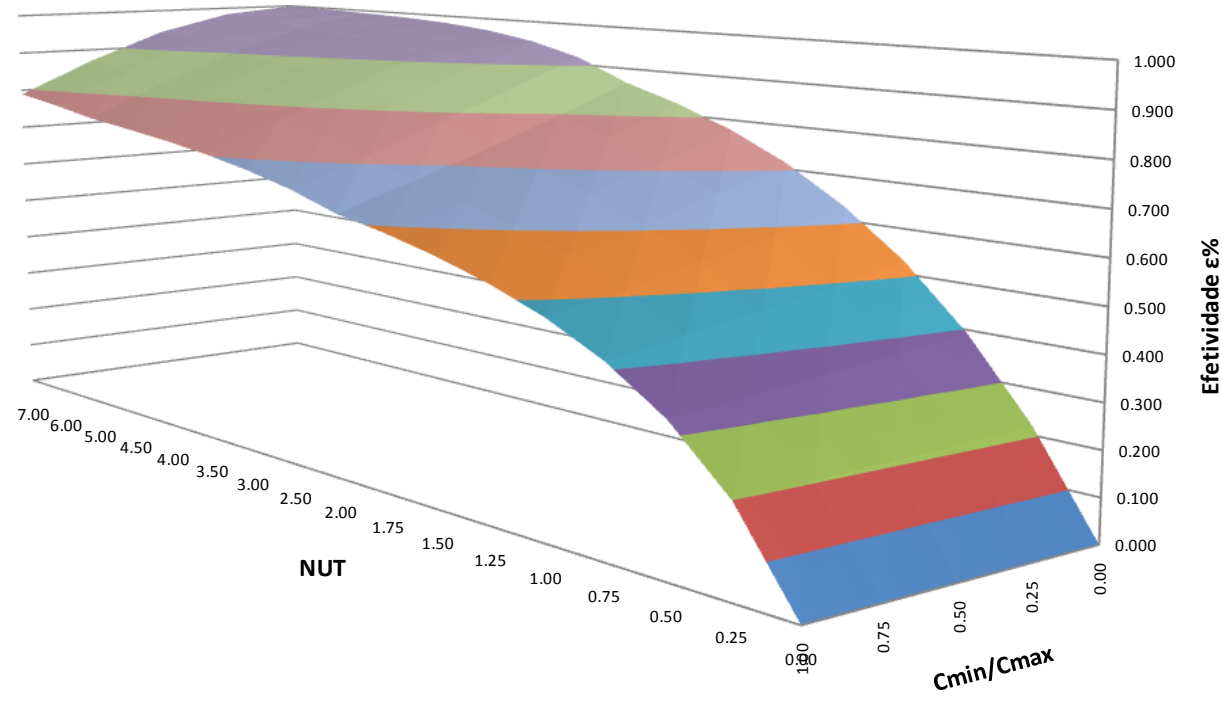

Figura 21 - Superfície que relaciona a efetividade de transferência de calor $(\varepsilon)$ com o número de unidades de transferência (NUT) e a razão entre as taxas de capacidade calorífica $\left(\mathrm{C}_{\min } / \mathrm{C}_{\max }\right)$. 

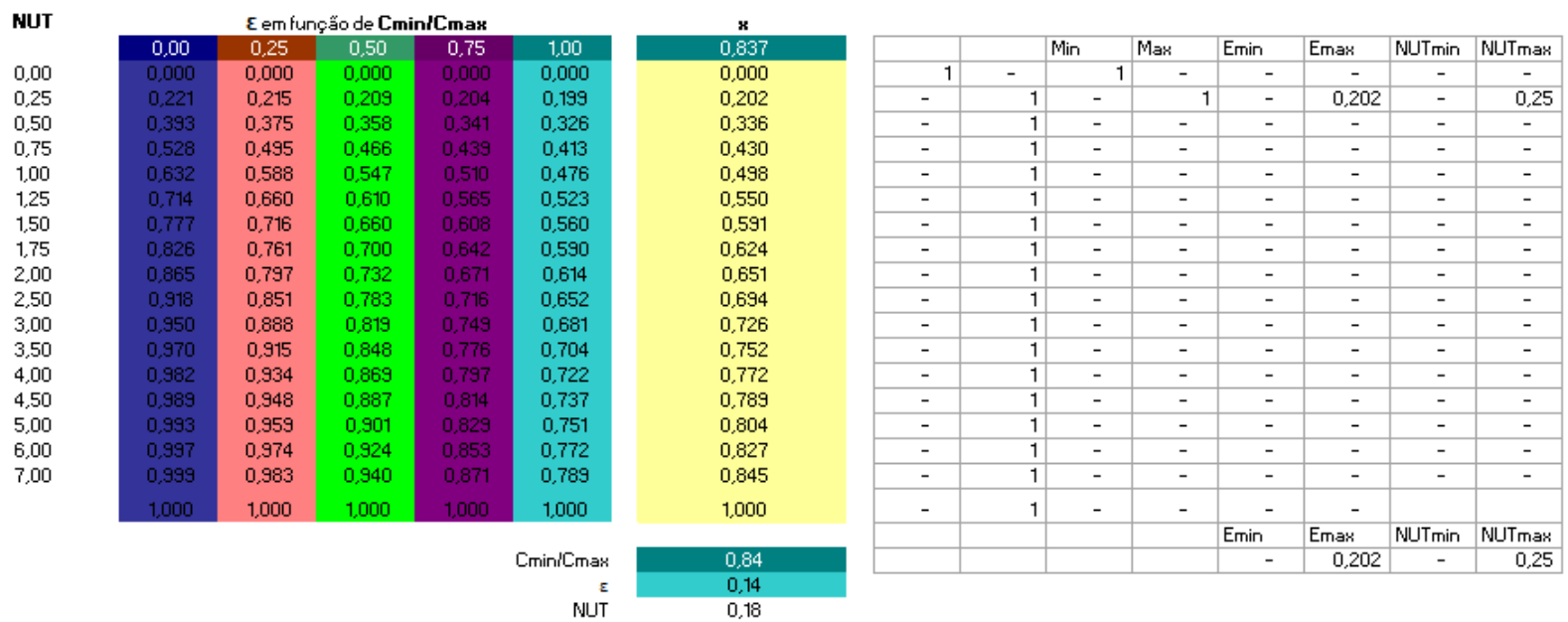

Figura 22 - Matriz para auxílio ao cálculo do número de unidades de transferência (NUT) com base nos dados de efetividade $(\varepsilon)$ e a razão entre as taxas de capacidade calorífica $\left(C_{\min } / C_{\max }\right)$.

\subsubsection{Processo iterativo}

O processo iterativo conclui a sequência de cálculos para o projeto de trocadores de calor. Nessa fase, é necessário inserir um valor para $\mathrm{StPr}^{2 / 3} / f$ que está disponível em uma tabela junto do detalhamento geométrico do núcleo, ao final da seção anterior. Segundo Kays e London (1984), uma boa estimativa para iniciar o processo iterativo é adotar o valor de 0,3 para $\mathrm{StPr}^{2 / 3} / \mathrm{f}$, ficando a critério do usuário e obviamente do tipo de problema, de dados e da análise de interesse.

O processo iterativo respeita integralmente a sequência de cálculos desenvolvida pelos autores. Para a ferramenta computacional foi então desenvolvido uma série de rotinas em que é possível o usuário visualizar os valores calculados e obter os resultados dentro da quantidade de iterações que desejar. 


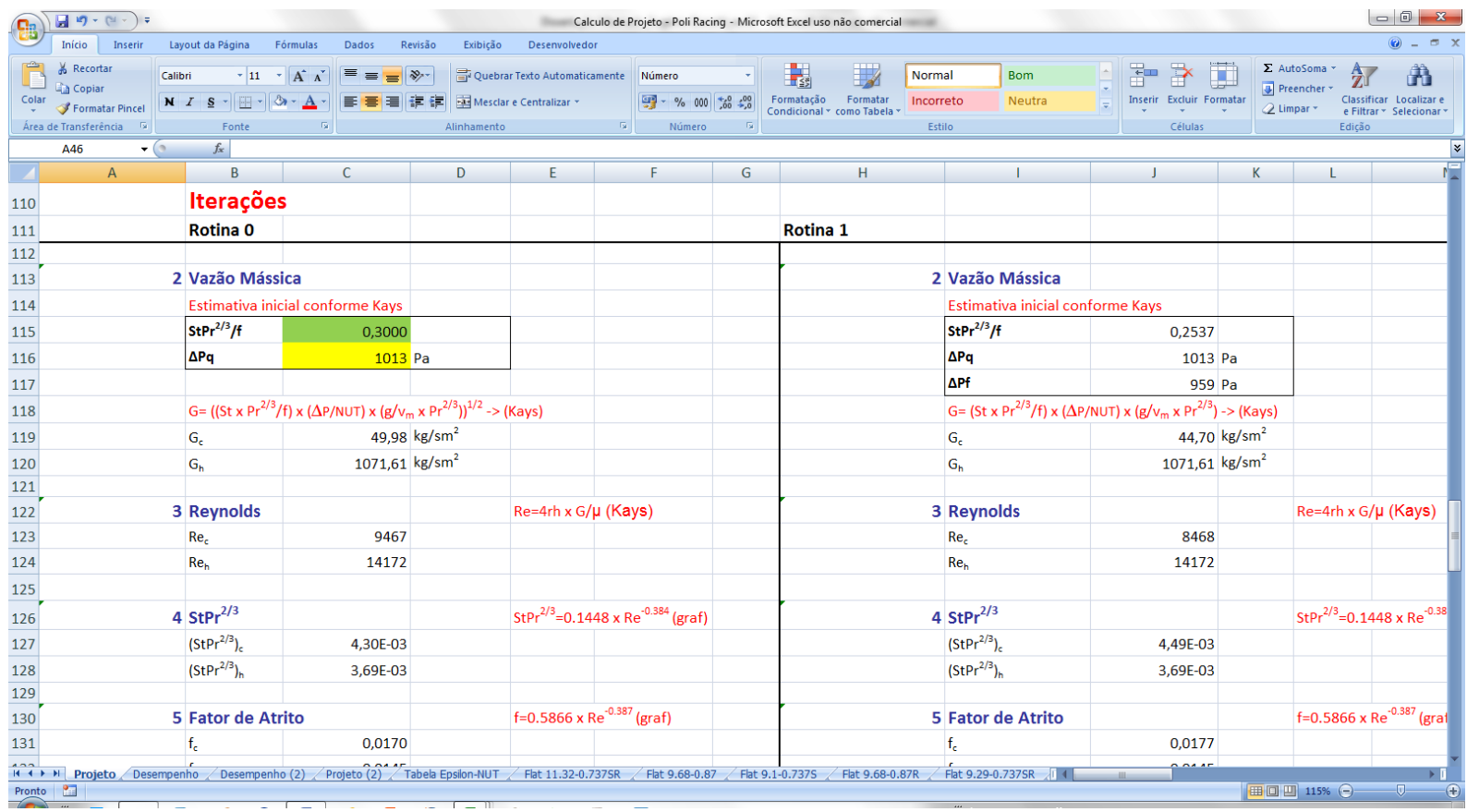

Figura 23 - Imagem do aplicativo TROCALC que contém os cálculos e iterações para a área e a perda de pressão do fluxo de ar pelo radiador.

Os cálculos seguem conforme a sequência:

1. Velocidade mássica $(\mathrm{G})$;

2. Número de Reynolds (Re);

3. Fator "j" de Colburn $\left(\mathrm{StPr}^{2 / 3}\right)$;

4. Fator de atrito (f);

5. Coeficiente de transferência de calor (h);

6. Eficiência da aleta $\left(\eta_{\mathrm{f}}\right)$;

7. Eficiência da superfície global $\left(\eta_{0}\right)$;

8. Coeficiente global de transferência de calor (U);

9. Cálculo de Área e Volume (A e V);

10. Perda de pressão $\left(\Delta \mathrm{P} / \mathrm{P}_{\mathrm{atm}}\right)$.

O aplicativo dispõe de cinco rotinas de cálculo para iteração, porém conforme Kays e London (1984), o processo de iteração é breve sendo possível obter valores satisfatórios com até 3 iterações. Caso o usuário tenha interesse em adicionar mais 
rotinas e aumentar o número de iterações, basta copiar os campos delimitados e inseri-los do lado direito da última rotina, respeitando a disposição dos elementos a fim de garantir plenamente o desenvolvimento dos cálculos. Automaticamente o cálculo da rotina adicional será estabelecido sem a necessidade de ajustes.

\section{2. ÁNALISE DE DESEMPENHO DE TROCADORES DE CALOR COMPACTO}

Nessa seção é apresentada a parte do aplicativo TROCALC que se destina aos cálculos para auxiliar a análise de desempenho de trocadores de calor compacto. A planilha é semelhante àquela apresentada na seção anterior e está dividida em quatro partes principais: dados de entrada, dados de propriedades dos fluidos, geometria do núcleo do trocador de calor e cálculos. Da mesma forma como a planilha anterior, as células a serem preenchidas pelo usuário são indicadas nas figuras que seguem na cor verde e as unidades devem respeitar o Sistema Internacional (SI).

As três primeiras seções (dados de entrada, dados de propriedades dos fluidos, geometria do núcleo do trocador de calor) são semelhantes ao aplicativo de cálculo de projeto, conforme é apresentado pelas Figuras de $17^{\underline{a}}$ a 19 . Uma particularidade para a seção de entrada de dados é a necessidade de inserção das dimensões principais do núcleo do trocador de calor que é objeto da análise, representadas por $a, b$ e c conforme Figura 24.

Para o caso de análise de desempenho não se faz necessário o uso de recurso iterativo, uma vez que as propriedades físicas do radiador já são conhecidas. 


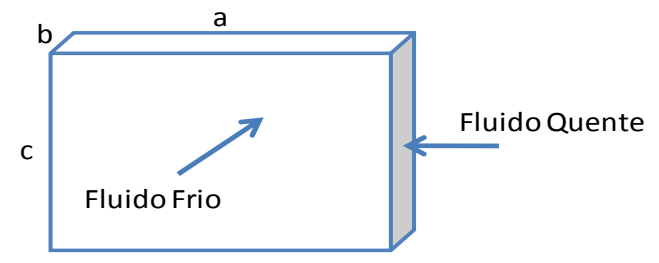

Figura 24 - Imagem da configuração do trocador de calor e a representação das dimensões principais.

Após a introdução dos dados, a quarta parte do aplicativo que está relacionada aos cálculos segue as seguintes etapas:

1. Velocidade mássica $(G)$;

2. Número de Reynolds $(R e)$;

3. Fator "j" de Colburn $\left(\mathrm{StPr}^{2 / 3}\right)$;

4. Fator de atrito (f);

5. Coeficiente de transferência de calor (h);

6. Eficiência da aleta $\left(\eta_{\mathrm{f}}\right)$;

7. Eficiência da superfície global $\left(\eta_{0}\right)$;

8. Coeficiente global de transferência de calor $(U)$;

9. Cálculo de efetividade $(\varepsilon)$ e NUT;

10. Temperaturas de saída dos fluidos ( $T_{\mathrm{fs}}$ e $\left.T_{\mathrm{qs}}\right)$;

11. Calor rejeitado pelo radiador $(\mathrm{q})$

12. Perda de pressão $\left(\Delta \mathrm{P} / \mathrm{P}_{\text {atm }}\right)$.

O valor calculado para a rejeição de calor pelo radiador deve então ser comparado com o limite estabelecido para o motor, geralmente com base na curva de potência do motor e na condição de uso do veículo. É possível obter resultados dessa análise para os dois fluidos envolvidos, desde que se disponha dos dados inicias.

A Figura 25 apresenta uma imagem da parte final do aplicativo de cálculo para desempenho, que justamente se difere da ferramenta de projetos. 


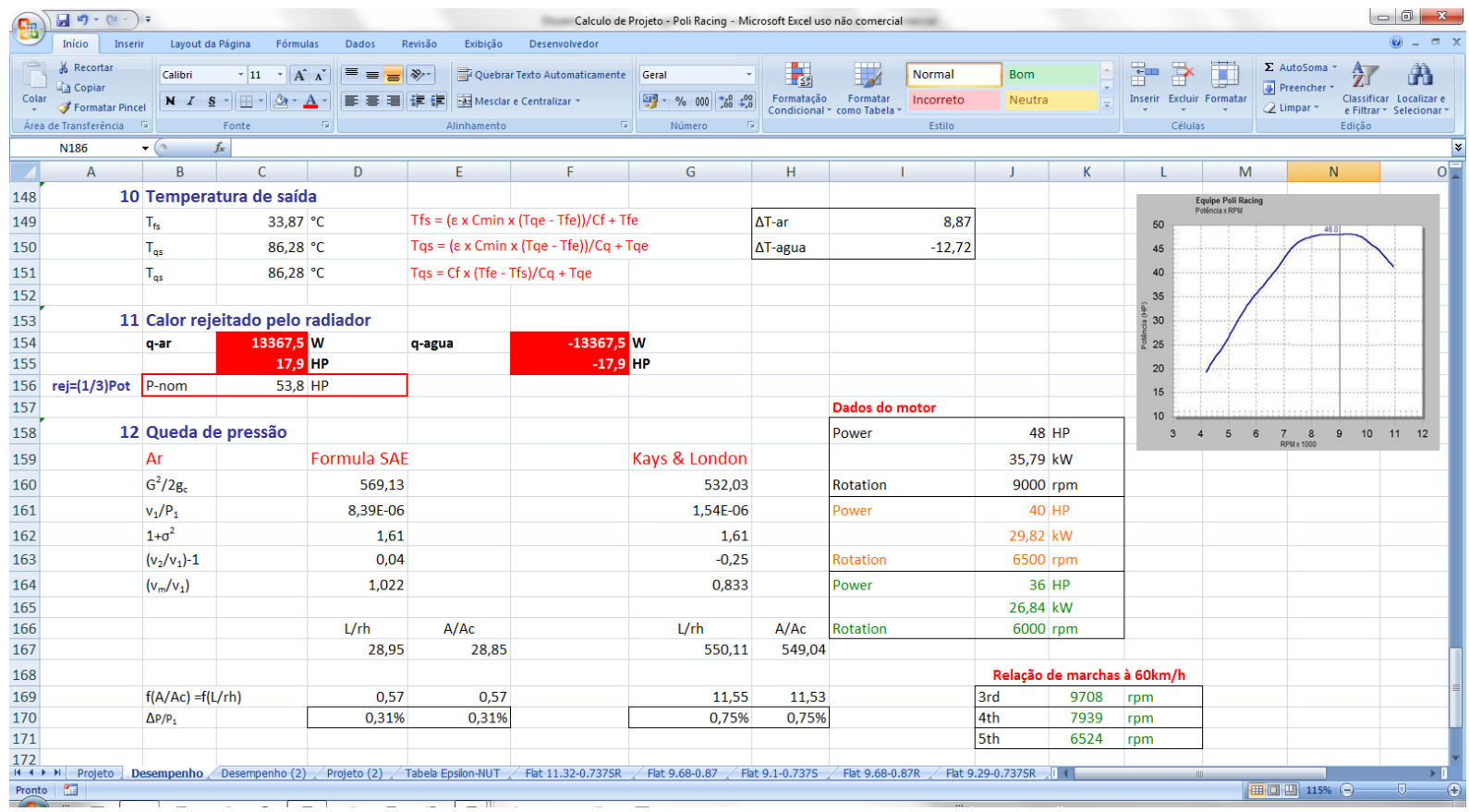

Figura 25 - Imagem do aplicativo TROACALC que contém os cálculos finais para análise de desempenho de trocadores de calor.

\subsection{ANÁLISE DOS RESULTADOS}

As planilhas para cálculo e análise de desempenho de trocadores de calor compacto foram desenvolvidas com base em programa comercial de operação de matrizes objetivando o uso de operações simples. Com isso, seu uso não exige computadores de alto processamento tampouco a necessidade de treinamento específico para operá-la. Uma forma de verificar a funcionalidade da ferramenta foi reproduzir um dos estudos de caso publicado por Kays e London (1984). O exemplo utilizado é o de número 1 que consta no Apêndice $B$ do texto destes autores.

Como em qualquer rotina de cálculo, uma análise cuidadosa sobre os valores extraídos da planilha deve auxiliar o desenvolvimento dos trabalhos, uma vez que há grande quantidade de dados e suas diversas unidades para serem incluídos e interpretados. Vale observar que a planilha não apresenta recurso para "aprovar" ou 
"rejeitar" resultados. Essa atividade analítica fica por conta do engenheiro que a utiliza como ferramenta de trabalho em seus desenvolvimentos. Portanto, apesar do usuário não necessitar de conhecimento computacional específico, é fundamental a base teórica em trocadores de calor e mecânica dos fluidos para leitura e interpretação dos dados inseridos e extraídos da planilha.

Outro ponto importante a ser observado é a utilização de coeficientes de segurança. Essa ferramenta de cálculo não dispõe desse recurso, deixando a critério do usuário a implementação desse fator caso julgue necessário. A razão por não incluir tais coeficientes está relacionada às diferentes abordagens que cada problema possa exigir de seus projetistas e também da particularidade de cada usuário em implementar ajustes conforme a disponibilidade de dados ou interesse de desempenho de cada projeto.

Após a fase de desenvolvimento dessa ferramenta computacional, no período de validação dos dados e encadeamento das formulações, percebeu-se uma oportunidade interessante de melhoria a ser registrada como sugestão para desenvolvimentos futuros: a inclusão de um banco de dados de propriedades físicas para os possíveis materiais e fluidos que são utilizados em trocadores de calor. Isso pode economizar no tempo de preenchimento da planilha e pode evitar enganos com a digitação dos dados ou das unidades.

Os dados para todas as geometrias de núcleo para trocadores de calor compacto para aplicação veicular e disponíveis no trabalho de Kays e London (1984) foram incluídos no mesmo arquivo da ferramenta de cálculo. Isso facilita a atividade de desenvolvimento, possibilitando comparações de resultados para diferentes geometrias e a identificar as características de cada proposta. Portanto, uma outra proposta de melhoria para esse estudo é também a atualização do banco de dados geométrico para o núcleo dos trocadores de calor. 


\section{ESTUDO DE CASO}

Esse capítulo apresenta um estudo de caso em que o conjunto duto-trocador de calor compacto adotado é o do veículo que participa da competição Fórmula SAE representando a equipe Poli Racing, equipe formada por alunos da Escola Politécnica da Universidade de São Paulo (EPUSP), como é detalhado a seguir. São implementadas diversas análises que utilizam como referência o veículo e o conjunto duto-trocador de calor selecionados, a saber:

- Aplicação da ferramenta computacional (TROCALC);

- Ensaio experimental do trocador de calor do veículo atual da equipe Poli Racing;

- Simulações numéricas com aplicativo de CFD para avaliar o comportamento aerodinâmico do conjunto duto-trocador de calor.

\subsection{CARACTERIZAÇÃO DO PROBLEMA}

A equipe de Fórmula SAE Poli Racing projetou e construiu um protótipo para a primeira participação na competição brasileira no ano de 2009 (Figura 26). Para esse primeiro protótipo, foi adquirido pela equipe um motor de $450 \mathrm{~cm}^{3}$ que usualmente equipa veículos quadriciclos da marca Yamaha ${ }^{\circledR}$. O sistema de arrefecimento desenvolvido originalmente para esse veículo foi utilizado no protótipo. A equipe manteve o sistema de admissão de combustível original do fabricante, realizando apenas a adaptação exigida pelas regras e não realizou adaptações de subsistemas para aumento de potência, como turbocompressores ou sistemas semelhantes.

Um dos propósitos das análises realizadas é verificar o desempenho do sistema de arrefecimento original aplicado ao protótipo Fórmula SAE e com base nos resultados 
oferecer propostas em que o sistema passa a ser otimizado, evoluindo também em termos aerodinâmicos.

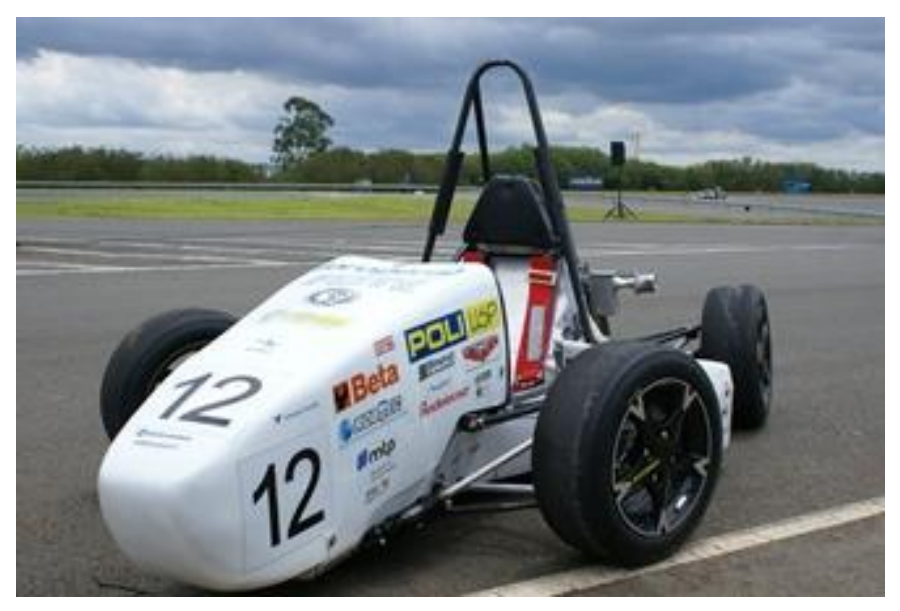

Figura 26 - Veículo Fórmula SAE desenvolvido pela equipe Poli Racing.

Para uma adequada caracterização do estudo de sistema de arrefecimento de um protótipo da Fórmula SAE, faz-se necessário um breve entendimento das regras e das etapas da competição conforme estipulado pela SAE, considerando como estas afetam esse subsistema. O regulamento da competição é publicado anualmente e neste estudo foram consideradas regras divulgadas para o ano de 2009.

\subsubsection{As regras da competição e o sistema de arrefecimento}

Para todas as partes que compõem o protótipo, a SAE determina algumas diretrizes e limitações. As seções que são fundamentais para o projeto de um trocador de calor estão relacionadas com o sistema de arrefecimento, sistema de motor e transmissão e os dispositivos aerodinâmicos. 
Para o sistema de arrefecimento há a restrição para o uso de líquido para arrefecimento que, conforme as regras, devem ser utilizadas água natural ou mistura de água com um fluido inibidor de corrosão respeitando a proporção máxima de 1,5\%. Anticongelantes a base de glicol ou lubrificantes são proibidos. Essa informação é fundamental para os cálculos relacionados ao projeto do sistema.

Para a parte relacionada ao sistema de motor e transmissão, somente são permitidos motores de 4 pistões e com o limite máximo de $610 \mathrm{~cm}^{3}$ de volume. Para o sistema de admissão de ar para a câmara de combustão, é imposta uma restrição através do uso de um tubo tipo convergente-divergente, que influencia consideravelmente o desempenho do motor. A restrição para esse dispositivo é dimensional, na junção entre os tubos e em função do tipo de combustível $(20 \mathrm{~mm}$ de diâmetro para veículos movidos à gasolina e 19 mm para etanol E-85).

Para os dispositivos aerodinâmicos, as regras limitam basicamente o uso de asas e de sistemas para efeito-solo. Não há restrições específicas relacionadas aos dutos ou difusores para sistema de arrefecimento.

\subsubsection{As etapas da competição}

A competição é composta por diversas etapas que são classificadas por estáticas e dinâmicas, possuindo pontuações máximas especificadas conforme indicado na Tabela 3. 
Tabela 3 - Quadro de apresentação dos eventos estáticos e dinâmicos da competição Fórmula SAE e as pontuações máximas possíveis para cada evento, conforme SAE (2009).

Etapas estáticas:

\begin{tabular}{|l|c|}
\hline Apresentação & 75 \\
\hline Projeto de engenharia & 150 \\
\hline Análise de custos & 100 \\
\hline
\end{tabular}

Etapas dinâmicas:

\begin{tabular}{|l|c|}
\hline Aceleração & 75 \\
\hline Skid-pad & 50 \\
\hline Autocross & 150 \\
\hline Consumo de combustível & 100 \\
\hline Endurance & 300 \\
\hline & \\
Total de pontos & 1000 \\
\hline
\end{tabular}

Ao analisá-las verifica-se que do total de pontos em disputa tem-se a maior parte dedicada a etapas dinâmicas, $67,5 \%$. As etapas de maior pontuação dependem dos diversos subsistemas do veículo em pleno funcionamento, e por isso é importante analisar estas para melhor definir os critérios para o projeto de subsistemas. Segue uma relação com um breve resumo das regras da competição em suas etapas. 
- Aceleração: é realizada em uma pista reta de 75 metros em que é avaliada a aceleração do veículo em pavimento plano;

- Skid-pad: o objetivo é verificar a habilidade do veículo em fazer curva em um circuito em forma de "8" com diâmetro médio 16,75 metros. A prova é completada após a passagem por duas vezes pelo circuito;

- Autocross: realizado para avaliar o quão manobrável é o veículo. Segundo a regra, o circuito para esse evento é desenhado para uma combinação de avaliação do desempenho de aceleração, frenagem e da facilidade em curvas;

- Endurance: o objetivo é avaliar o desempenho geral do veículo e atestar a durabilidade e confiabilidade através de um circuito fechado. O veículo deve percorrer um total de $22 \mathrm{~km}$ para completar o evento. A velocidade média estimada para o percurso de enduro está compreendida entre 48 e $57 \mathrm{~km} / \mathrm{h}$, com velocidade máxima estimada de $105 \mathrm{~km} / \mathrm{h}$. O circuito é misto e a porção reta onde é atingida a velocidade máxima estimada possui não mais que 60 metros;

- Consumo de combustível: está atrelado ao endurance e é medido ao final desse evento o nível do reservatório de combustível e comparado com os demais competidores;

Conforme a descrição das etapas, a prova que deve exigir mais do sistema de arrefecimento é o endurance. Os dados apresentados para as velocidades média e máxima devem ser utilizados como referência para os cálculos do trocador de calor. Pode-se dizer que o motor não é exigido a sua máxima potência durante essa prova e isso favorece o desenvolvimento de um sistema geometricamente menor e consequentemente na diminuição de massa do veículo que afeta diretamente o consumo de combustível (prova que representa 10\% da pontuação total). 
Outro fator importante para o menor consumo de combustível é o arrasto aerodinâmico do veículo. Com isso é necessário apontar como critério para o projeto do veículo a construção da carenagem que favoreça a passagem do ar para o sistema duto-trocador de calor e que ofereça o menor coeficiente de arrasto possível.

\subsection{ANÁLISE DE DESEMPENHO DE TROCADOR DE CALOR COMPACTO ORIGINAL UTILIZANDO A FERRAMENTA COMPUTACIONAL}

\subsubsection{Parâmetros de entrada}

Para esse estudo, foram apresentados pela equipe os dados de entrada necessários para compor a análise de desempenho. As dimensões do núcleo do trocador de calor são de $(300 \times 190 \times 25,4) \mathrm{mm}$, que representa a área frontal de $57000 \mathrm{~mm}^{2}$ e volume de $1447800 \mathrm{~mm}^{3}$. A geometria do núcleo do radiador que mais se aproxima da utilizada nesse radiador é a 11.32-0.737-SR, fornecida por Kays e London (1984). O material do radiador é alumínio, que apresenta condutividade térmica $\mathrm{k}=173 \mathrm{~W} / \mathrm{mK}$ conforme a mesma referência.

As temperaturas dos fluidos foram estimadas em $\mathrm{T}_{\mathrm{fe}}=25^{\circ} \mathrm{C}$, temperatura ambiente para o ar, e $\mathrm{T}_{\mathrm{qe}}=99^{\circ} \mathrm{C}$, temperatura limite de abertura da válvula termostática. $\mathrm{O}$ fluido de arrefecimento utilizado pela equipe é água sem aditivos. A pressão externa adotada é de $1,01 \times 10^{5} \mathrm{~Pa}$. Todas as propriedades dos fluidos necessárias para compor os cálculos serão utilizadas conforme esses dados de temperatura e pressão. 
A velocidade de $60 \mathrm{~km} / \mathrm{h}$ foi identificada como sendo a velocidade média do circuito durante o evento endurance ${ }^{1}$. A estimativa inicial de vazão para o ar é de $1,50 \mathrm{~kg} / \mathrm{s}$, considerando a área de $0,057 \mathrm{~m}^{2}$, a massa específica do ar sendo aproximadamente $1,18 \mathrm{~kg} / \mathrm{m}^{3}$, conforme Incropera e DeWitt (1998), e que não há redução significativa da velocidade do fluxo livre até a entrada do radiador. A vazão para o líquido de arrefecimento é variável conforme as rotações do motor e para esse caso foi estabelecido como valor médio $0,25 \mathrm{~kg} / \mathrm{s}^{1}$

A seguir é apresentado o gráfico que relaciona a potência com as rotações por minuto do motor (Figura 27) fornecido pela equipe. Conforme a curva azul do gráfico, que representa a condição original do quadriciclo da Yamaha ${ }^{\circledR}$, a máxima potência de 48 HP ocorre em 9000 rpm. Considerando que 1/3 desse valor é fluxo de calor rejeitado no radiador, significa que o valor adequado para futura comparação com o desempenho do trocador de calor é de $16 \mathrm{HP}$ ou 11,93 kW.

A relação entre potência nominal e fluxo de calor na proporção de 1:3 foi estimada através da publicação de Plint e Martyr (1999), conforme Tabela 4, e Quim (2007), em que menciona que mais de um terço da energia térmica produzida pela combustão interna do motor é dissipada através do sistema de arrefecimento. Quim (2007) inclusive sustenta essa relação citando a publicações de Crook (2005).

Tabela 4 - Balanço de energia em termos de perdas de calor por unidade de potência útil considerando alguns tipos de motores, conforme Plint e Martyr (1999).

\begin{tabular}{lccc}
\hline & $\begin{array}{c}\text { Motor automotivo } \\
\text { movido a gasolina }\end{array}$ & $\begin{array}{c}\text { Motor automotivo } \\
\text { movido a diesel }\end{array}$ & $\begin{array}{c}\text { Motor pesado de } \\
\text { média velocidade }\end{array}$ \\
\hline Potência útil & 1,00 & 1,00 & 1,00 \\
Fluxo de calor para liquido de arrefecimento & 0,90 & 0,70 & 0,40 \\
Fluxo de calor para óleo de arrefecimento & 0,00 & 0,00 & 0,05 \\
Fluxo de calor para sistema de exaustão & 0,90 & 0,70 & 0,65 \\
Convecção e radiação & 0,20 & 0,20 & 0,15 \\
\hline Total & 3,00 & 2,60 & 2,25 \\
\hline
\end{tabular}

\footnotetext{
${ }^{1}$ Dados disponíveis em www.fsae.com - Grupo de discussão das equipes da FSAE. Acessado em 10 de março de 2009.
} 


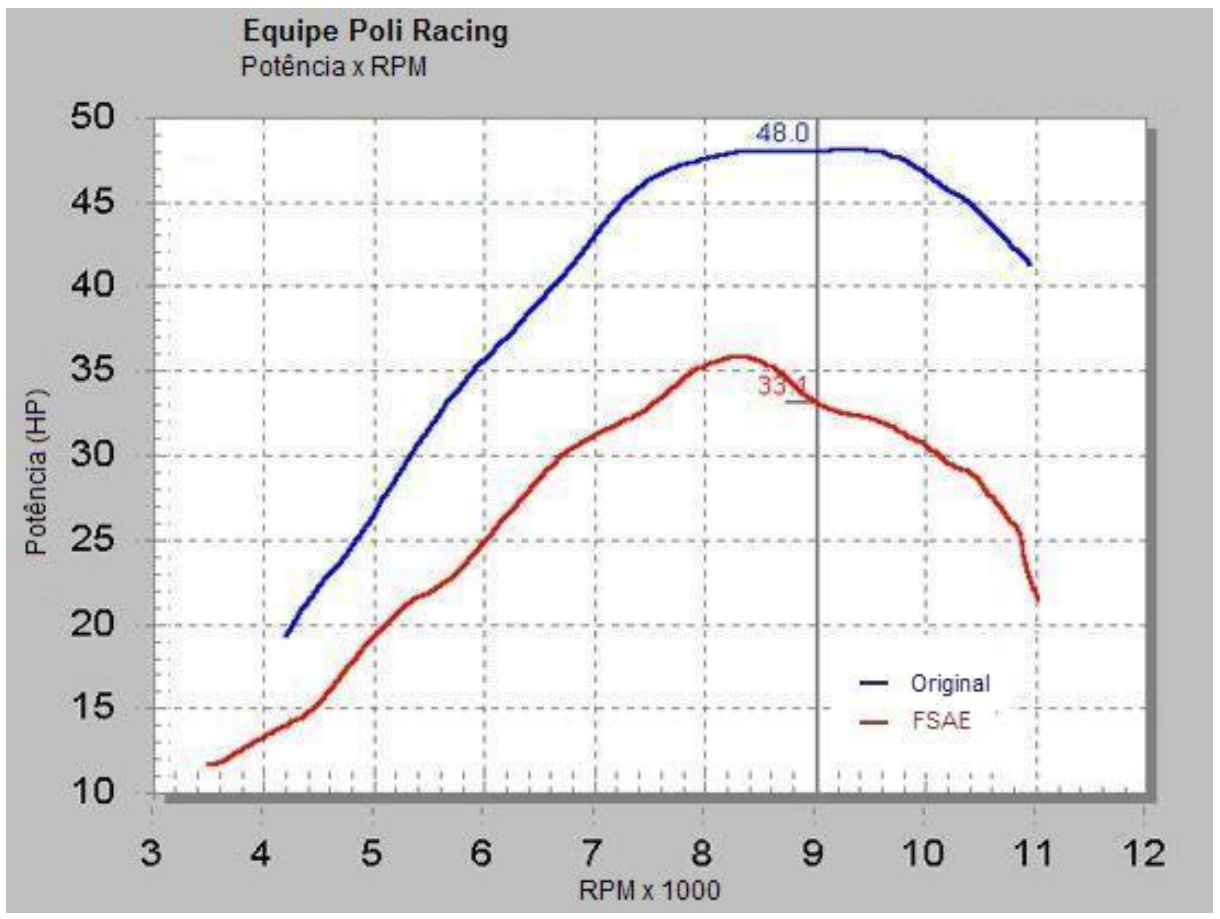

Figura 27 - Gráfico da relação de potência e rotações por minuto do motor Yamaha® de $400 \mathrm{~cm}^{3}$. A curva azul representa a condição original de funcionamento do motor; a vermelha representa a adequação do motor às restrições impostas pelas regras da Fórmula SAE.

A equipe apresentou também uma relação de marchas e rotações para a velocidade do protótipo, conforme a seguinte tabela:

Tabela 5 - Quadro da relação de marchas e as devidas rotações por minuto do motor considerando as velocidades específicas.

\begin{tabular}{|c|c|c|}
\hline Velocidade (km/h) & Marcha & RPM \\
\hline 20 & 10 & 3500 \\
\hline 40 & $2 \underline{0}$ & 5500 \\
\hline 60 & 30 & 9700 \\
\hline 80 & 40 & 7500 \\
\hline 100 & 50 & 7700 \\
\hline
\end{tabular}


Ao relacionar as informações da Tabela 5 e da Figura 27, conclui-se que o valor a ser considerado para a rejeição de calor está na faixa entre 8000 e 10000 rotações por minuto. O maior valor apresentado nessa região é de $33 \mathrm{HP}$, o que representa 24,61 kW. Porém, como apenas 1/3 desse valor é destinado ao radiador, o valor a ser considerado para projeto é de $8,20 \mathrm{~kW}$. A redução em relação ao valor aferido na condição original é $31 \%$ menor.

Os dados a serem verificados nessa análise de desempenho serão as temperaturas de saída dos fluidos, a taxa de transferência de calor que o radiador é capaz de dissipar e a perda de pressão através do radiador.

\subsubsection{Apresentação e análise de resultados}

Com a aplicação do TROCALC para avaliação do desempenho do trocador de calor, obtém-se:

- As temperaturas de saídas dos fluidos $\left(\mathrm{T}_{\mathrm{fs}}=33,9^{\circ} \mathrm{C}\right.$ e $\left.\mathrm{T}_{\mathrm{qs}}=86,3^{\circ} \mathrm{C}\right)$;

- O valor do fluxo de transferência de calor no radiador ( $q=13,37 \mathrm{~kW})$;

- Valor da relação entre a perda de pressão através do radiador e a pressão de entrada $\left(\Delta \mathrm{P} / \mathrm{P}_{\mathrm{atm}}=0,31 \%\right)$.

Comparando-se o valor calculado para a taxa de transferência de calor $(q=13,37 \mathrm{~kW})$ com o valor obtido através do gráfico da Figura 27 ( $q=11,93 \mathrm{~kW})$, percebe-se que o radiador atende satisfatoriamente as necessidades de rejeição de calor do motor na condição original, apresentando uma diferença de $12 \%$ acima do estimado. Essa diferença pode representar o coeficiente de segurança estabelecido pelo fabricante.

Para a comparação com a condição de operação do protótipo da Fórmula SAE, representada pela curva vermelha na Figura $27,(q=8,20 \mathrm{~kW}$ ) obtém-se uma diferença de $39 \%$ superior ao resultado obtido pelo TROCALC. 
Nesse cenário entende-se que o trocador de calor está superdimensionado para as condições do veículo da Fórmula SAE. Para o desenvolvimento de um protótipo competitivo, é necessário o projeto de um novo radiador dedicado à rejeição de calor da configuração adaptada a competição.

\subsection{PROJETO DE NOVO TROCADOR DE CALOR COMPACTO UTILIZANDO FERRAMENTA COMPUTACIONAL}

\subsubsection{Parâmetros de entrada}

Esse item tem como finalidade apresentar o processo de projeto de trocador de calor compacto aplicado ao protótipo da equipe Poli Racing de Fórmula SAE, utilizando o aplicativo computacional TROCALC.

O objetivo específico do projeto é obter valores calculados com uso da nova geometria do trocador de calor (área frontal e volume) e a perda de pressão do fluxo ao atravessar o núcleo deste. Está sendo considerada a necessidade de rejeição de calor no radiador de $8,20 \mathrm{~kW}$ como ponto de partida de acordo com estimativa estabelecida em 6.2.1.

Os dados de entrada são similares àqueles utilizados no item anterior de análise de desempenho. São utilizadas as temperaturas estabelecidas para os fluidos na entrada do radiador $\mathrm{T}_{\mathrm{fe}}=25^{\circ} \mathrm{C}$ e $\mathrm{T}_{\mathrm{qe}}=99^{\circ} \mathrm{C}$ e a pressão atmosférica $1,01 \times 10^{5} \mathrm{~Pa}$, e a vazão para o líquido de arrefecimento de $0,25 \mathrm{~kg} / \mathrm{s}$. As propriedades dos fluidos são mantidas as mesmas.

Para definir a vazão do lado do ar, considerou-se que a velocidade do veículo e a velocidade do fluxo livre será a mesma utilizada anteriormente, $60 \mathrm{~km} / \mathrm{h}$. Para 
favorecer uma melhor comparação, é mantida a mesma velocidade do fluxo na entrada do trocador de calor. Contudo é necessário estimar um novo valor de vazão, uma vez que a área do novo trocador de calor deve ser menor. Considerando a possibilidade de redução da carga térmica em até 39\%, conforme os cálculos do item anterior, um primeiro valor estimado para a área frontal de $36000 \mathrm{~mm}^{2}$ é adotado e, consequentemente o valor de vazão resulta em 0,60 kg/s.

A geometria do núcleo do radiador e o material são mantidos os mesmos utilizados na análise anterior, referência 11.32-0.737-SR (KAYS; LONDON, 1984) e alumínio, respectivamente, de forma a permitir uma comparação direta dos resultados.

\subsubsection{Apresentação e análise de resultados}

A aplicação da ferramenta computacional TROCALC usando o modo de projeto de trocador de calor oferece a taxa de fluxo de calor de 8,84 kW. Como resultado, esse valor satisfaz a necessidade de rejeição de calor do motor com a configuração de admissão para a Fórmula SAE estimada em 8,20 kW. A diferença entre os valores é de $8 \%$ e pode ser adotada como margem de segurança. Para esses cálculos foram realizadas três iterações.

Fixado esse valor de taxa de rejeição de calor, a área frontal calculada é de $35700 \mathrm{~mm}^{2}$ e o volume é de $892404 \mathrm{~mm}^{3}$. Ao comparar com os valores de área e volume do trocador original, esses valores calculados são 37\% menores. Mantendo a mesma largura do trocador de calor original, $b=25,4 \mathrm{~mm}$, são possíveis algumas configurações dimensionais. Uma possibilidade de construção de radiador é utilizar as dimensões $(220 \times 160 \times 25,4)$ mm, porém os critérios limitantes para as possíveis configurações do trocador de calor serão avaliadas posteriormente. Considerando a massa especifica do alumínio, $\rho=2702 \mathrm{~kg} / \mathrm{m}^{3}$ conforme Incropera e DeWitt (1998), é esperada uma redução de massa de $1,5 \mathrm{~kg}$. 
A perda de pressão foi calculada em $\Delta \mathrm{P} / \mathrm{P}_{\mathrm{atm}}=0,65 \%$, o que representa um aumento de $110 \%$ em relação à perda de pressão original. Esses valores devem ser avaliados em conjunto com resultados de análise aerodinâmica computacional e testes experimentais em laboratório, pois dependem diretamente da geometria do veículo. 


\subsection{ENSAIO EXPERIMENTAL DO TROCADOR DE CALOR ORIGINAL}

Com a finalidade de mensurar parâmetros relativos ao trocador de calor original do veículo adotado como estudo de caso e validar a ferramenta computacional TROCALC, foi estabelecido uma proposta de ensaio experimental do sistema de arrefecimento.

Foram programados testes realizados no Laboratório de Instrumentação em Mecânica dos Fluidos da Escola Politécnica da Universidade de São Paulo com o veículo Fórmula SAE da equipe Poli Racing. Os resultados esperados na realização dos ensaios são valores para a perda de pressão, valores de vazão do fluxo de ar através do sistema e fluxo de calor através do trocador de calor existente.

Durante a avaliação, o veículo permaneceu estacionado na área externa próxima ao Laboratório, seu motor era acionado e mantido em rotação constante previamente estabelecida. Os ensaios ocorreram no dia 27 de março de 2010 com início as atividades às $8: 00 \mathrm{~h}$ e encerramento às $22: 00 \mathrm{~h}$, aproximadamente. Todas as condições originais do veículo foram mantidas para a realização do experimento. $O$ combustível solicitado pela equipe e utilizado no abastecimento do veículo foi gasolina aditivada da alta octanagem, que é vendida em postos de gasolina da marca Petrobras ${ }^{\circledR}$. O nome comercial do combustível é gasolina podium ${ }^{\circledR}$. O sistema de arrefecimento foi alimentado com água natural sem aditivos, dentro das regras da competição.

O ensaio utilizou duas bancadas do Laboratório que foram adaptadas para atender as necessidades do ensaio como será detalhado nos próximos itens. 


\subsubsection{Preparação de ensaios e fabricação de dispositivos}

Para a realização dos testes, foram utilizados equipamentos e facilidades existentes no Laboratório de Instrumentação em Mecânica dos Fluidos. Foi também necessária a fabricação de dispositivos para proporcionar as devidas condições para realização dos testes. A seguir há uma breve descrição de cada elemento desenvolvido:

- Suporte para radiador: foi desenvolvido um suporte exclusivo para a realização dos testes com o veículo. O suporte foi projetado e construído com perfil metálico em "L", de forma a proporcionar o reposicionamento do trocador de calor em condições favoráveis à realização do ensaio experimental. Isso permitia o acoplamento da coifa que traz o fluxo de ar de modo similar ao que ocorre em um veículo em movimento. Uma imagem desse suporte é apresentada pela Figura 28;

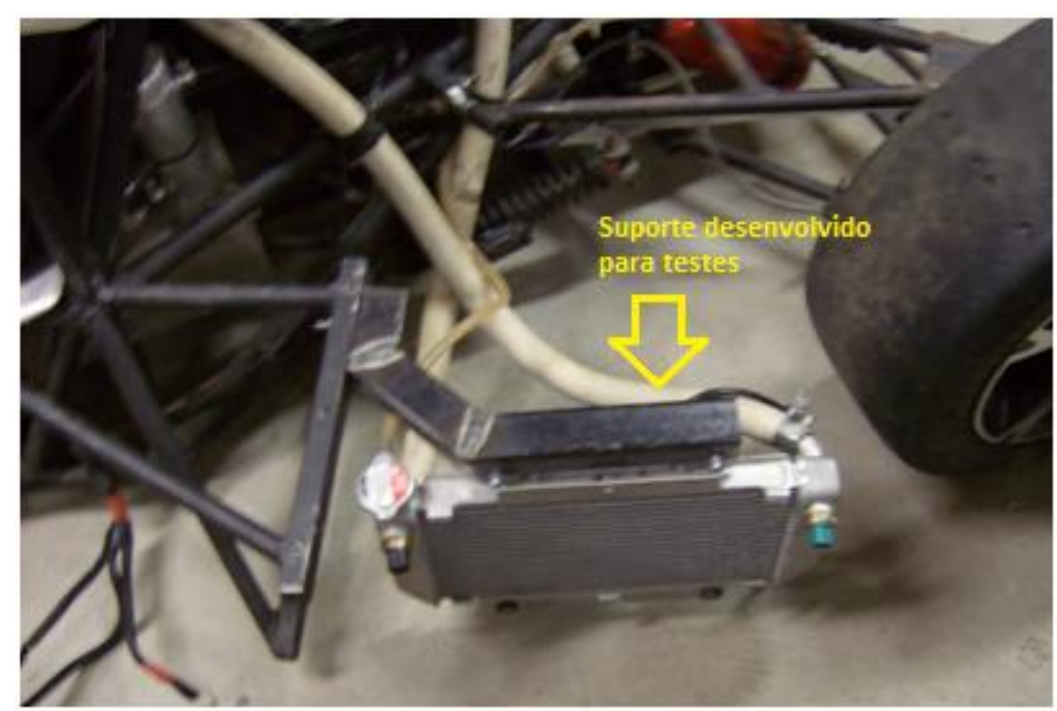

Figura 28 - Imagem apresentando o suporte desenvolvido para a realização dos testes experimentais. 
- Coifa: foi desenvolvido um dispositivo de junção do radiador com o duto acoplado ao sistema de geração de fluxo de ar (aparato experimental existente no Laboratório). Esse elemento foi construído em papel especial, espesso e de alta resistência, conhecido como "papel paraná", e unificado com fitas adesivas de alta resistência, conforme Figura 29. A escolha desse material se deve a maior flexibilidade para manuseio, uma vez que a geometria deve respeitar a entrada circular do duto e a saída de seção quadrada para radiador.

- Selagem: foi realizada utilizando espuma de alta densidade e fita adesiva de alta resistência para que não houvesse "fuga" de ar no espaço compreendido entre o radiador e a coifa, conforme apresentado pela Figura 30;

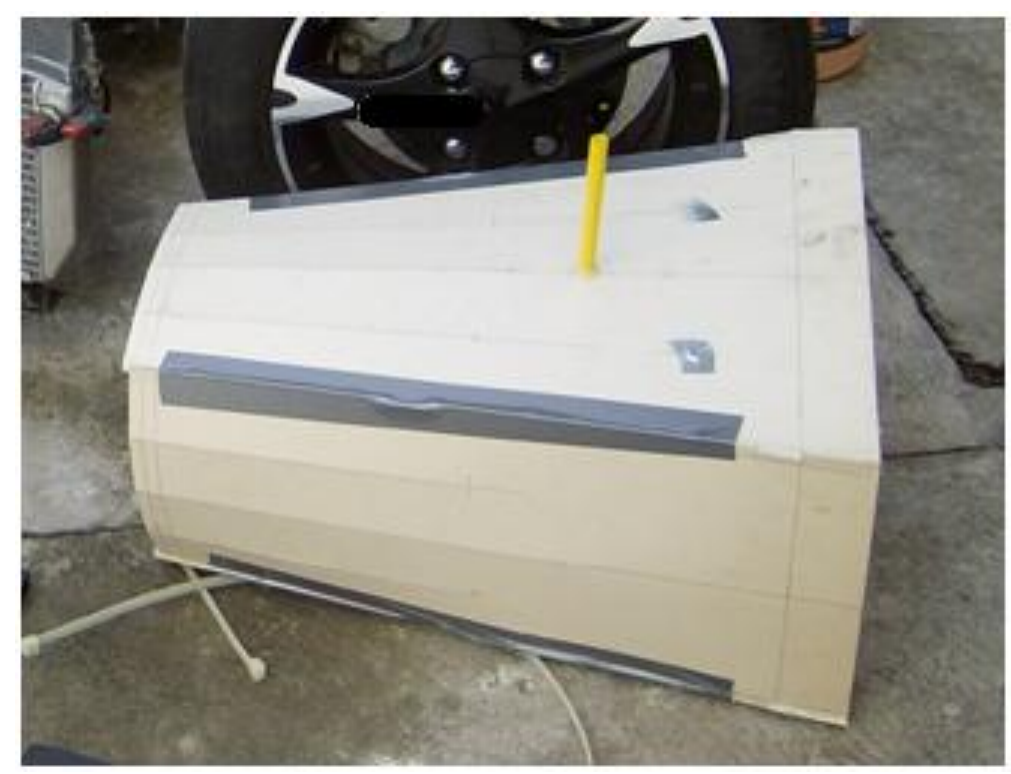

Figura 29 - Coifa desenvolvida para a realização dos testes experimentais. 


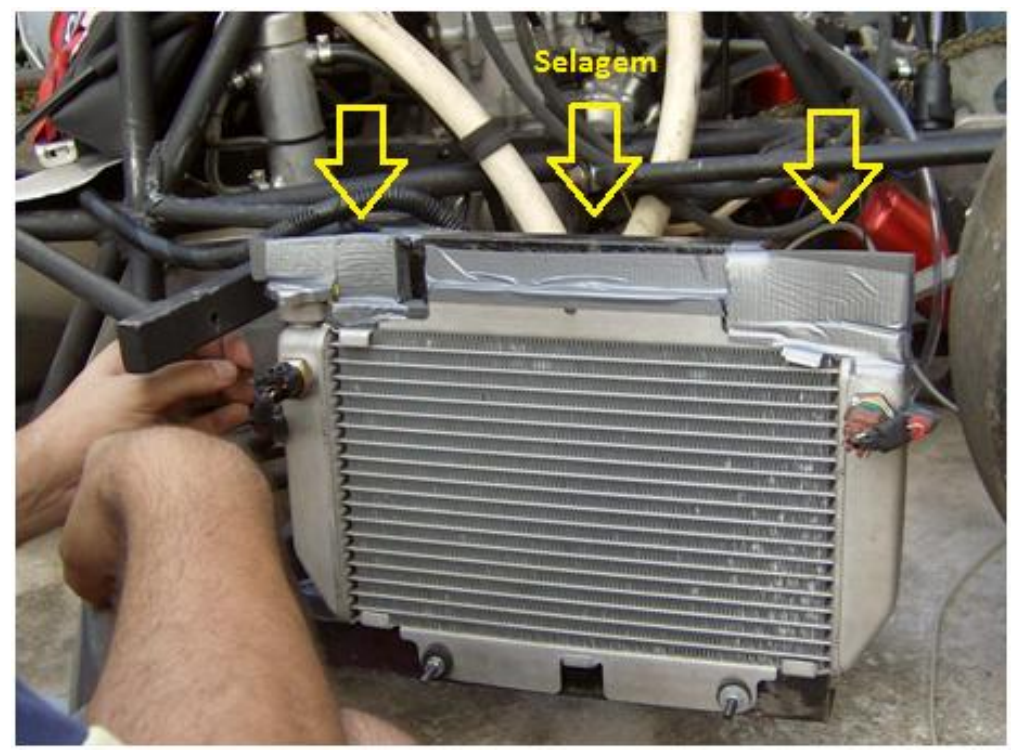

Figura 30 - Imagem apresentando o desenvolvimento da selagem no contorno do radiador.

- Suporte para medidores: a fim de localizar os medidores de temperatura e minimizar a influência da radiação do radiador sobre os mesmos, foram desenvolvidos dois pequenos suportes utilizando-se de tubos plásticos, de 20 $\mathrm{mm}$ de diâmetro. Esses suportes foram localizados a montante e a jusante do radiador, de forma a efetivar a medição da transferência de calor e adequada blindagem à radiação. Para a medição de pressão, foi utilizado um sistema de flange em que possuíam tubos metálicos rígidos de $150 \mathrm{~mm}$ de diâmetro. Em um dos tubos foi acoplado a coifa e no outro o tubo flexível que trazia o fluxo de ar. No tubo metálico conectado ao flexível haviam quatro tomadas de pressão interligadas pelo método chamado "triplo T" conforme proposto por Mariani (1995). O objetivo dessa disposição é viabilizar a medida de pressão estática à montante do radiador. Esses dispositivos podem ser visualizados pela Figura 31 (a);

- Tubo metálico flexível: para o acoplamento entre o aparato experimental do Laboratório de Instrumentação Mecânica dos Fluidos com os sistemas desenvolvidos para medição de temperatura e pressão, foi utilizado tubo 
flexível metálico de $150 \mathrm{~mm}$ de diâmetro, conforme apresentado pela Figura 31 (b).

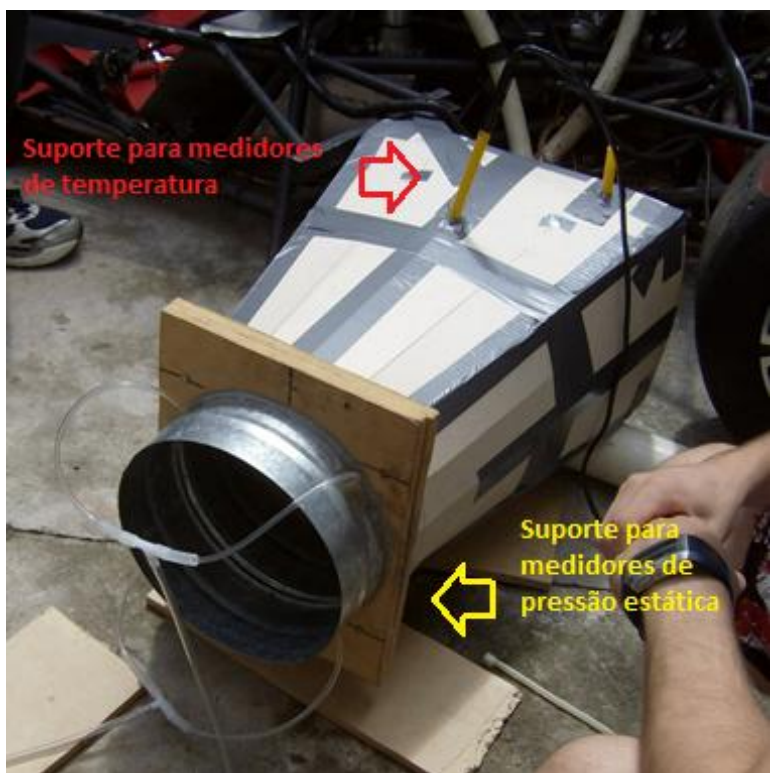

(a)

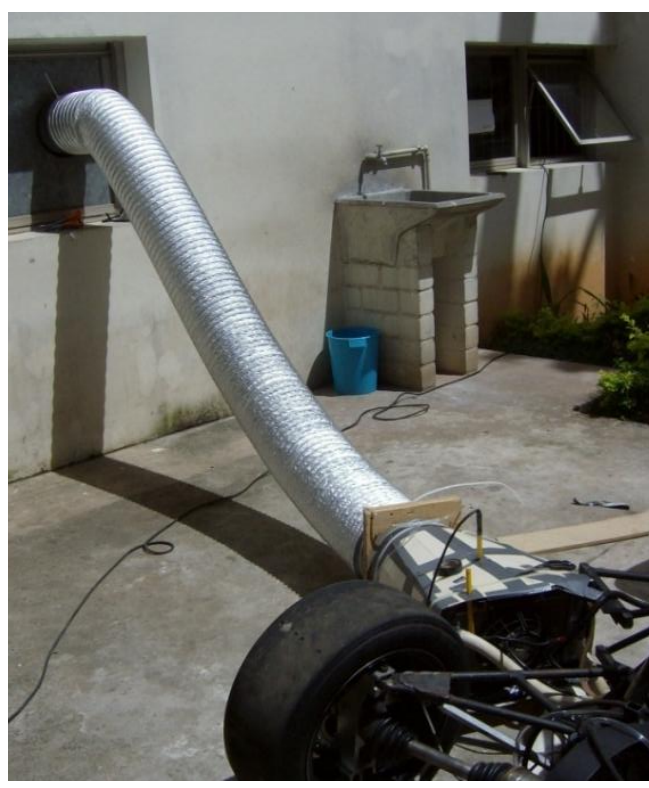

(b)

Figura 31 - (a) Suportes desenvolvidos para proporcionar a medição de temperatura e pressão; (b) tubo metálico flexível para junção do gerador de fluxo com os equipamentos desenvolvidos para medição.

\subsubsection{Instrumentação e procedimento para aquisição de dados}

O procedimento adotado para a realização das medições foi simular condições do veículo em uso, considerando situações que possam ocorrem durante a competição. O escopo foi avaliar o veículo em situações controladas e em regime constante considerando uma faixa de velocidade e rotação do motor. A simulação de veículo parado e com motor ligado, condição conhecida como "marcha lenta", é também importante, uma vez que nessa condição o fluxo de ar no trocador dependerá exclusivamente do ventilador próprio acoplado junto ao radiador. 
O processo para aquisição de dados foi desenvolvido conforme a recomendação técnica SAE (2008). As medições ocorreram sempre com o motor pré-aquecido a partir do momento em que a válvula termostática era aberta e o ventilador do sistema de arrefecimento do veículo entrava em funcionamento, de forma a garantir a passagem de água pelo radiador. Durante a aquisição dos dados, o motor era colocado sob a rotação de interesse relacionada diretamente com a potência e consequentemente com a rejeição térmica esperada.

Para a realização desse experimento, foram utilizadas duas bancadas para aquisição de dados. Para a obtenção do fluxo de ar em regime permanente, direcionado ao radiador, foi utilizada a bancada interna do Laboratório de Instrumentação em Mecânica dos Fluidos que possui o aparato gerador de fluxo e a instrumentação para monitoramento da vazão e propriedades psicrométricas do ar. O aparato gerador de fluxo é um sistema composto basicamente por uma linha de escoamento de ar e um conjunto motor-ventilador, com demais sistemas auxiliares que permitem a aquisição de dados em um computador específico, com software desenvolvido para esse fim. Com essas instalações disponíveis, foi possível o registro das medições da diferença de pressão na entrada e saída do radiador, a pressão atmosférica, as temperaturas de bulbo seco e úmido, a umidade relativa do ar, o volume específico de ar, a pressão parcial de vapor e a entalpia do ar úmido. Para a determinação das propriedades físicas do ar, foi utilizado no interior do laboratório o psicrômetro de aspiração. As medições de temperaturas de bulbo seco e úmido (TBS e TBU) são necessárias para cálculo da massa específica do ar. A instrumentação e processo de medição na bancada interna foram similares aos detalhados no trabalho de Mariani (1995). A ilustração desse aparato pode ser vista nas Figuras 32 e 33.

Para as medições de temperatura do ar na entrada e saída do radiador, foram necessários aparelhos para medição (termômetros) conforme descrição a seguir:

- Para o fluxo de ar, medidor de temperatura "Instruterm" THR- 080 (números de série P842472, localizado à montante do radiador, e P842474, à jusante), conforme apresentados pela Figura 34; 
- Para o fluxo de líquido de arrefecimento (água), aparelho medidor de temperatura do tipo pirômetro óptico "Raytek" Raynger MX, número de série 207636-01010004.

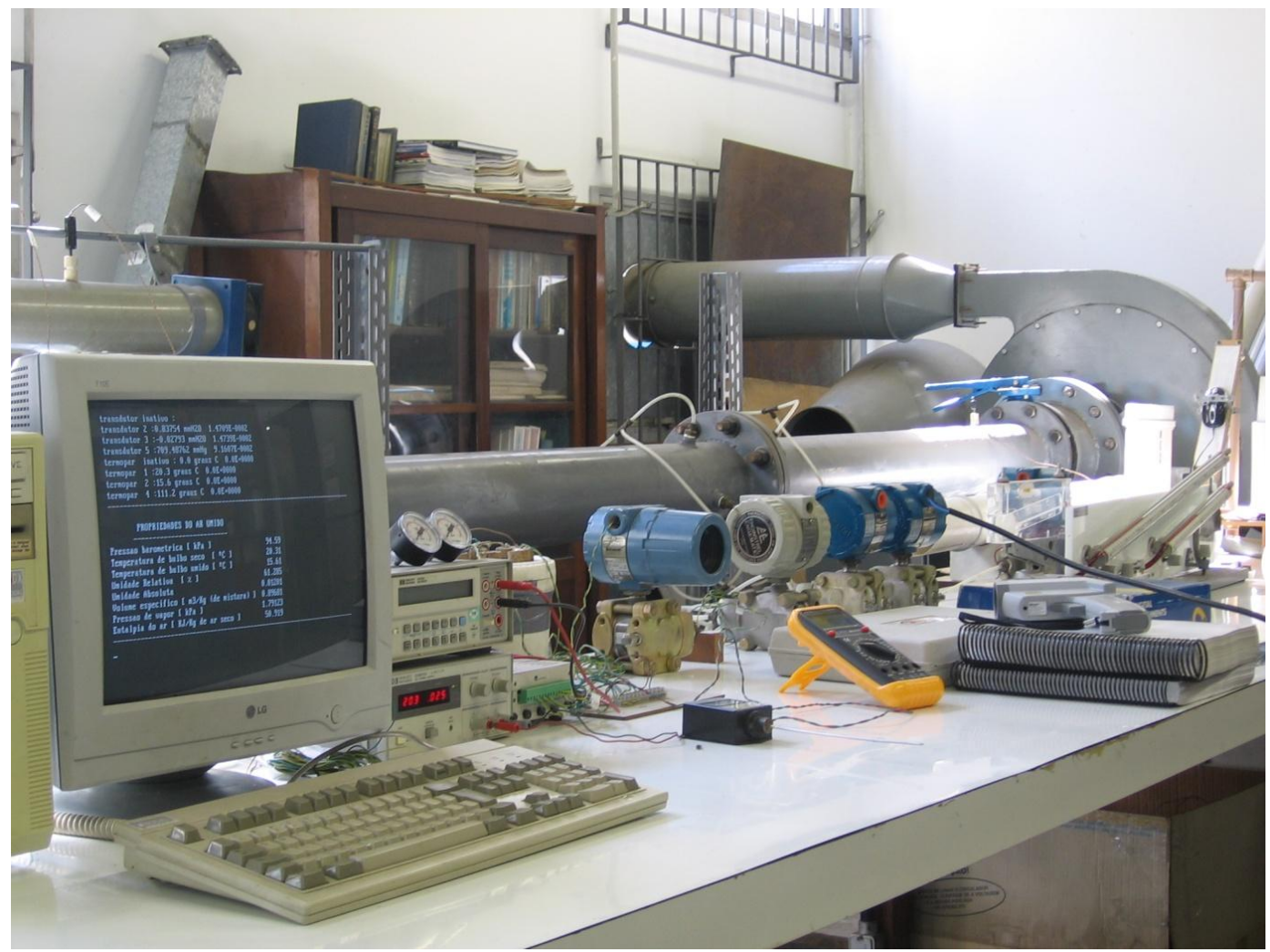

Figura 32 - Imagem da instrumentação, do conjunto motor-ventilador e parte da tubulação pertencente ao aparato gerador de fluxo do Laboratório de Instrumentação em Mecânica dos Fluidos. 


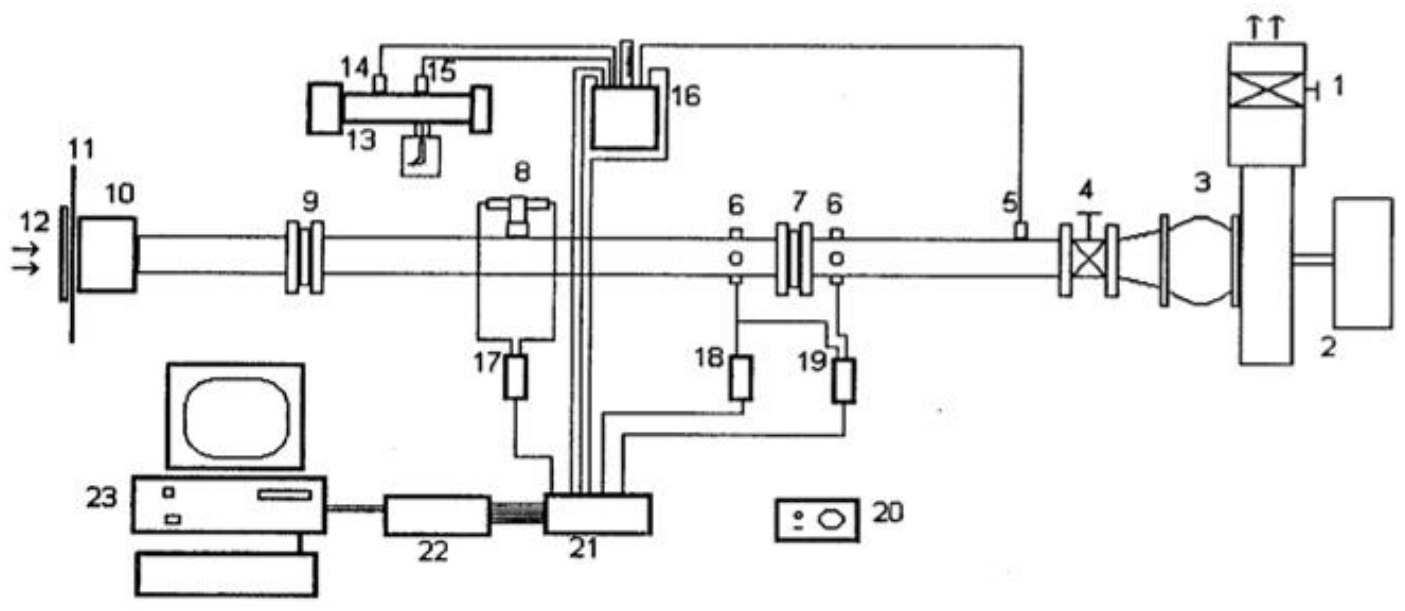

\section{Legenda:}

1 - Válvula borboleta (descarga)

2 - Conjunto moto-ventilador

9 - Condicionador de escoamento

17 - Transdutor $n^{\circ} 1$ ou $n^{\circ} 2$ (DPmult.)

10 - Bocal

3 - Junta de expansão de borracha 11 - Anteparo

4 - Válvula borboleta (sucção) 12 - Tela

5 - Termopar $n^{\circ} 4$ (temp. ar duto) 13 - Psicrômetro

6 - Tomadas de pressão estática

7 - Placa de orifício

14 - Termopar $n^{\circ} 1$ (TBS)

15 - Termopar $n^{\circ} 2$ (TBU)

8 - Medidor de vazăo multifuros

16 - Junta fria (gelo $\left.0^{\circ} \mathrm{C}\right)$

18 - Transdutor $n^{\circ} 3$ (Pestática)

19 - Transdutor $n^{\circ} 4$ (DPplaca)

20 - Fonte DC para transdutores

21 - Condicionador de sinal

22 - Conversor AVD

23 - Microcomputador PC

Figura 33 - Bancada interna do aparato experimental com gerador de fluxo de ar, extraído de Mariani (1995).
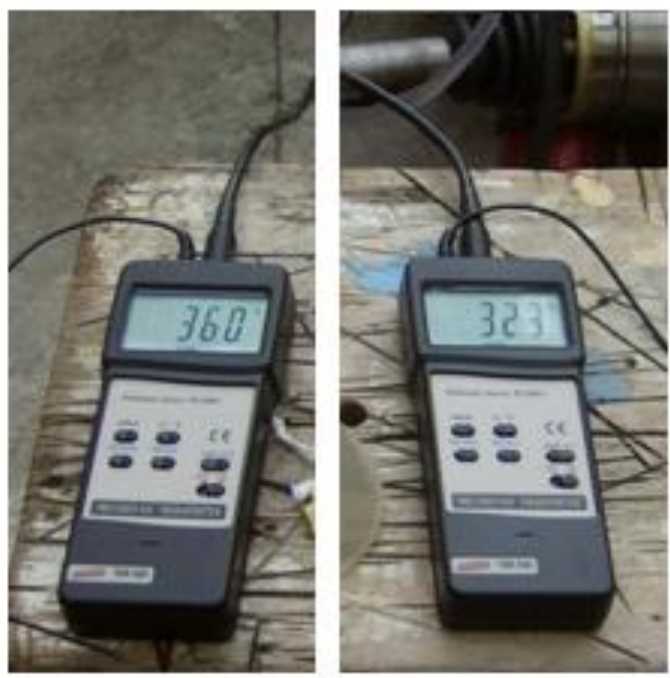

Figura 34 - Instrumentos de medição de temperatura do fluxo de ar no momento em que eram verificadas as temperaturas de entrada (LD) e saída (LE) de ar pelo radiador. 
Para registro das medições de temperatura do ar, foi montada uma segunda bancada para aquisição dois dados no lado externo do laboratório (Figura 35). Os instrumentos de medição foram ligados a dois computadores, que possuía software específico para leitura e armazenamento dos dados. A leitura dos instrumentos era realizada através do computador e apresentadas na tela em tempo real. No momento da estabilização do fluxo, um comando era emitido pelo operador e o programa de aquisição de dados permitia que os mesmos fossem armazenamento em arquivos com formato de tabelas, para posterior edição.

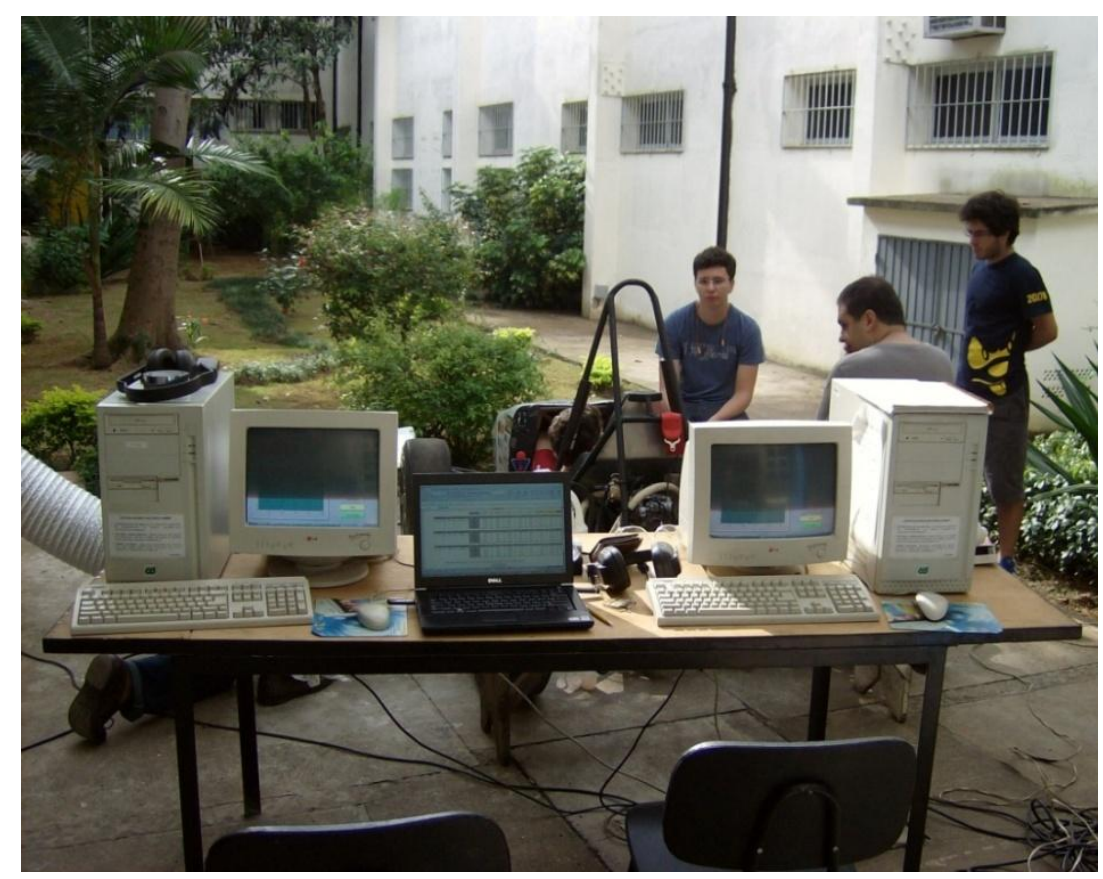

Figura 35 - Bancada externa disposta com os computadores interligados com os instrumentação para medições de temperatura e registro dos dados.

Para a medição de temperatura do líquido de arrefecimento com o pirômetro ótico, as medições foram feitas apontando e acionando o medidor para os tubos de entrada e saída do líquido no radiador. Os registros ocorreram no momento em que as temperatura do fluxo de ar apresentavam tendência a estabilização dos valores medidos, mantendo o medidor a uma distância média de $0,5 \mathrm{~m}$ do foco da medição. 
No procedimento adotado varia-se a vazão do fluxo de ar sobre o trocador de calor com o objetivo de simular diferentes velocidades de deslocamento do veículo. Para cada valor de vazão, o sistema de aquisição de dados da bancada interna usando o programa CENTRAL coleta as informações dos instrumentos. Conforme descreve Mariani (1995), ao iniciar o ensaio é importante verificar a estabilidade dos valores das temperaturas que determinaram as propriedades físicas do ar, e o zero nas leituras dos transdutores de pressão antes de iniciar o movimento do ar. No início de cada medição, o ventilador era acionado mantendo a válvula número 4 do aparato experimental fechada. Em seguida, as válvulas eram abertas e ajustadas para atender valores de pressões diferenciais para a placa de orifício correspondente aos valores de Reynolds pré-estabelecidos.

\subsubsection{Apresentação de dados medidos e resultados calculados}

Nos ensaios com o veículo Fórmula SAE foram obtidos dados e resultados divididos em duas partes. A primeira parte trata da perda de pressão e do cálculo de vazão, proveniente da instrumentação pertencente ao aparato experimental (gerador de fluxo). Na segunda são apresentados os resultados relacionados à transferência de calor, dados que foram registrados através dos termômetros dispostos junto ao veículo, conforme descrito anteriormente. Foi necessária uma coordenação das duas bancadas de testes de forma a obter resultados conjugados. $O$ teste foi planejado para uma série de ensaios adotando-se diferentes vazões. Dentro dessas condições foi possível obter três conjuntos de dados conjugados. 


\subsubsection{Medição de propriedades psicrométricas, perdas de pressão e vazão do ar}

Os valores que seguem foram extraídos dos ensaios numerados de 1 a 3 . Tais dados foram tratados com análise estatística para a determinação de incertezas. A Tabela 6 apresenta para cada ensaio a quantidade de dados utilizados para compor os resultados na coluna "dados".

Para calcular as incertezas, foram utilizadas recomendações indicadas na publicação do INMETRO (2008). As incertezas do tipo A foram estabelecidas a partir de cálculos estatísticos aplicados ao conjunto de amostras registradas. Para incertezas do tipo $B$ foram utilizadas recomendações existentes em trabalhos anteriores que utilizaram a mesma instrumentação. A combinação das incertezas foi calculada realizando a soma quadrática dos valores obtidos para os dois tipos e resultou nas incertezas combinadas expressas nas tabelas a seguir.

Tabela 6 - Apresentação de dados medidos para temperaturas de bulbo seco, TBS, bulbo úmido, TBU, e pressões para os ensaios realizados com veículo Fórmula SAE.

\begin{tabular}{|c|c|c|c|c|c|c|c|c|c|c|c|c|c|}
\hline \multirow{3}{*}{$\begin{array}{c}\text { Ensaio } \\
1 \\
\end{array}$} & \multirow{3}{*}{$\begin{array}{c}\text { Condição } \\
0 \mathrm{~km} / \mathrm{h}\end{array}$} & \multirow{3}{*}{\begin{tabular}{|c|} 
Dados \\
35 \\
\end{tabular}} & \multirow{2}{*}{\multicolumn{2}{|c|}{\begin{tabular}{|c|} 
DP. Placa \pm Inc. \\
$\mathbf{P a}$ \\
\end{tabular}}} & \multirow{2}{*}{\multicolumn{2}{|c|}{$\begin{array}{c}\text { DP. Rad } \pm \text { Inc. } \\
\mathrm{Pa}\end{array}$}} & \multirow{2}{*}{\multicolumn{2}{|c|}{$\begin{array}{c}\text { Patm } \pm \text { Inc. } \\
\mathrm{kPa}\end{array}$}} & \multirow{3}{*}{$\begin{array}{c}\Delta \mathrm{P} / \mathrm{Patm} \\
\% \\
0,001 \%\end{array}$} & \multirow{2}{*}{\multicolumn{2}{|c|}{$\begin{array}{c}\text { TBS } \pm \text { Inc. } \\
{ }^{\circ} \mathrm{C}\end{array}$}} & \multirow{2}{*}{\multicolumn{2}{|c|}{$\begin{array}{c}\text { TBU } \pm \text { Inc. } \\
{ }^{\circ} \mathrm{C}\end{array}$}} \\
\hline & & & & & & & & & & & & & \\
\hline & & & 7,78 & 0,57 & 0,59 & 0,05 & 94,6 & 0,5 & & 27,4 & 0,2 & 23,0 & 0,2 \\
\hline 2 & $20 \mathrm{~km} / \mathrm{h}$ & 100 & 2449 & 12 & 308 & 2 & 94,7 & 0,5 & $0,33 \%$ & 25,7 & 0,2 & 23,1 & 0,2 \\
\hline 3 & $30 \mathrm{~km} / \mathrm{h}$ & 50 & 5870 & 29 & 414 & 2 & 94,8 & 0,5 & $0,44 \%$ & 26,0 & 0,2 & 22,7 & 0,2 \\
\hline
\end{tabular}


Tabela 7 - Apresentação de resultados de vazão, velocidade, massa específica e número de Reynolds para os ensaios realizados com veículo Fórmula SAE.

\begin{tabular}{|c|c|c|c|c|c|c|c|c|c|c|c|c|c|}
\hline \multirow{3}{*}{$\begin{array}{c}\text { Ensaio } \\
1 \\
\end{array}$} & \multirow{3}{*}{$\begin{array}{l}\text { Condição } \\
0 \mathrm{~km} / \mathrm{h}\end{array}$} & \multirow{2}{*}{\multicolumn{2}{|c|}{$\begin{array}{l}\text { Reynolds } \pm \text { Inc. } \\
\text { (tubulação) }\end{array}$}} & \multirow{2}{*}{\multicolumn{2}{|c|}{$\begin{array}{l}\text { Reynolds } \pm \text { Inc. } \\
\text { (radiador) }\end{array}$}} & \multirow{2}{*}{\multicolumn{2}{|c|}{\begin{tabular}{|c|}
$\begin{array}{c}\text { Massa Específica do } \\
\text { Ar } \pm \text { Inc. }\end{array}$ \\
$\mathrm{kg} / \mathrm{m}^{3}$ \\
\end{tabular}}} & \multirow{2}{*}{\multicolumn{2}{|c|}{$\begin{array}{c}\text { Q Placa } \pm \text { Inc. } \\
\mathrm{kg} / \mathrm{s} \\
\end{array}$}} & \multirow{2}{*}{\multicolumn{2}{|c|}{$\begin{array}{c}\text { V. Placa } \pm \text { Inc. } \\
\mathrm{m} / \mathrm{s} \\
\end{array}$}} & \multirow{2}{*}{\multicolumn{2}{|c|}{$\begin{array}{c}\text { V. Rad. } \pm \text { Inc. } \\
\mathrm{m} / \mathrm{s}\end{array}$}} \\
\hline & & & & & & & & & & & & & \\
\hline & & $2,18 \mathrm{E}+04$ & $1 \mathrm{E}+03$ & 87 & 4 & 1,08 & 0,02 & 0,0205 & 0,0008 & 1,00 & 0,09 & 0,43 & 0,02 \\
\hline 2 & $20 \mathrm{~km} / \mathrm{h}$ & $3,77 \mathrm{E}+05$ & $1 \mathrm{E}+04$ & $1,51 \mathrm{E}+03$ & $4 \mathrm{E}+01$ & 1,09 & 0,02 & 0,35 & 0,01 & 17,1 & 0,8 & 7,3 & 0,1 \\
\hline 3 & $30 \mathrm{~km} / \mathrm{h}$ & $5,8 \mathrm{E}+05$ & $2 \mathrm{E}+04$ & $2,33 \mathrm{E}+03$ & $7 \mathrm{E}+01$ & 1,09 & 0,02 & 0,55 & 0,01 & 26,4 & 1,5 & 11,3 & 0,3 \\
\hline
\end{tabular}

$\begin{array}{ll}\text { Legenda } & \\ \text { Ensaio } & \text { Número do ensaio realizado } \\ \text { Condição } & \text { Condição de velocidade pretendida } \\ \text { DP. Placa } & \text { Pressão diferencial na placa de orificio } \\ \text { DP. Rad } & \text { Pressão diferencial no radiador } \\ \text { Patm } & \text { Pressão atmosférica local } \\ \text { TBS } & \text { Temperatura de bulbo seco local } \\ \text { TBU } & \text { Temperatura de bulbo úmido local } \\ \text { Inc } & \text { Incerteza combinada (tipo A e tipo B) } \\ \text { Q. Placa } & \text { Vazão calculada na placa de orificio } \\ \text { V. Placa } & \text { Velocidade calculada na plava de orificio } \\ \text { V. Rad. } & \text { Velocidade calculada na entrada do radiador }\end{array}$

O primeiro ensaio foi realizado com o ventilador do gerador de fluxo desligado. Por se tratar justamente dos testes realizados em "marcha lenta", a movimentação do fluido e consequentemente a transferência de calor foi viabilizada pelo deslocamento de ar promovido pelo próprio ventilador acoplado junto ao radiador.

O cálculo para Reynolds no trocador de calor foi desenvolvido utilizando diâmetro hidráulico, da mesma forma como é apresentado por Kays e London (1984). Para o cálculo da velocidade mássica $\mathrm{G}$, foi considerada a área do fluxo livre do radiador, de modo similar ao adotado pela ferramenta computacional.

$$
R e=\frac{4 r_{h} G}{\mu}
$$




\subsubsection{Resultados de transferência de calor}

Esse item apresenta os gráficos relacionados a cada medição e em seguida uma planilha que resume as informações que resultam nos valores de troca de calor. Nos gráficos, os valores de temperatura em ${ }^{\circ} \mathrm{C}$ estão representados no eixo $\mathrm{Y}$ em função do tempo no eixo X. Para todos os ensaios, adotou-se o valor de $1007 \mathrm{~J} / \mathrm{kgK}$ para o calor específico do ar conforme Incropera e DeWitt (1998).

O ensaio ํo 1 foi realizado com o motor do veículo em sua rotação mínima, situação conhecida como "marcha lenta", em que é simulada a condição do veículo estacionado com o motor ligado. Essa situação geralmente ocorre durante a competição da Fórmula SAE, no momento em que é exigido aos competidores aguardarem preparados antes de adentrarem em algum evento dinâmico. Nessa condição, o motor apresentou rotação média de 1500 rpm.

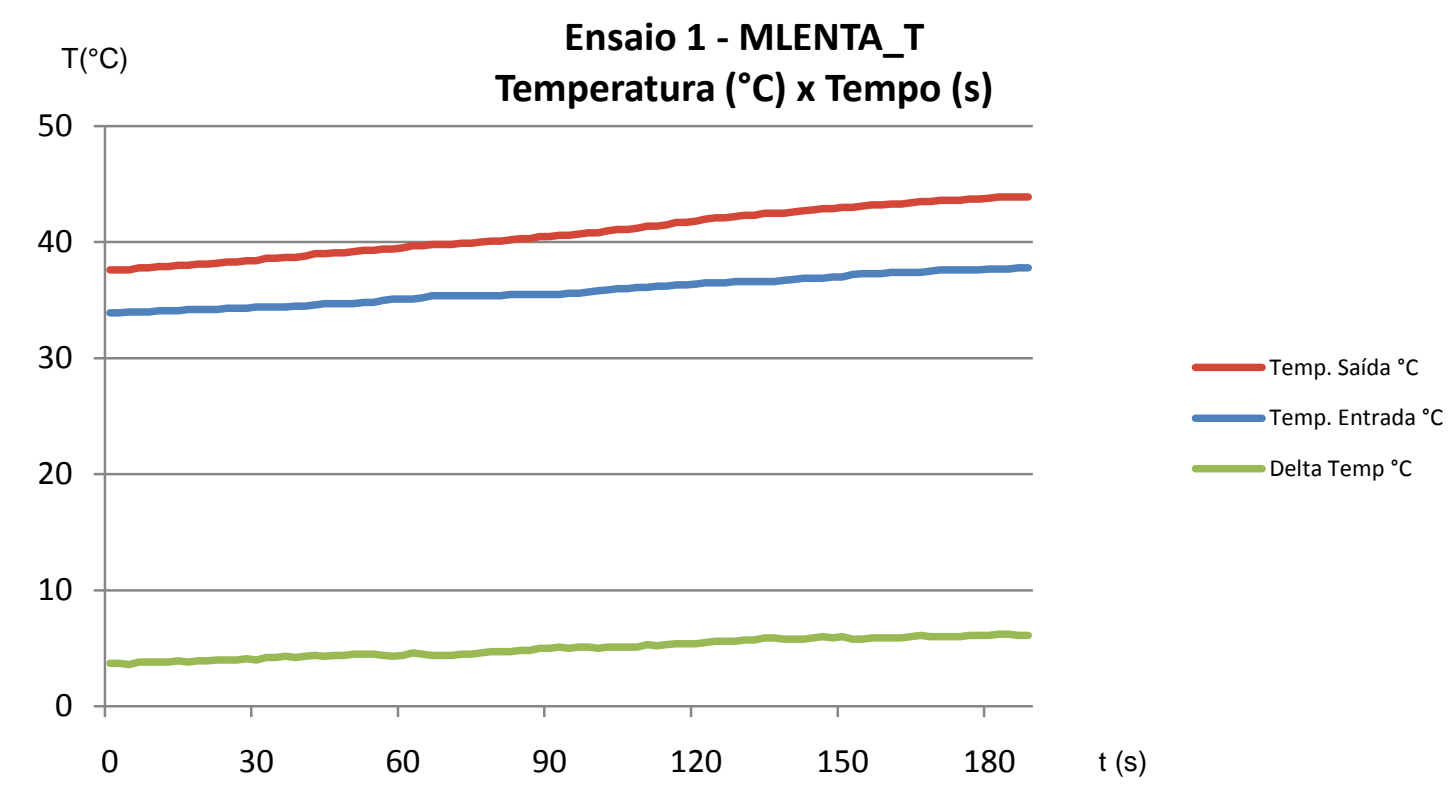

Figura 36 - Gráfico de Temperatura $\left({ }^{\circ} \mathrm{C}\right)$ x Tempo (s) para a condição de "marcha lenta". 
Ao avaliar o gráfico da Figura 36, percebe-se que as curvas apresentam uma tendência ascendente e de forma constante. Essa característica explica-se pelo aquecimento do ar proveniente do gerador de fluxo, que permaneceu ligado antes da aquisição dos dados. Com isso, foram tomados os valores médios de temperatura de entrada e saída e realizados os devidos cálculos para a transferência de calor. Nesse caso, foram consideradas as temperaturas médias de entrada e saída como $35.8 \stackrel{\circ}{\circ} \mathrm{C}$ e $40.8 \stackrel{\circ}{\circ}$ respectivamente e foi obtido o valor para a transferência de calor equivalente a $100 \mathrm{~W}$.

Para o ensaio № 2, foi simulada a condição do veículo com o motor em 3500 rpm, representando uma simulação de condução em linha reta com velocidade aproximada de $20 \mathrm{~km} / \mathrm{h}$ em primeira marcha.

\section{Ensaio 2}

$\mathrm{T}\left({ }^{\circ} \mathrm{C}\right) \quad$ Temperatura $\left({ }^{\circ} \mathrm{C}\right) \times$ Tempo $(\mathrm{s})$

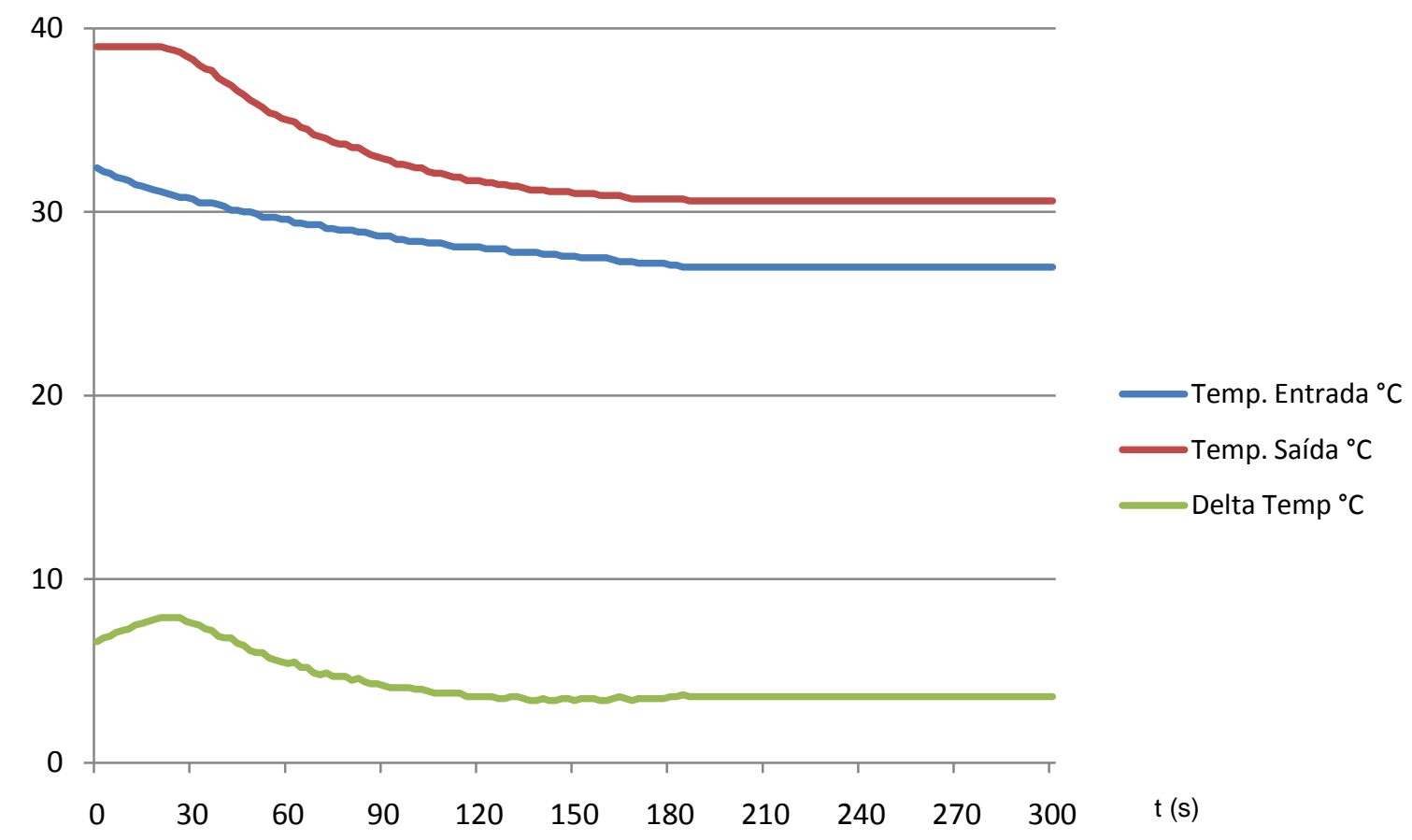

Figura 37 - Gráfico de Temperatura $\left({ }^{\circ} \mathrm{C}\right) \times$ Tempo (s) para a condição de primeira marcha a $20 \mathrm{~km} / \mathrm{h}$. 
O gráfico da Figura 37 apresenta que ocorreu uma estabilização de troca de calor a partir do instante $t=90$ segundos, aproximadamente. Nesse caso, a rejeição térmica calculada foi de $1280 \mathrm{~W}$, considerando as temperaturas de entrada de $27,0 \stackrel{\circ}{\circ} \mathrm{C}$ e de saída de $30.6 \stackrel{\circ}{\circ}$.

Para o ensaio $n^{\circ}$ 3, o veiculo foi ajustado para a rotação de 5500 rpm, simulando a condição de velocidade próxima de $30 \mathrm{~km} / \mathrm{h}$ em 2o marcha em pista plana.

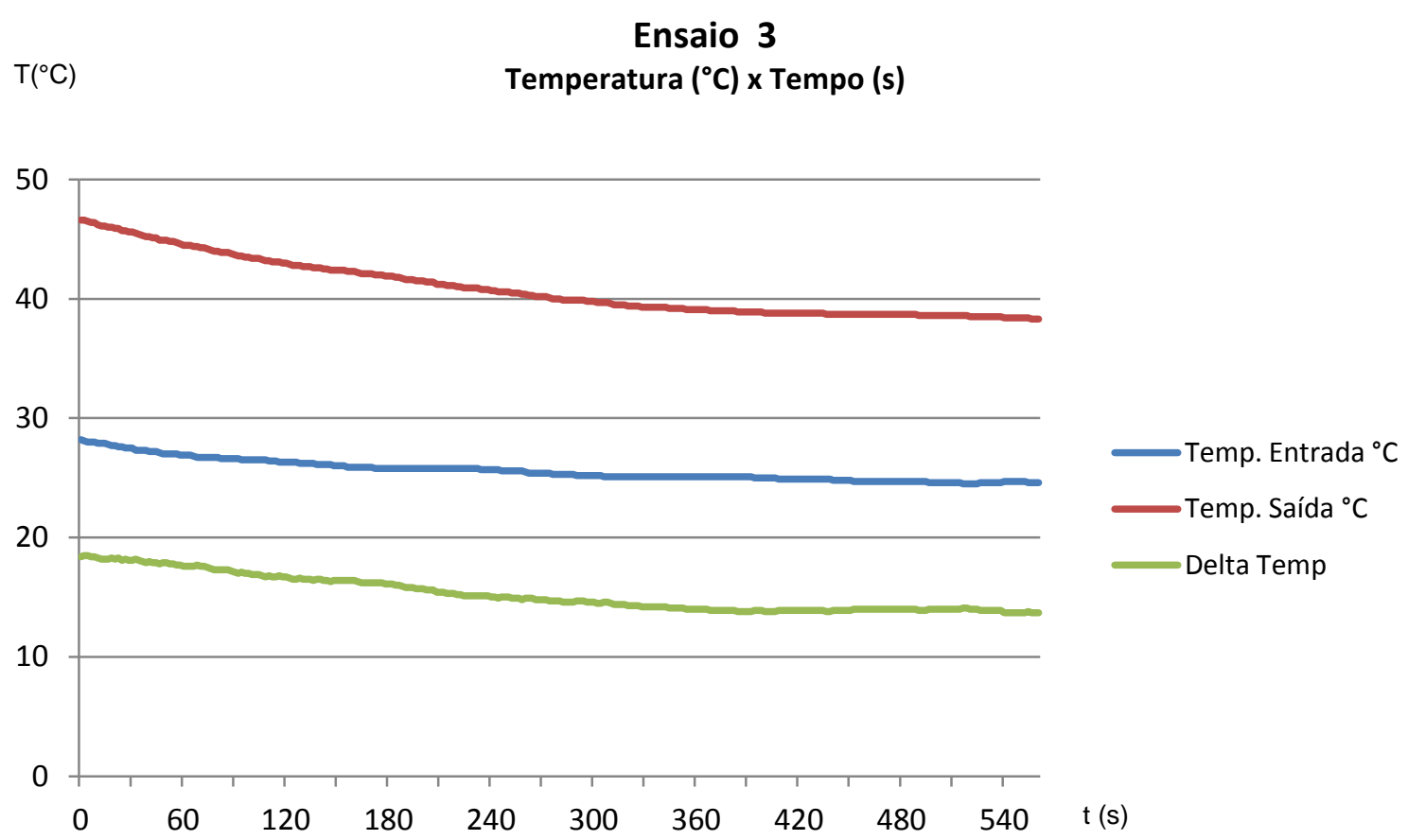

Figura 38 - Gráfico de Temperatura $\left({ }^{\circ} \mathrm{C}\right) \times$ Tempo (s) para a condição de segunda marcha a $40 \mathrm{~km} / \mathrm{h}$.

Nesse caso, nota-se que as condições de temperatura entraram em regime permanente após $t=360$ segundos do início de registro dos dados, conforme gráfico da Figura 38. As temperaturas verificadas foram de $24.6{ }^{\circ} \mathrm{C}$ e $38.6{ }^{\circ} \mathrm{C}$, respectivamente para entrada e saída do radiador. Com isso, a transferência de calor calculada é de $7703 \mathrm{~W}$. 


\section{A seguir segue uma planilha que foi utilizada durante os testes para registro e cálculos dos dados de interesse, conforme SAE (2008).}

Tabela 8 - Registro das informações dos testes.

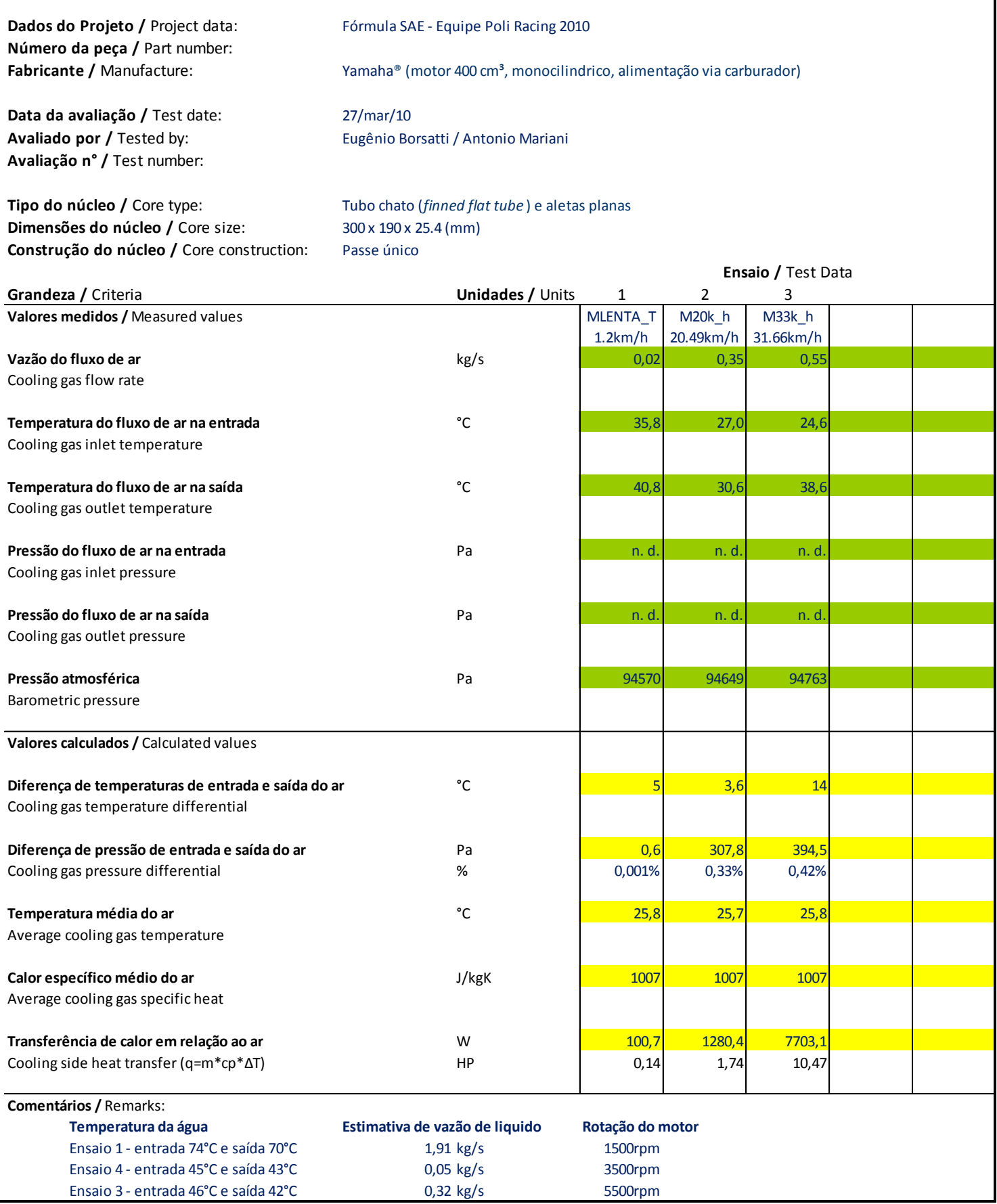




\subsubsection{Considerações e análise dos resultados experimentais}

Com a determinação das diversas grandezas através dos testes realizados, é possível realimentar a ferramenta computacional com tais dados e comparar com as informações calculadas anteriormente. Isto pode ser feito tanto para as informações de desempenho do trocador de calor, quanto para o do projeto do novo trocador de calor.

As velocidades que foram possíveis para o fluxo de ar na entrada do trocador de calor estão um pouco maiores que o valor de $30 \mathrm{~km} / \mathrm{h}$. Inicialmente esses valores foram considerados baixos pois o critério de projeto para desenvolver o novo trocador adotava $60 \mathrm{~km} / \mathrm{h}$. Esses valores podem ser revistos considerando as características construtivas do protótipo, em que as barras de suspensão e o pneu dianteiro esquerdo estão à montante do fluxo e próximos da entrada do duto do radiador. Essa característica pode gerar perdas significativas para o fluxo na entrada, sendo necessário rever esse dado na ferramenta de cálculo. Uma avaliação dessa condição é realizada para um protótipo virtual do veículo utilizando CFD.

Os valores encontrados nos dois primeiros ensaios para a pressão diferencial na placa de orifício e no radiador estão relativamente baixos em comparação aos demais testes. Essa ocorrência está diretamente ligada ao fato do gerador de fluxo estar desligado no momento das medições, de forma a simular a condição de veículo parado com o motor ligado. O fluxo nesses ensaios foi determinado somente pelo ventilador disponível no veículo.

Para a relação de pressão diferencial no radiador e velocidade na entrada do sistema, pode-se observar a Tabela 9 e o gráfico da Figura 39, em que foi estimada a curva de tendência linear para os dados aferidos. Com esses resultados, é possível estimar valores de pressão diferencial para outras velocidades dentro do intervalo, caso seja do interesse de revisão do projeto. 
Tabela 9 - Relação de pressão diferencial em função da velocidade para as condições avaliadas experimentalmente com veículo Fórmula SAE.

\begin{tabular}{|c|c|c|c|}
\hline \multirow{2}{*}{ Ensaio } & \multirow{2}{*}{$\Delta \mathbf{P} /$ Patm } & \multicolumn{2}{|c|}{ V. Rad. \pm Inc. } \\
\cline { 2 - 4 } & $\%$ & \multicolumn{2}{|c|}{$\mathbf{~ m / s}$} \\
\hline P1 & $0,001 \%$ & 0,43 & 0,02 \\
\hline P2 & $0,006 \%$ & 0,37 & 0,01 \\
\hline P3 & $0,33 \%$ & 7,3 & 0,1 \\
\hline P4 & $0,44 \%$ & 11,3 & 0,3 \\
\hline P5 & $0,42 \%$ & 11,3 & 0,3 \\
\hline P6 & $0,53 \%$ & 11,3 & 0,3 \\
\hline P7 & $0,43 \%$ & 9,3 & 0,2 \\
\hline
\end{tabular}

\section{$\Delta \mathrm{P} / \mathrm{P}_{\text {atm }}(\%) \times$ Velocidade $(\mathrm{m} / \mathrm{s})$}

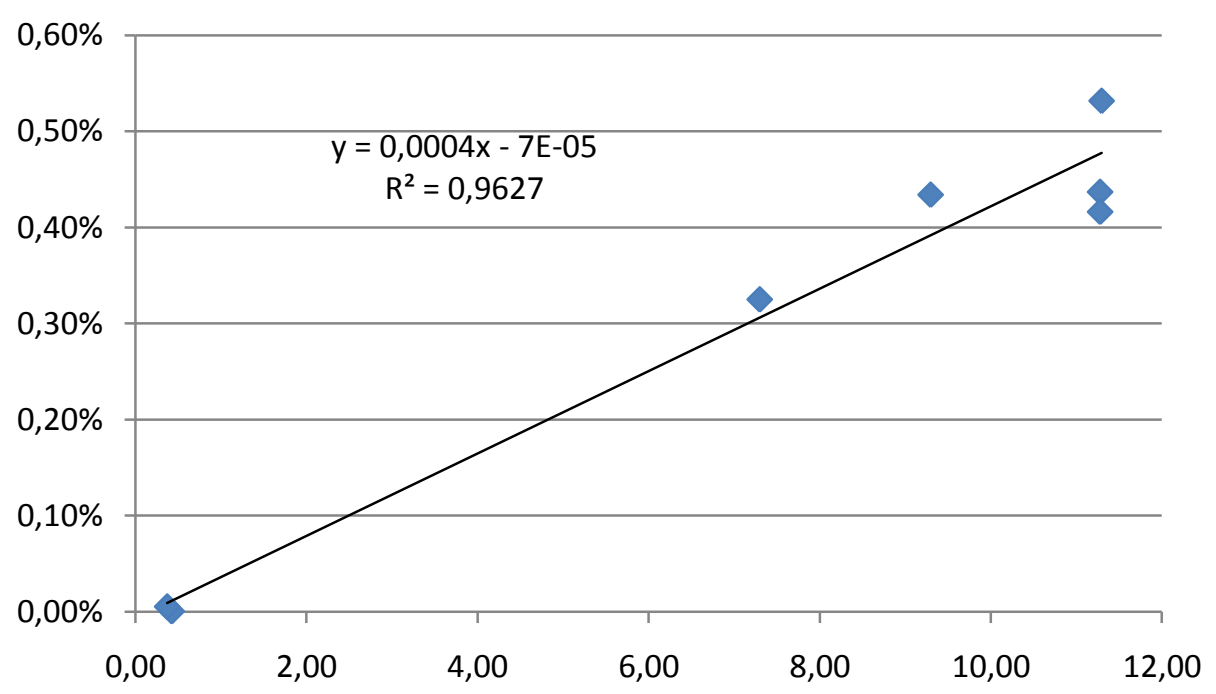

Figura 39 - Gráfico da relação de pressão diferencial em função da velocidade para as condições avaliadas experimentalmente, similar à adotada por Gattei, Rossi, Cardile (2008) e Quim (2007).

Para os valores de temperatura medidos na entrada e saída da água no trocador de calor com o pirômetro ótico, notam-se valores abaixo dos resultados esperados. Segundo informações da equipe e o que se sabe sobre a prática dos construtores desses sistemas, a válvula termostática é aberta com temperaturas próxima da 
temperatura de ebulição da água. Pode ter ocorrido alguma interferência do material das mangueiras ou dos tubos de alumínio, que eram o foco da medição. De qualquer forma, são considerados apenas os diferenciais de temperatura para o cálculo da vazão do líquido de arrefecimento.

\subsection{SIMULAÇÃO NUMÉRICA}

Para estudar o comportamento do escoamento de ar no sistema duto-trocador de calor, comparar a geometria existente no veículo atualmente com alternativas propostas para melhoria e considerar os aspectos aerodinâmicos envolvidos foram realizadas simulações numéricas.

Com a aplicação de programas de simulação foi possível gerar informações para as grandezas de interesse, como distribuição de velocidades, de pressões, vazão e coeficiente de arrasto.

As avaliações virtuais numéricas foram realizadas utilizando um conjunto de programas de computador, utilizados amplamente por diversas empresas e universidades envolvidas no ramo de simulações de engenharia. O programa utilizado para essas avaliações numérica do comportamento das grandezas no escoamento foi o FLUENT ${ }^{\circledR}$. Para o desenvolvimento das malhas geométricas foram utilizados os programas Hypermesh ${ }^{\circledR}$, para gerar as malhas de superficiais e 0 programa TGrid $^{\circledR}$, para as malhas volumétricas.

As propriedades e grandezas que definem o estado para o ar, pressão atmosférica, temperatura, massa específica, viscosidade dinâmica, calor específico, e condutividade térmica, foram mantidas as mesmas utilizadas nos cálculos do projeto e desempenho do radiador. As avaliações foram realizadas sob a condição de regime permanente, com o fluido sendo considerado incompressível, isotérmico e escoamento turbulento. O modelo de turbulência escolhido para essas avaliações é

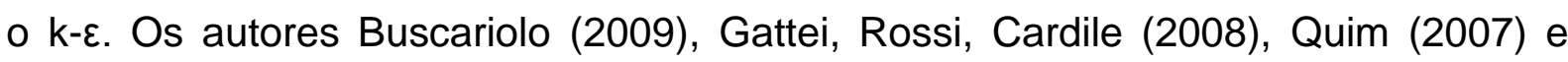


Hucho (1987) apresentam estudos utilizando esse modelo em projetos semelhantes e concluem que é o mais indicado para simulações aerodinâmicas de veículos. Quim (2007) cita inclusive outros três trabalhos nessa área que utilizaram esse mesmo modelo para aplicação veicular.

De forma análoga, foram utilizadas as referências de Buscariolo (2009) e Quim (2007) para a função de parede e para definir as condições de contorno para simulação. A simulação foi realizada com base na geometria da seção de ensaios do túnel de vento da General Motors, localizado em Warren nos Estados Unidos, cujas dimensões reais são $(5,4 \times 10,4 \times 23)$ metros.

Outros dados importantes implementados nessa simulação numérica do escoamento de ar em torno do veículo são que as rodas dos modelos foram colocadas em movimento, como se o veículo estivesse se deslocando em trajetória retilínea uniforme a uma velocidade de $60 \mathrm{~km} / \mathrm{h}$. Ou seja, ao longe, a velocidade relativa entre o ar e o veículo foi admitida como sendo $16,7 \mathrm{~m} / \mathrm{s}(\cong 60 \mathrm{~km} / \mathrm{h})$. O radiador foi simulado como uma parede permeável com resistência ao escoamento determinada pelo gráfico da Figura 39, obtido experimentalmente.

\subsubsection{Alternativas para o sistema duto-trocador de calor}

O desenvolvimento dos protótipos virtuais, isto é, dos desenhos em três dimensões para representar o veículo com o sistema duto-trocador de calor nas simulações numéricas, foram utilizados recursos disponíveis no laboratório dedicado à equipe Poli Racing. O desenho original do veículo foi cedido pela equipe e as demais propostas foram desenvolvidas com auxílio dos computadores do laboratório que possuem licença do programa UG $N X 5^{\circledR}$, necessário para o desenvolvimento da geometria. 
Foram adotados quatro protótipos detalhados nas Figuras de 40 a 43 . . O primeiro caso retrata a condição original do veículo, protótipo $A$, enquanto as demais são alternativas propostas que representam a evolução desta situação inicial, identificados por protótipos B, C e D.

O foco dessas propostas foi direcionado para a região do duto lateral e do sistema de arrefecimento e, por essa razão, todos os protótipos receberam simplificações em regiões que não estão relacionadas com estas. A vantagem em realizar essas simplificações está no menor tempo exigido para a preparação da superfície para a geração das malhas geométricas e para o processamento das informações pelo programa de cálculo. As simplificações estão nas regiões internas do veículo, na estrutura tubular, no detalhamento das rodas, do sistema de freios e do motor.

O protótipo A representa o veículo conforme foi desenvolvido pela equipe, respeitando a geometria original do duto lateral, conforme Figura 40, seu posicionamento e dimensões do sistema de arrefecimento. O núcleo do radiador existente possui dimensões de $(300 \times 190 \times 24,5) \mathrm{mm}$.

Os protótipos B, C e D apresentam uma nova geometria para o duto lateral, que considerou o conceito de duto divergente-convergente, conforme exposto pelo trabalho de Christoffersen et al. (2008) e ilustrado pela Figura 45. Há uma relação de áreas da seção transversal de 1:2 na parte frontal, com comprimento de $370 \mathrm{~mm}$ a montante do radiador, e 5:1 na parte posterior com comprimento de $290 \mathrm{~mm}$. O desenho do duto foi desenvolvido com a finalidade de reduzir sua contribuição para o arrasto do veículo. Esses protótipos também apresentam a nova geometria proposta para o radiador, conforme exposto anteriormente, com dimensões calculadas em $(220 \times 160 \times 24,5) \mathrm{mm}$. 


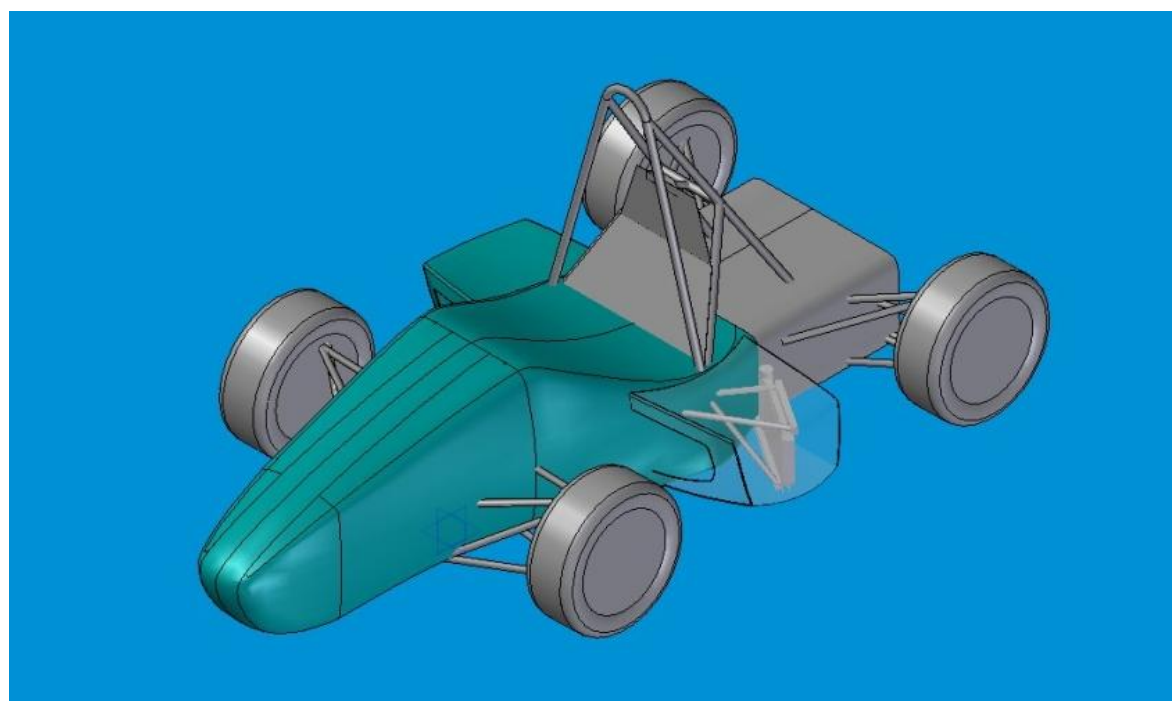

Figura 40 - Protótipo A: desenho do veículo Fórmula SAE com configuração original.

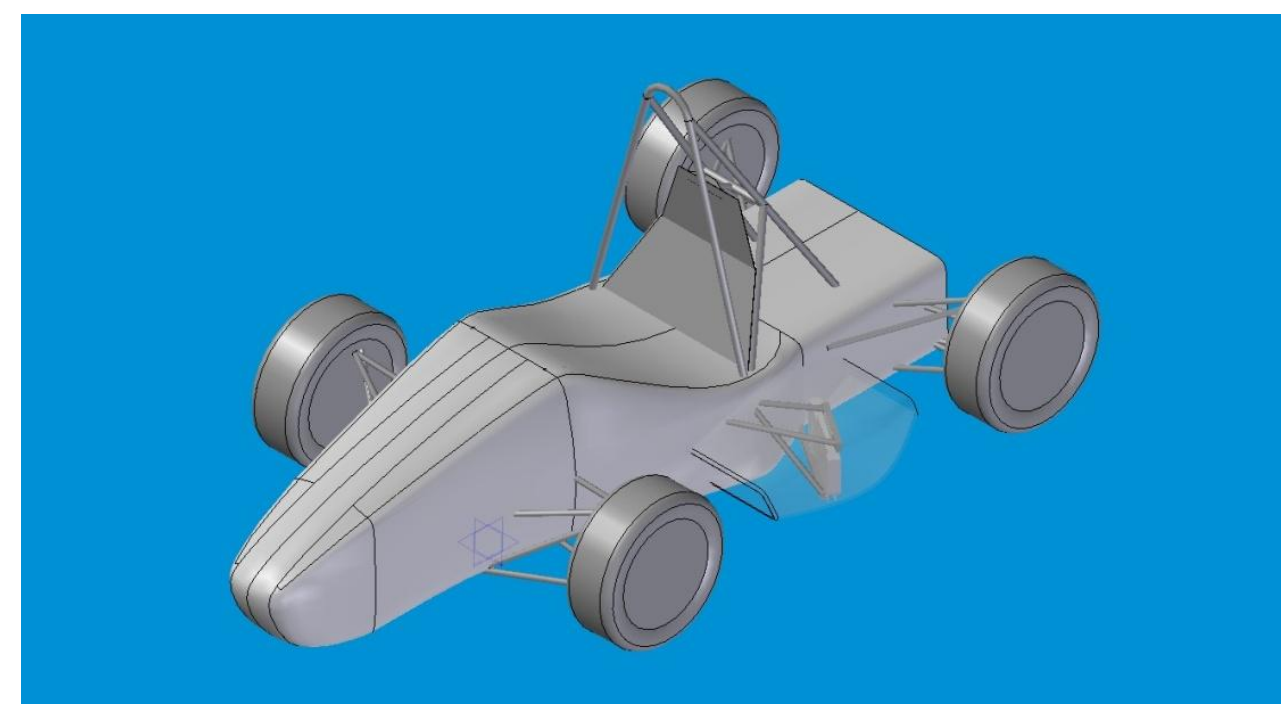

Figura 41 - Protótipo B: desenho do veículo Fórmula SAE com novos dutos, trocador de calor com dimensões reduzidas fixado na mesma posição do protótipo $A$. 


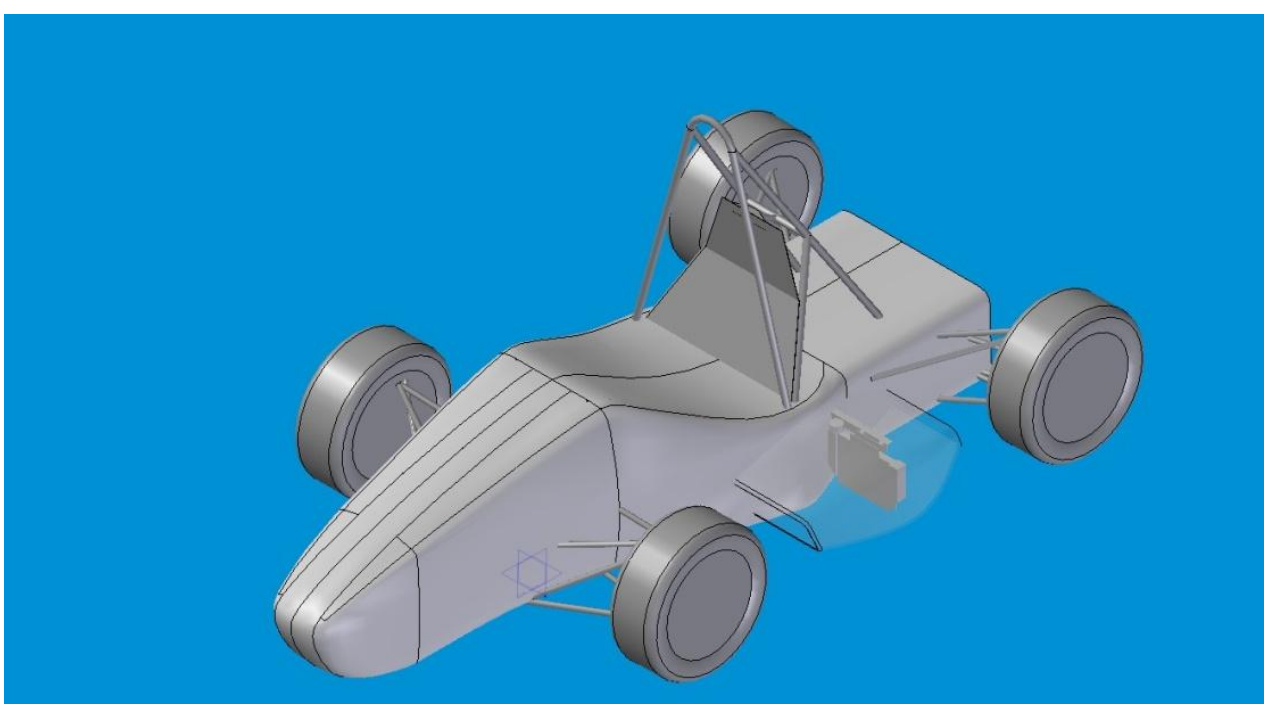

Figura 42 - Protótipo C: desenho do veículo Fórmula SAE com duto similar ao protótipo B, trocador de calor com novas dimensões e posicionamento perpendicular ao eixo longitudinal do veículo.

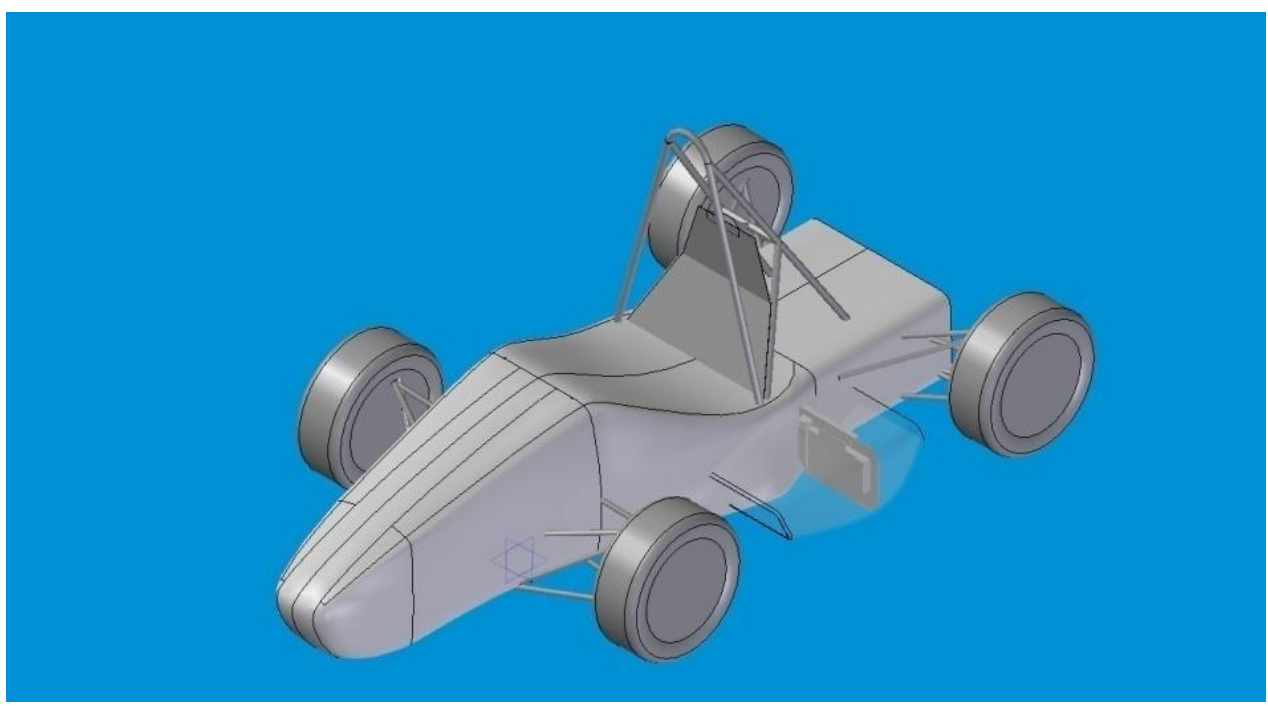

Figura 43 - Protótipo D: desenho do veículo Fórmula SAE com duto e trocador de calor com dimensões e posicionamento idênticos ao protótipo $\mathrm{C}$, mas com vedação no contorno do radiador. 


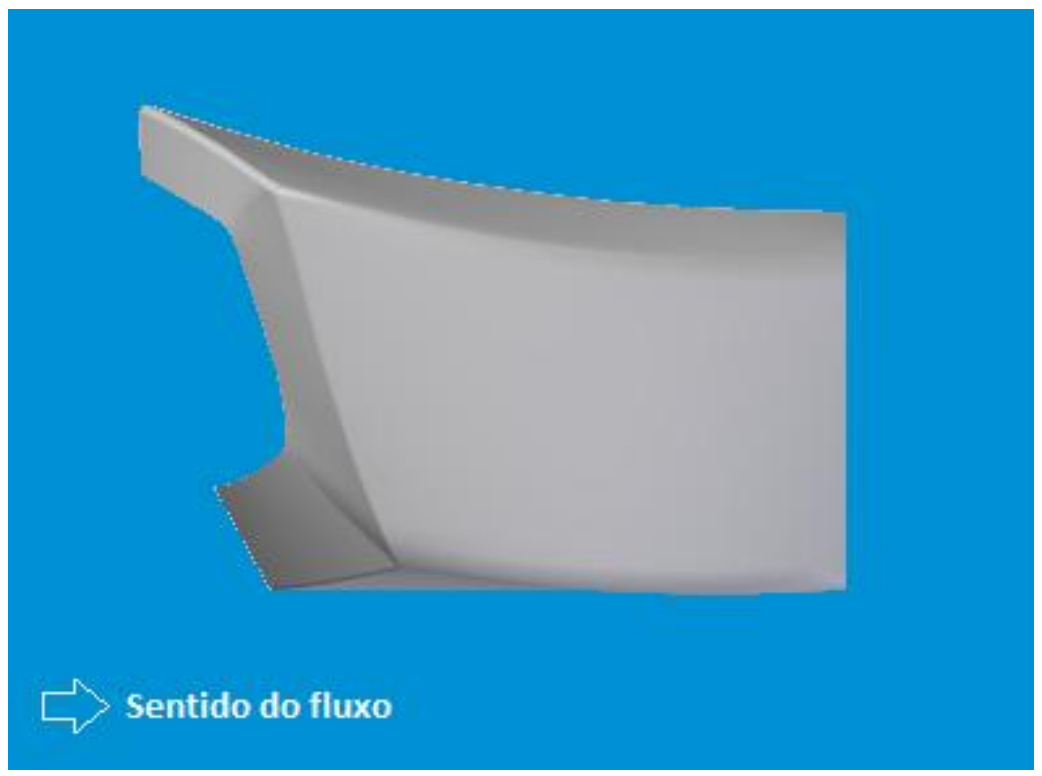

Figura 44 - Vista lateral do duto que contém o trocador de calor instalado no protótipo A.

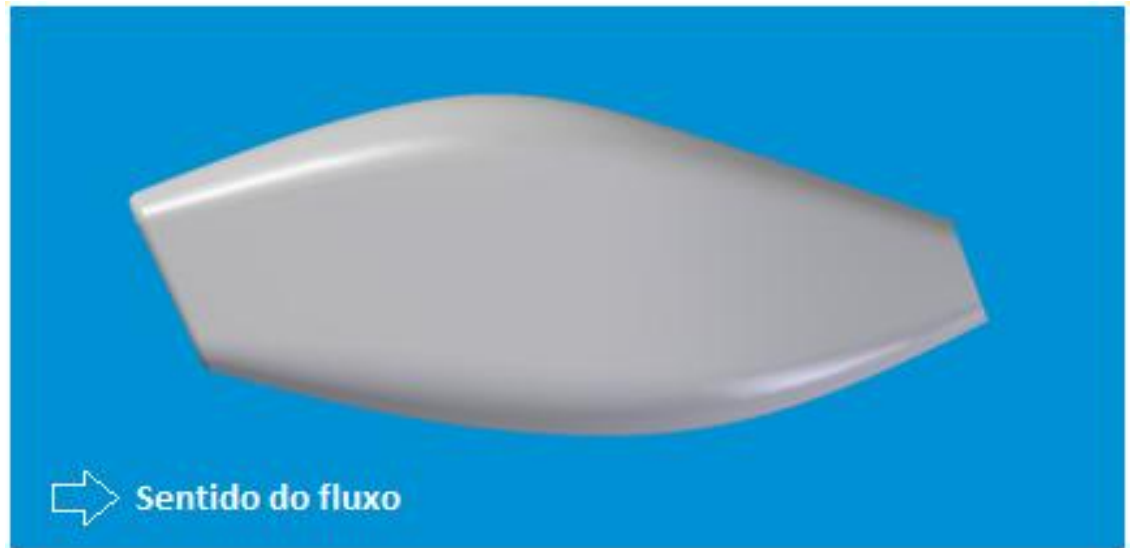

Figura 45 - Vista lateral do modelo proposto para o duto lateral das três propostas (protótipos B, C e D), considerando o conceito de duto divergente-convergente. 
Tabela 10 - Áreas das seções transversais do duto que contém o trocador de calor nos protótipos B, $C$ e $D$ e razão entre as áreas.

\begin{tabular}{|l|c|}
\hline \multicolumn{1}{|c|}{ Identificação da seção transversal } & Área $\left(\mathbf{m m}^{2} \mathbf{}\right)$ \\
\hline A1 = Área de entrada do duto & 50953 \\
\hline A2 = Área intermediária (radiador) & 104637 \\
\hline A3 = Área de saida do duto & 19044 \\
\hline \multicolumn{1}{|c|}{ Comparação entre áreas } & Razão \\
\hline Razão de divergência - A1/A2 & $1 / 2$ \\
\hline Razão de convergência - A2/A3 & $5 / 1$ \\
\hline
\end{tabular}

Os protótipos B, C e D diferenciam-se pelo posicionamento do trocador de calor e pela utilização ou não de vedação no seu entorno conforme indicações nas Figuras 41, 42 e 43. A proposta de vedação do protótipo $D$ coincide com a condição em que foram realizados os ensaios experimentais que direciona o fluxo de ar interno ao duto a passar exclusivamente pelo núcleo do radiador.

\subsubsection{Resultados}

As atividades de geração de malhas, pré-processamento e simulação numérica foram desenvolvidos utilizando recursos existentes na empresa General Motors. Para as atividades de processamento das simulações foi utilizado um sistema computacional (cluster) com 32 processadores localizado nos Estados Unidos.

Os resultados obtidos são:

- Força e coeficiente $\left(\mathrm{C}_{\mathrm{D}}\right)$ de arrasto para todo o veículo em cada protótipo;

- Vazão de ar que atravessa o núcleo do trocador de calor; 
- Gráficos com a distribuição de pressões em regiões localizadas na superfície do veículo;

- Distribuição de pressões nas superfícies do trocador de calor;

- Gráficos com apresentação da orientação do escoamento visualizado a partir de vetores velocidade em planos pré-definidos;

\subsubsection{Força e coeficiente de arrasto e vazão em massa de ar}

Os resultados numéricos obtidos pelo programa de simulação numérica estão organizados na Tabela 11 a seguir, de forma a facilitar a visualização e interpretação. Tem-se os valores de área e volume dos radiadores, a vazão verificada na região do núcleo dos trocadores de calor, os valores para a força e para 0 coeficiente de arrasto $\left(\mathrm{C}_{D}\right)$. A área frontal projetada, e os parâmetros de arrasto consideram o veículo como um todo, e não apenas o conjunto duto-trocador.

$\mathrm{Na}$ Tabela 11 há, também, correlações percentuais para auxiliar a análise comparativa entre os diferentes protótipos. 
Tabela 11 - Resumo dos dados de vazão em massa, área frontal projetada, força e coeficiente de arrasto para os quatro casos estudados.

\begin{tabular}{|c|c|c|c|c|}
\hline Grandezas (unidades) & Protótipo A & Protótipo B & Protótipo C & Protótipo D \\
\hline Dimensões do núcleo do radiador (mm) & $300 \times 190 \times 25,4$ & $220 \times 160 \times 25,4$ & $220 \times 160 \times 25,4$ & $220 \times 160 \times 25,4$ \\
\hline Área do núcleo do radiador $\left(\mathrm{mm}^{2}\right)$ & 57000 & 32000 & 32000 & 32000 \\
\hline Volume do núcleo do radiador $\left(\mathrm{mm}^{3}\right)$ & 1447800 & 812800 & 812800 & 812800 \\
\hline Área e volume - comparação com protótipo $\mathrm{A}$ & $100 \%$ & $56,1 \%$ & $56,1 \%$ & $56,1 \%$ \\
\hline Vazão verificada no radiador (kg/s) & 0,724 & 0,184 & 0,188 & 0,414 \\
\hline Vazão - comparação com protótipo $A$ & $100 \%$ & $25,4 \%$ & $26,0 \%$ & $57,2 \%$ \\
\hline Resultante das forças de arrasto $(\mathrm{N})$ & 116,5 & 109,66 & 111,03 & 110,37 \\
\hline Coeficiente de arrasto $\left(c_{D}\right)$ & 0,847 & 0,832 & 0,838 & 0,833 \\
\hline$C_{D}$ - Comparação com protótipo $A$ & $100 \%$ & $98,23 \%$ & $98,95 \%$ & $98,36 \%$ \\
\hline Área frontal projetada $\left(\mathrm{m}^{2}\right)$ & 0,81 & 0,77 & 0,78 & 0,78 \\
\hline Área frontal - Comparação com protótipo A & $100 \%$ & $95,8 \%$ & $96,3 \%$ & $96,3 \%$ \\
\hline
\end{tabular}

Convém salientar que no protótipo A, o veículo possui dois dutos laterais, sendo que possui trocador de calor disponível em apenas um dos lados. Esta definição está relacionada à escolha da equipe Poli Racing, que optou em manter um duto não funcional para simetria do veículo, sem outra função específica. Para os protótipos $\mathrm{B}, \mathrm{C}$ e D, essa opção de dois dutos foi desconsiderada, havendo apenas um duto contendo o radiador.

\subsubsection{Distribuição de pressões}

A seguir são apresentados os resultados gráficos extraídos da aplicação do programa FLUENT ${ }^{\circledR}$ para os quatro protótipos avaliados. Foram desenvolvidas imagens da distribuição de pressões do escoamento de ar sobre o modelo virtual do veículo todo, Figuras 46 e 47 . Distribuições de pressão especificamente nos trocadores de calor avaliados estão nas Figuras 48 a 55, para todos os quatro modelos adotados do conjunto duto-trocador. Nestas imagens está representado apenas o trocador, mas na simulação ele foi considerado posicionado internamente 
ao duto, conforme configurações já apresentadas. Todos os valores para as pressões são dados em unidades do SI, ou seja, em pascal.

As imagens gráficas com as distribuições de pressão têm a finalidade de possibilitar avaliação com enfoque mais qualitativo e comparativo. Devem ser observadas as regiões de interesse e, em relação ao sistema duto-trocador, avaliar se há condições favoráveis para motivar a passagem de ar através do trocador de calor, de modo a garantir vazão de ar necessária que efetive a taxa de transferência estabelecida.

É também possível avaliar e comparar se os posicionamentos adotados para o trocador de calor estão adequados para distribuir o escoamento de ar em toda sua área. As demais partes da carenagem do veículo possuem distribuições de pressão semelhantes nos quatro modelos estudados, sendo que análises não relacionadas ao sistema duto-trocador não fazem parte deste estudo.

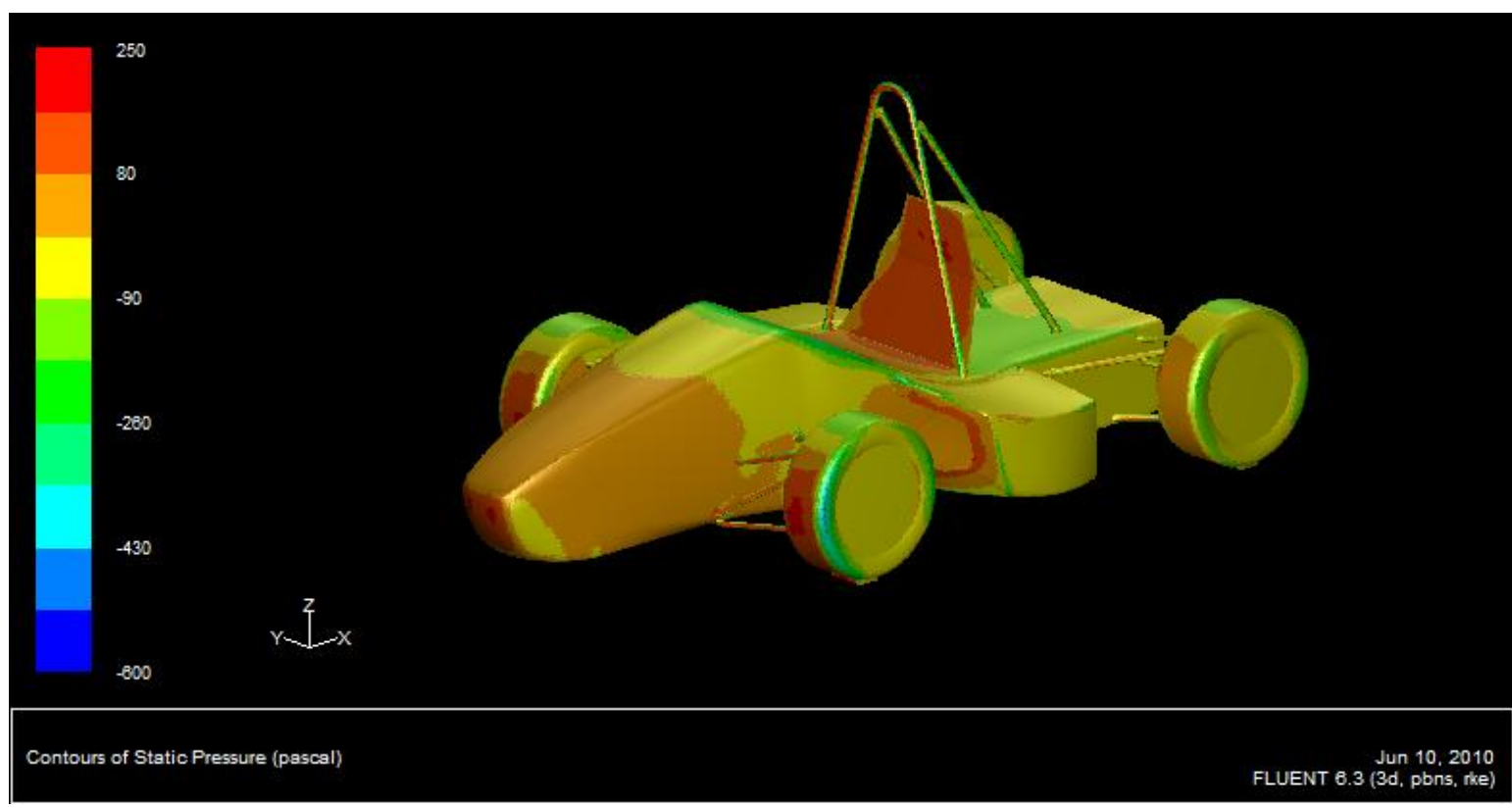

Figura 46 - Distribuição de pressões sobre o modelo, representando o protótipo A. 


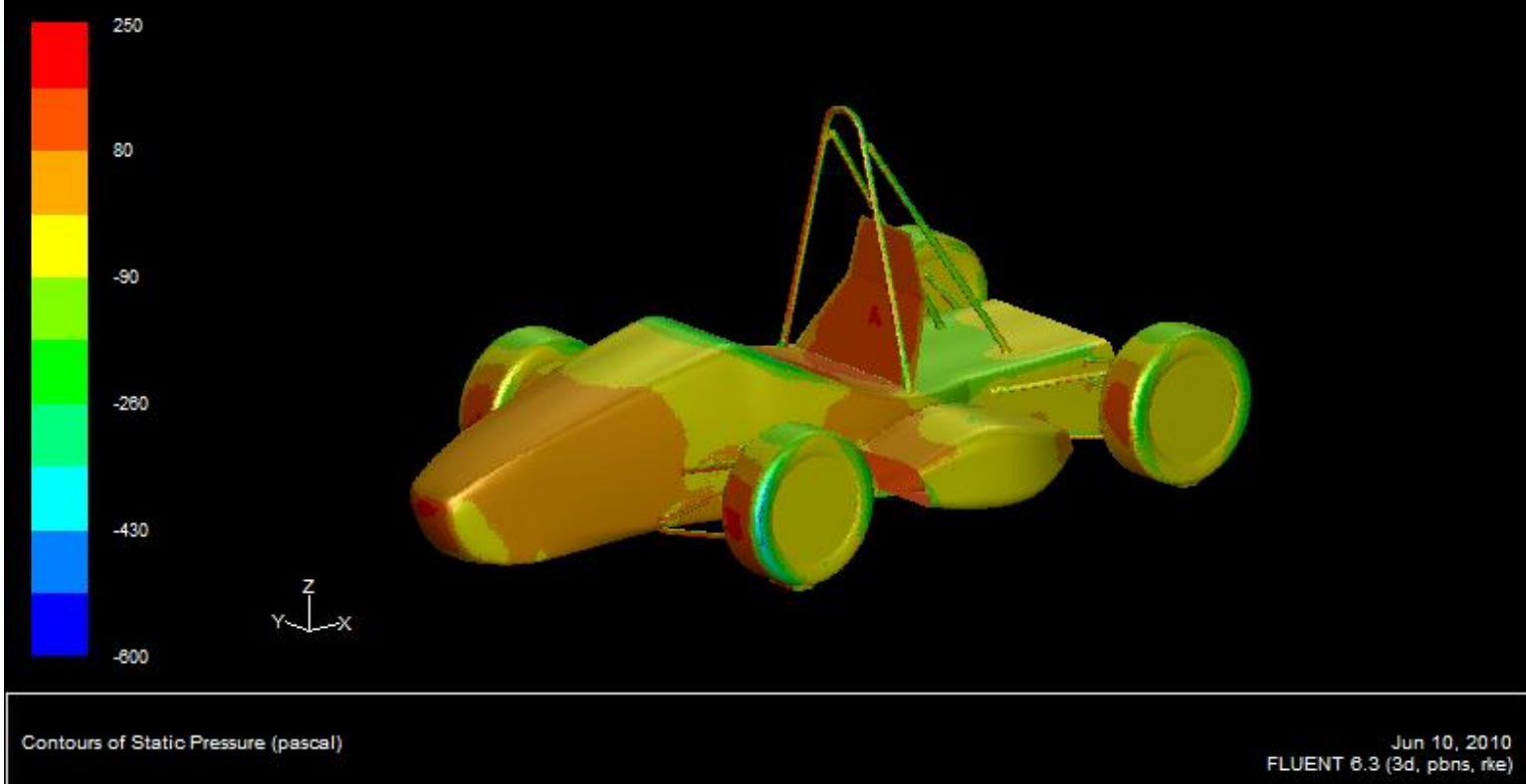

Figura 47 - Distribuição de pressões sobre o modelo, representando os protótipos B, C e D.

A diferença nas distribuições de pressão sobre os modelos dos veículos está sendo provocada pela geometria do duto lateral. Dos resultados expressos nas Figuras 46 e 47, verifica-se que o protótipo A apresenta uma região de pressão mais baixa na entrada do duto do trocador em comparação à mesma região para os demais protótipos. 


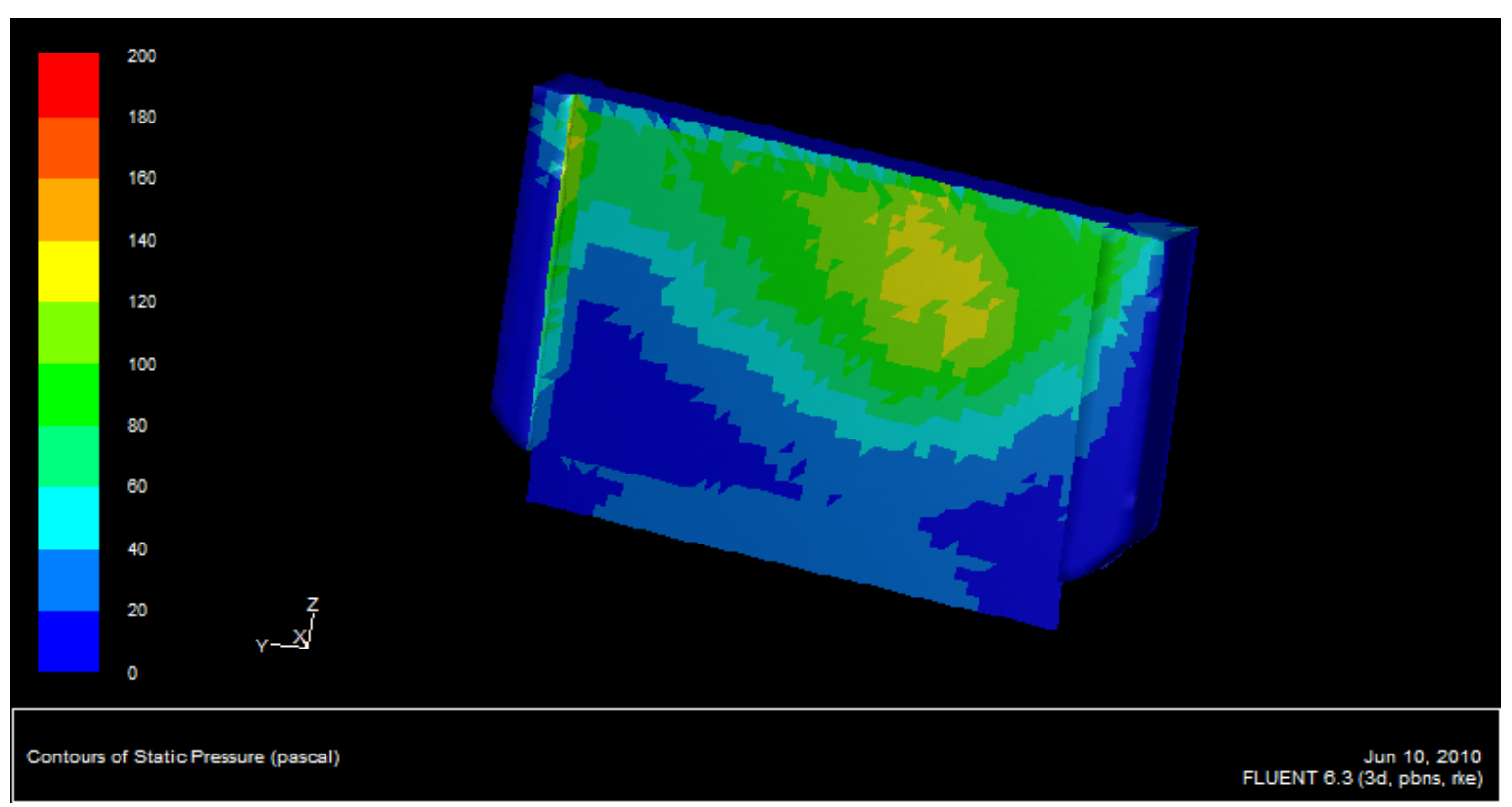

Figura 48 - Gráfico de distribuição de pressões na região frontal do trocador para o protótipo A.

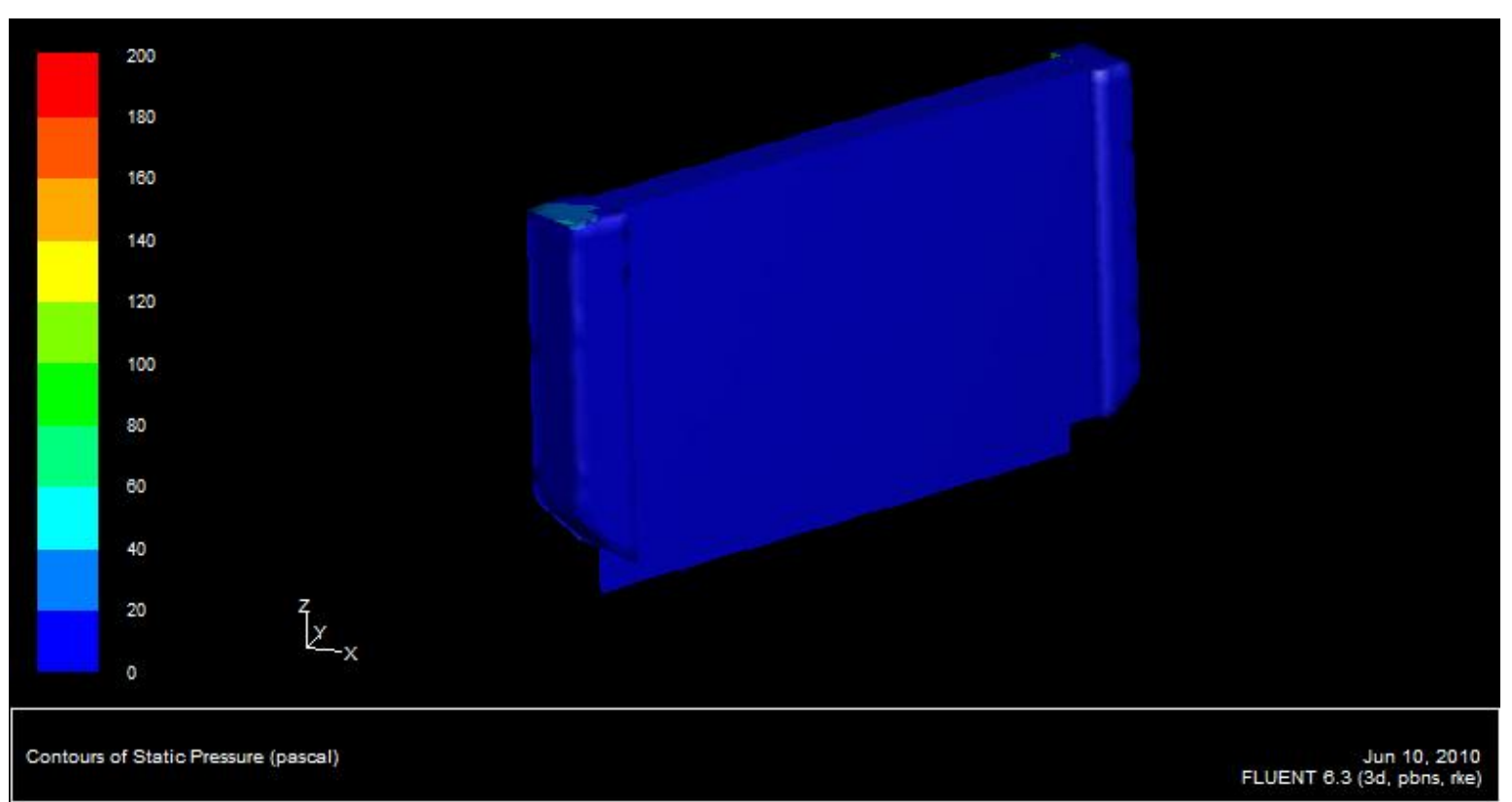

Figura 49 - Gráfico de distribuição de pressões na região posterior do trocador para o protótipo A. 
Observando as Figuras 48 e 49, verifica-se que o protótipo A apresenta uma distribuição desbalanceada na face frontal, com uma região de maior pressão na parte superior do radiador. Se comparado com a face posterior, pode-se concluir que há expectativa de baixa vazão de ar através do radiador, dada a proximidade dos valores de pressão entre as faces frontal e posterior, e por conseqüência há baixa probabilidade de troca de calor em determinadas regiões.

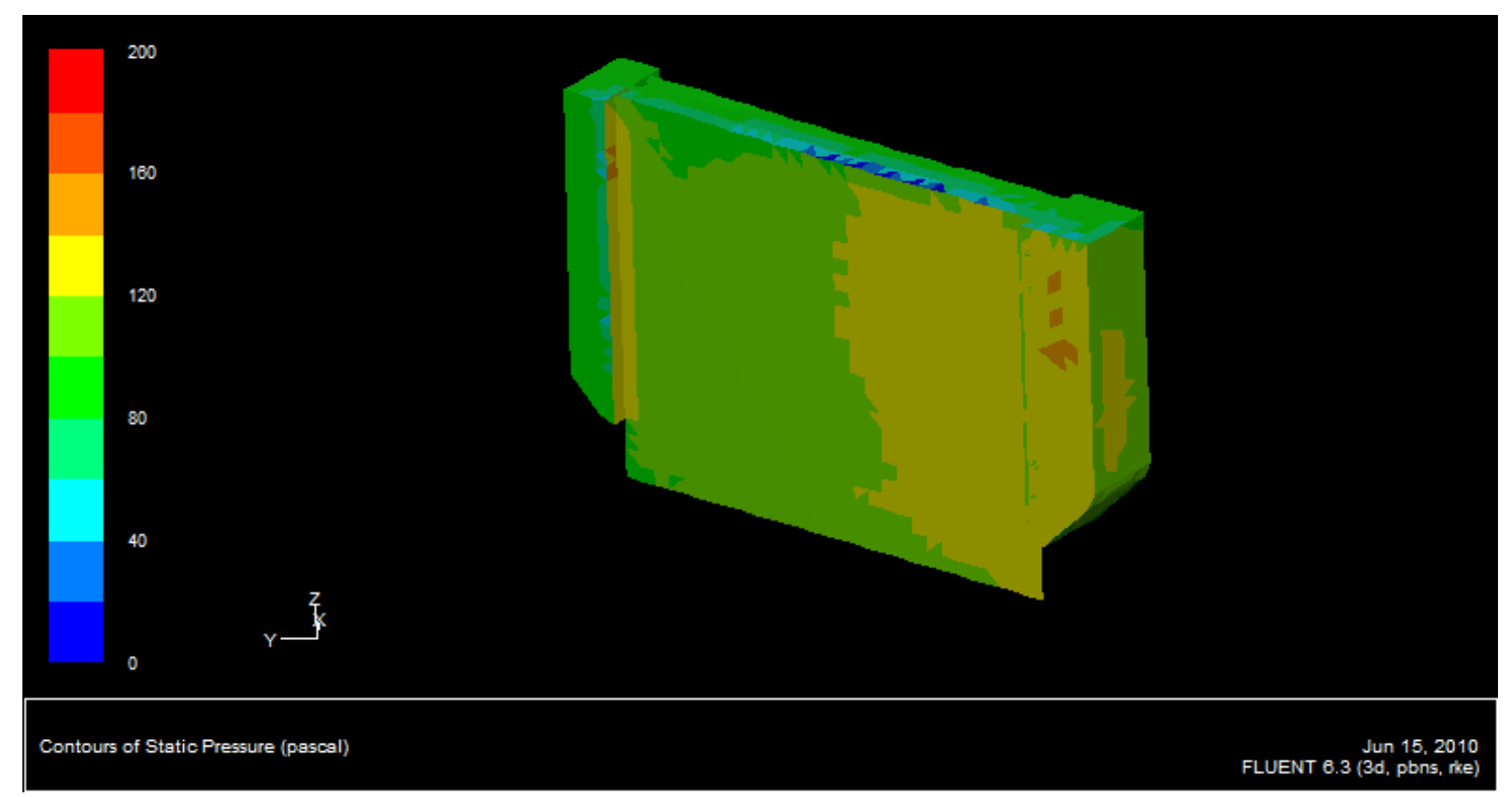

Figura 50 - Gráfico de distribuição de pressões na região frontal do trocador para o protótipo B.

Os protótipos B e C apresentam comportamento semelhante, com os gráficos das Figuras 50 a 53 revelando um desbalanceamento na distribuição de pressão na região frontal, com maior intensidade no lado direito da face frontal. De forma análoga ao protótipo $\mathrm{A}$, há expectativa de reduzida vazão de ar e troca de calor em função do lado posterior, que apresenta valores de pressão estática próxima a face posterior. 


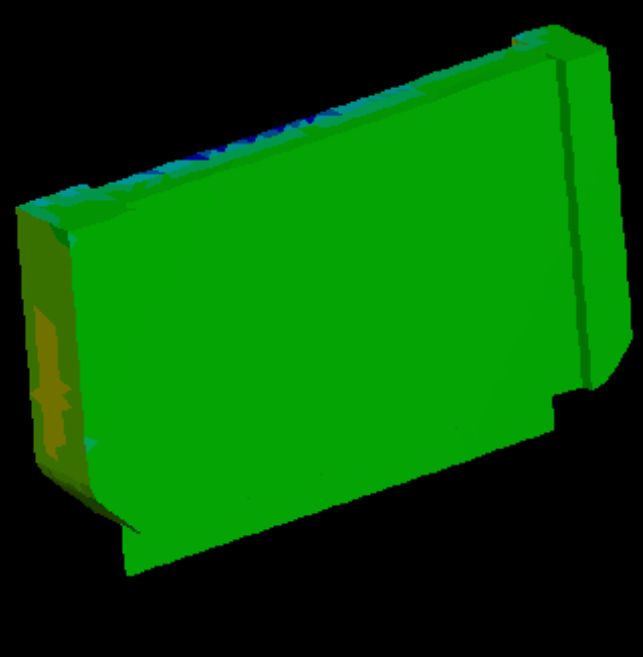

Figura 51 - Gráfico de distribuição de pressões na região posterior do trocador para o protótipo B.

Figura 52 - Gráfico de distribuição de pressões na região frontal do trocador para o protótipo C. 


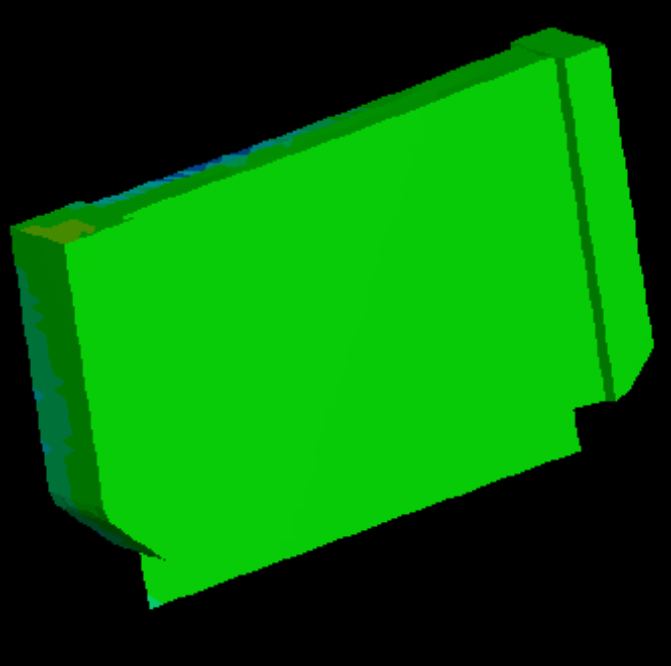

Figura 53 - Gráfico de distribuição de pressões na região posterior do trocador para o protótipo C.

Figura 54 - Gráfico de distribuição de pressões na região frontal do trocador para o protótipo D. 
Figura 55 - Gráfico de distribuição de pressões na região posterior do trocador para o protótipo D.

A análise comparativa entre a distribuição de pressão nos trocadores nos diversos protótipos indica que o protótipo $\mathrm{D}$ possui a distribuição mais uniforme dentre as quatro propostas. 


\subsubsection{Visualização de escoamento de ar a partir do campo de velocidades}

A seguir são apresentados os resultados da simulação numérica obtidos a partir da visualização do escoamento do ar que interage com o sistema duto-trocador de calor instalado no veículo Fórmula SAE. Essa visualização é feita a partir do campo de vetores velocidade em regiões específicas e de interesse, de modo que seja possível avaliar o comportamento do fluxo de ar.

Foram selecionadas as vistas superiores para os resultados gráficos que estão nas Figuras 56 a 59, que traz um conjunto de vetores velocidade contidos em um plano paralelo ao solo (plano $\mathrm{XY}$ ) e perpendicular ao eixo $Z$, interceptando o trocador de calor em sua linha média.

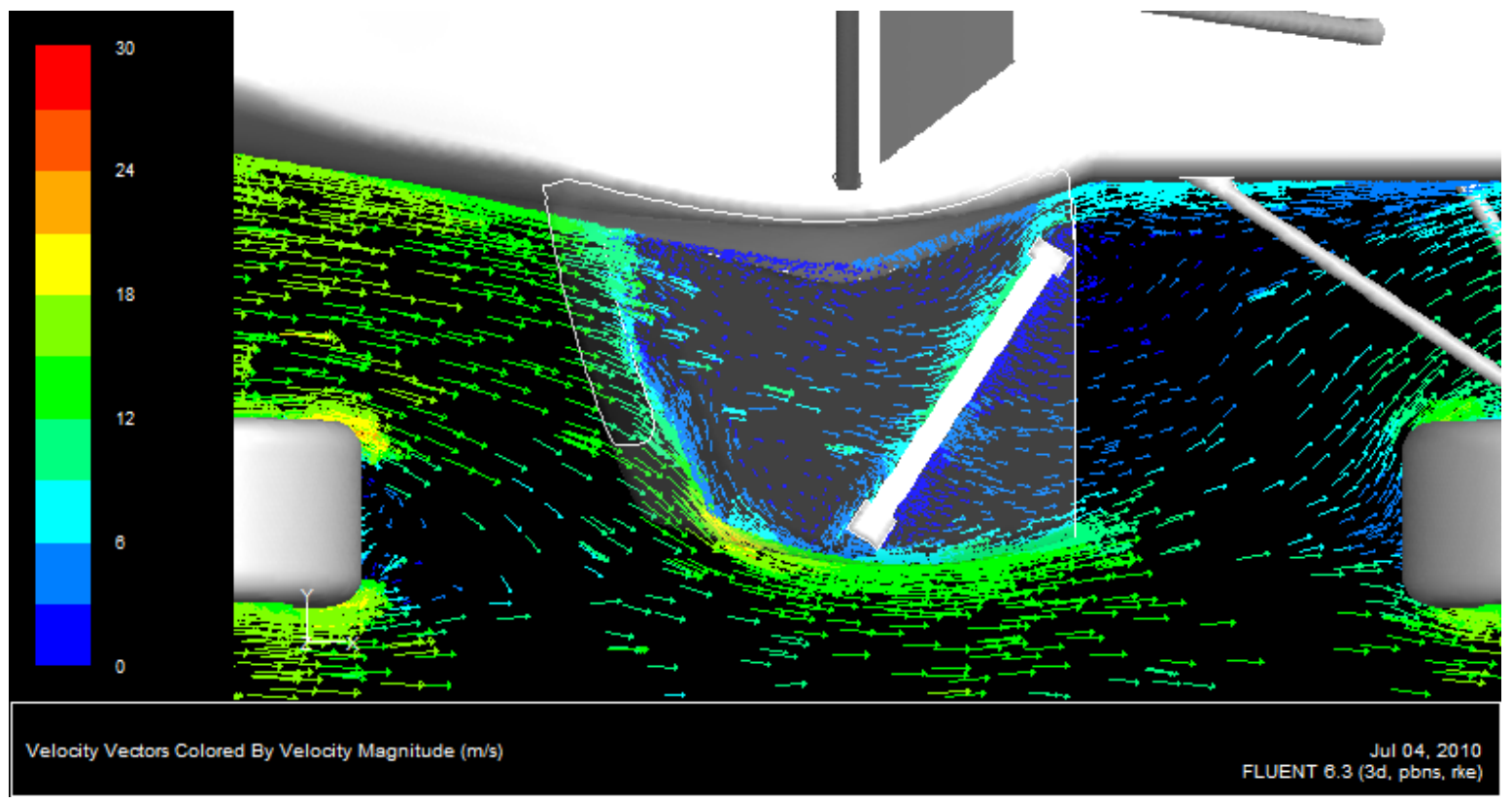

Figura 56 - Vista superior da distribuição de vetores de velocidade na região próxima ao radiador para o protótipo $\mathrm{A}$. 


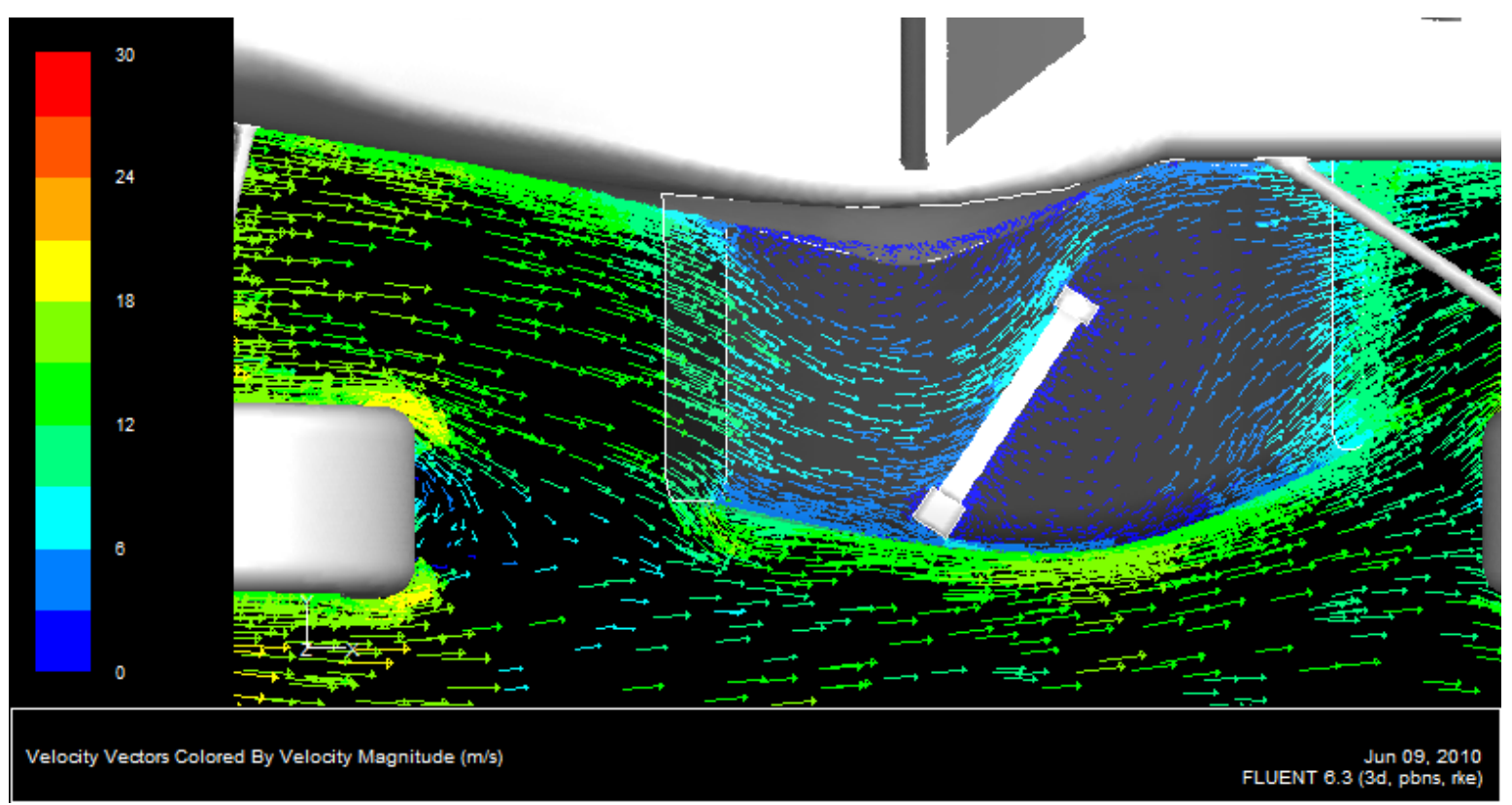

Figura 57 - Vista superior da distribuição de vetores de velocidade na região próxima ao radiador para o protótipo $\mathrm{B}$.

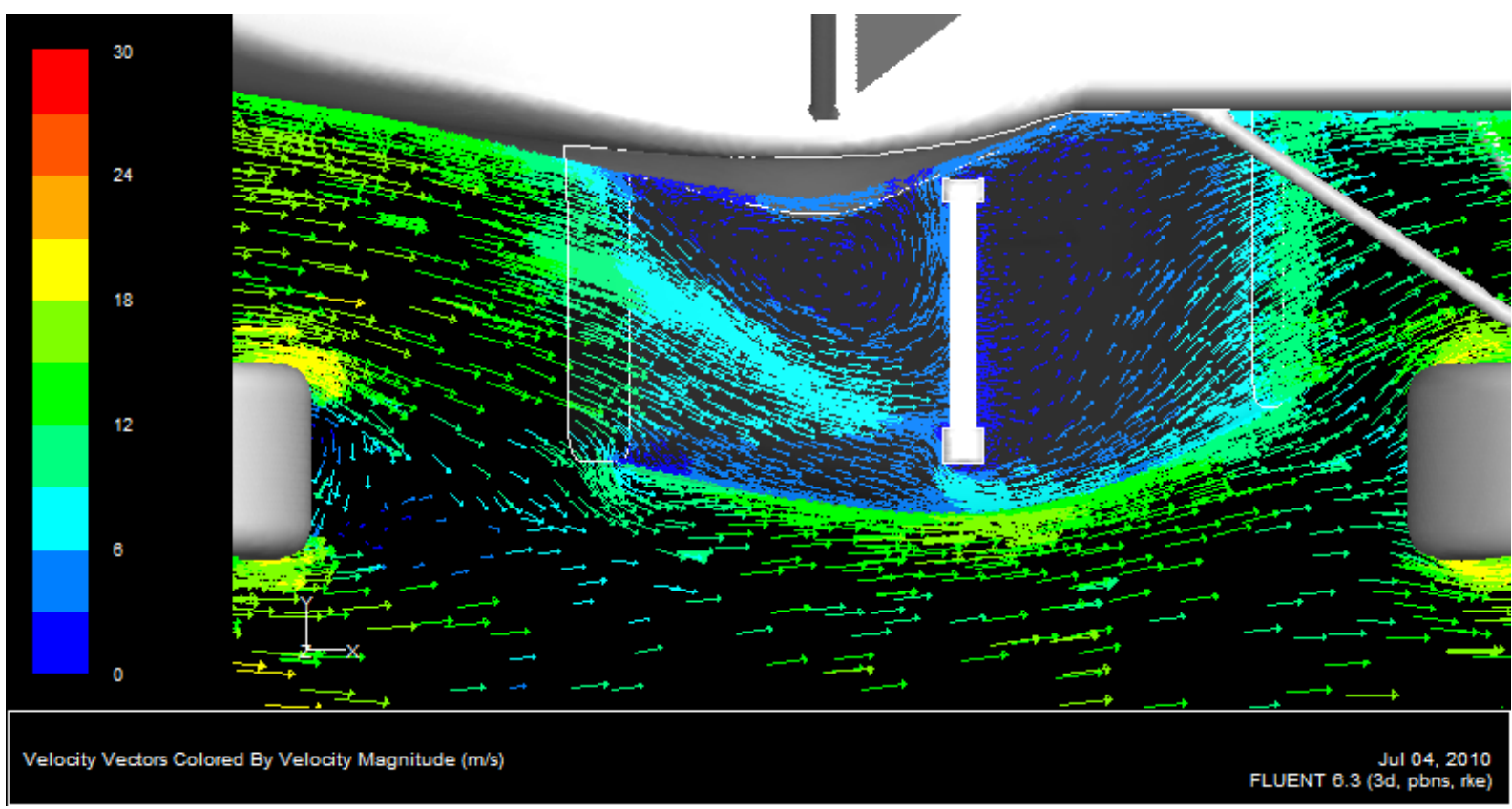

Figura 58 - Vista superior da distribuição de vetores de velocidade na região próxima ao radiador para o protótipo $\mathrm{C}$. 


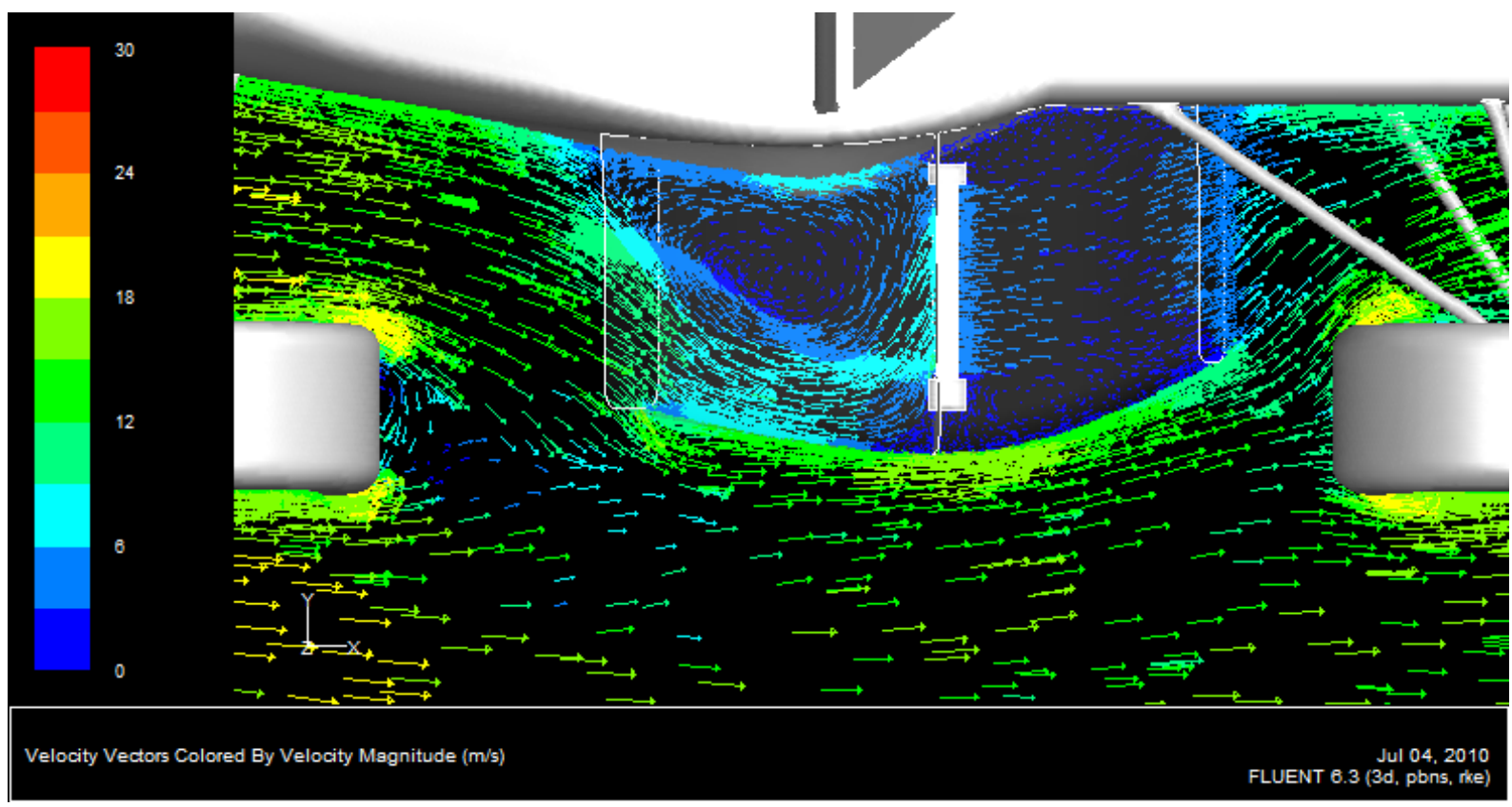

Figura 59 - Vista superior da distribuição de vetores de velocidade na região próxima ao radiador para o protótipo $\mathrm{D}$.

A partir da observação das imagens contidas nas figuras 56 e 59 que trazem os quatro modelos propostos pode-se verificar que:

- Na região interna ao duto que contém o trocador de calor há redução significativa da magnitude dos vetores velocidade comparando com as velocidades no meio externo. O intervalo de variação para as velocidades decresce de $(9$ a 15) $\mathrm{m} / \mathrm{s}$ na região externa ao duto, para (3 a 6 ) $\mathrm{m} / \mathrm{s}$ ou para ( 0 a 3 ) $\mathrm{m} / \mathrm{s}$ na maior parte das regiões internas, dependendo do protótipo adotado.

- Há formação de áreas com recirculação do escoamento no interior do duto, à montante do trocador de calor, claramente identificadas nos protótipos $\mathrm{A}, \mathrm{C} \mathrm{e}$ D.

- Observando os valores de velocidade próximos às faces de entrada e saída do trocador de calor, verifica-se que os maiores valores ocorrem no protótipo 
D. Nos protótipos A, B e C têm-se para os vetores velocidade próximos às faces dos trocadores as seguintes tendências: módulo reduzido ou ter orientação em direções paralelas a estas faces. Nesta última situação, a orientação dos vetores acompanha o escoamento que contorna o trocador de calor, passando nas frestas entre este e o duto.

- Os escoamentos nas seções de saídas do duto divergente-convergente dos protótipos B, C e D possui uma maior densidade de vetores e tendência de aumento de valores para o módulo da velocidade quando comparados ao do protótipo A.

- Nas regiões externas ao duto, verifica-se que a magnitude dos vetores velocidade está compatível com a velocidade relativa veículo-ar, e que na proximidade dos pneus existe uma aceleração adicional provocada pela rotação destes, condição imposta para a simulação. 


\section{ANÁLISE DOS RESULTADOS E CONCLUSÕES}

Neste capítulo são retomadas e analisadas as várias etapas percorridas durante o estudo de trocador de calor compacto inserido em duto, para veículos de competição, assim como avaliados os resultados e apresentadas as conclusões.

\subsection{ANÁLISE DOS RESULTADOS}

A etapa inicial preocupou-se com metodologias para projetar, dimensionar e avaliar os trocadores de calor e como resultado desta etapa o aplicativo TROCALC foi desenvolvido. Em seguida foi adotado um trocador de calor de um veículo de competição como estudo de caso. Foi proposto ensaio experimental do trocador de calor instalado no veículo escolhido para fossem obtidos os resultados térmicos e associados ao escoamento. Na última etapa foi realizada a aplicação de simulação numérica usando programa de Dinâmica dos Fluidos Computacional (CFD) para conhecer as características do escoamento na região do sistema duto-trocador de calor possibilitando complementar as análises anteriores, e acrescentar avaliação aerodinâmica de alternativas para este sistema.

Analisando a evolução de todo projeto conclui-se que teve significativa importância estabelecer o estudo de caso a partir de um veículo real, o carro Fórmula SAE da equipe Poli Racing da Escola Politécnica da USP. Os dados deste veículo, e dos similares da mesma competição foram ponto de referência para desenvolvimentos e testes realizados. Este fato possibilitou a correlação de resultados e modelos escolhidos, teste de aplicativos, estabelecimento de procedimentos e realização de ensaios experimentais no próprio veículo. 
Há uma motivação extra trazida pela competição na qual o veículo Fórmula SAE participa. Isto leva a um desenvolvimento contínuo de estudos para redimensionar o sistema de arrefecimento do veículo com base em cálculos obtidos pelo aplicativo TROCALC. Com base nos dados obtidos, o projeto de novo trocador de calor foi oferecido à equipe com dimensões adequadas às regras da competição.

Nos próximos tópicos são analisados e discutidos os resultados de cada uma das etapas.

\subsubsection{A ferramenta computacional TROCALC}

O primeiro passo para desenvolver 0 aplicativo TROCALC foi identificar a metodologia para elaboração de projeto e análise de desempenho de trocadores de calor. O trabalho de Kays e London (1984), mencionado pela maioria das publicações avaliadas, apresenta metodologia que foi tomada como a principal referência pelo presente projeto e mostrou-se adequada e eficiente.

Dentre os métodos DMLT e Efetividade-NUT estudados e avaliados para apresentação de soluções para trocadores de calor, o método Efetividade-NUT apresentou-se mais apropriado e foi utilizado no desenvolvimento da ferramenta computacional denominada TROCALC.

A ferramenta TROCALC foi estruturada usando como base uma planilha eletrônica da Microsoft Excel ${ }^{\circledR}$. No seu desenvolvimento foi utilizado um conjunto de equações e parâmetros de forma a auxiliar os cálculos relacionados a trocadores de calor compactos. Ela apresentou-se prática, sua operação foi testada inicialmente com cálculos de trocadores de calor encontrados na literatura, e em seguida com os parâmetros do trocador de calor compacto existente no veículo Fórmula SAE.

Um resultado interessante deste aplicativo foi a incorporação de bancos de dados empíricos que relacionam diferentes geometrias para trocadores de calor. Foram 
convertidas em equações ajustadas as relações publicadas por Kays e London (1984), para facilitar sua utilização pelo programa de computador.

Os resultados dos testes foram:

- A análise de desempenho realizada com a condição original do trocador de calor escolhido, de dimensão de $(300 \times 190 \times 25,4) \mathrm{mm}$, apresentou a capacidade de transferência de calor de $q=13,37 \mathrm{~kW}$, valor dentro do limite de rejeição de calor conforme gráfico apresentado pela equipe, que fornece como limite máximo $11,93 \mathrm{~kW}$.

- Para a temperatura de entrada do $\operatorname{ar} \mathrm{T}_{\mathrm{fe}}=25^{\circ} \mathrm{C}$, obteve-se a temperaturas de saída dos de $\mathrm{T}_{\mathrm{fs}}=33,9^{\circ} \mathrm{C}$, que representa um valor de $\Delta \mathrm{T}=8,9^{\circ} \mathrm{C}$;

- A perda de pressão através do trocador de calor $\Delta \mathrm{P} / \mathrm{P}_{\mathrm{atm}}=0,31 \%$.

Os dados de temperatura foram o ponto de partida para 0 projeto de um novo trocador de calor aplicado ao veículo Fórmula SAE.

Para essa condição foram obtidos os seguintes resultados:

- As dimensões para o novo trocador de calor de $(220 \times 160 \times 25,4) \mathrm{mm}$;

- $O$ valor de transferência de calor $q=8,84 \mathrm{~kW}$,

- A perda de pressão através do trocador de calor $\Delta \mathrm{P} / \mathrm{P}_{\mathrm{atm}}=0,65 \%$.

Com base nesses resultados, pode-se observar que:

- A capacidade do novo trocador de calor respeita o valor máximo de 8,20 kW estabelecido para a aplicação do veículo Fórmula SAE. A diferença obtida é de é de $8 \%$ acima do valor de referência; 
- A diferença de volume obtida com o novo trocador de calor é $37 \%$ menor que a condição original, o que representa uma redução em massa de alumínio de $1,5 \mathrm{~kg}$. O radiador original possui massa aproximada de $4 \mathrm{~kg}$;

\subsubsection{Ensaio experimental}

Após o desenvolvimento da ferramenta TROCALC, foram realizados os testes em laboratório com o veículo Fórmula SAE. Foram fabricados os dispositivos necessários para viabilizar os ensaios e foram selecionados instrumentos para a realização dos ensaios. A recomendação técnica da SAE (2008) foi utilizada como base para desenvolver o procedimento de ensaio para medição de transferência de calor em trocadores de calor com aplicação automotiva. Os dados obtidos foram tratados estatisticamente para cálculo das incertezas.

Foram realizados três ensaios estáticos com o veículo em laboratório simulando diferentes condições e foram obtidos dados de transferência de calor e perda de pressão no interior no trocador de calor.

Dentre os resultados obtidos, destacam-se os seguintes dados do ensaio $n^{\circ}-3$ :

- As medidas de temperaturas para o ar foram de $T_{f e}=24,6^{\circ} \mathrm{C}$ e $T_{f s}=38,6^{\circ} \mathrm{C}$, obtendo-se um valor de $\Delta \mathrm{T}=14^{\circ} \mathrm{C}$;

- O valor de transferência de calor obtida foi de $q=7,70 \mathrm{~kW}$;

- A relação de perda de pressão medida foi de $\Delta P / P_{\text {atm }}=0,42 \%$.

Os dados obtidos experimentalmente foram utilizados para novos cálculos com o aplicativo TROCALC e os resultados obtidos foram similares àqueles medidos em teste. Para o valor de transferência de calor obtido no ensaio $n^{\circ} 3$, a ferramenta 
computacional apresentou o valor de $7,75 \mathrm{~kW}$. A diferença representa apenas $0,6 \%$ acima do valor medido.

\subsubsection{Simulação numérica}

Quatro protótipos diferentes do veículo Fórmula SAE foram desenvolvidos utilizando ferramenta CAD e avaliados em programa de simulação numérica. Foi desenvolvida uma nova geometria para o duto, com base no conceito divergente-convergente, utilizada para os protótipos B, C e D. Os dados gráficos obtidos apresentaram o comportamento do escoamento no entorno do sistema duto-trocador de calor e a distribuição de pressões no trocador de calor.

Os dados de $C_{D}$ apresentaram valores similares para os quatro protótipos desenvolvidos, pois não houve variações relevantes no valor de área projetada. $\mathrm{O}$ protótipo $D$ apresentou uma redução de $C_{D}$ de apenas $1,64 \%$ em relação ao protótipo A.

Para as duas condições estudadas, o protótipo $D$ foi o que apresentou melhor resultado em comparação aos demais modelos. A distribuição de pressão no trocador de calor apresentou-se com boa uniformidade na maior parte da região de entrada e saída do trocador. Os valores na entrada variaram entre (80 a 120) Pa na região frontal e entre (0 a 20) Pa na parte posterior, a melhor condição em relação aos demais protótipos.

De forma geral, pode-se afirmar que é apresentada uma área de recirculação de fluxo na parte frontal dos protótipos $A, C$ e $D$. No protótipo $B$ essa recirculação não é evidente, porém é apresentada uma região de descolamento na mesma região. Por se tratar de um fato comum nas quatro propostas, é possível que esse comportamento do fluxo esteja relacionado com a geometria do veículo independente do duto lateral. Nota-se que o perfil lateral do veículo não apresenta geometria em concordância com o duto divergente-convergente. 
Algumas alternativas podem ser adotadas para evitar esse comportamento de recirculação do escoamento e proporcionar melhores condições para o fluxo na região de entrada do sistema duto-trocador de calor. Pode-se fazer uso de difusores na região a montante do trocador de calor para que ocorra a organização do escoamento. Outra possibilidade seria criar aberturas laterais na superfície da vedação na região mais próxima ao compartimento do piloto (cockpit), de modo que o próprio fluxo encontre condições de eliminar a recirculação. Pode-se também reavaliar o posicionamento do radiador ou mesmo na geometria do veículo, porém essas alternativas podem acarretar modificações de maior impacto à estrutura do veículo.

Com base nos demais dados obtidos, destacam-se os seguintes resultados para 0 protótipo A:

- A vazão calculada no radiador de $0,72 \mathrm{~kg} / \mathrm{s}$;

- A relação de queda de pressão $\Delta \mathrm{P} / \mathrm{P}_{\mathrm{atm}}=0,08 \%$.

Esses dados foram utilizados para novos cálculos com o aplicativo TROCALC e os resultados e análise comparativa é apresentada a seguir.

\subsubsection{Comparação dos resultados}

A análise conjunta dos resultados obtidos através do aplicativo TROCALC, dos testes em laboratório e da simulação numérica, foi ajustada em uma tabela que permite uma comparação direta dos dados. 
O objetivo é dispor dados obtidos e avaliar o aplicativo TROCALC apresentando uma relação de integração com outras ferramentas tradicionais de desenvolvimento de sistemas de arrefecimento utilizadas nesse estudo.

Tabela 12 - Resumo dos dados calculados pela ferramenta computacional, dos testes experimentais e da simulação numérica com base no veículo Fórmula SAE da equipe Poli Racing.

\begin{tabular}{|l|c|c|c|c|c|}
\hline \multicolumn{1}{|c|}{ Grandezas (unidades) } & TROCALC - 01 & CFD - Modelo A & Ensaio no 3 & TROCALC - 02 & TROCALC - 03 \\
\hline Vazão ar (kg/s) & 1,50 & 0,72 & 0,55 & 0,55 & 0,55 \\
\hline Vazão líquido (kg/s) & 0,25 & nd & 0,32 & 0,32 & 0,32 \\
\hline Temperatura da ar na entrada $\left({ }^{\circ} \mathrm{C}\right)$ & 25,0 & nd & 24,6 & 24,6 & 24,6 \\
\hline Temperatura do ar na saída $\left({ }^{\circ} \mathrm{C}\right)$ & 33,9 & nd & 38,6 & 38,6 & 28,9 \\
\hline Temperatura do líquido na entrada $\left({ }^{\circ} \mathrm{C}\right)$ & 99,0 & $\mathrm{nd}$ & 46,0 & 46,0 & 46,0 \\
\hline Temperatura do líquido na saída $\left({ }^{\circ} \mathrm{C}\right)$ & 77,5 & $\mathrm{nd}$ & 42,0 & 42,0 & 44,2 \\
\hline Pressão atmosférica $(\mathrm{Pa})$ & 101000 & 101000 & 94763 & 94763 & 94763 \\
\hline Calor rejeitado $(\mathrm{W})$ & 13367 & $\mathrm{nd}$ & 7703 & 7753 & 2404 \\
\hline Pressão diferencial $(\%)$ & 0,31 & 0,08 & 0,42 & 0,07 & 0,07 \\
\hline
\end{tabular}

Legenda

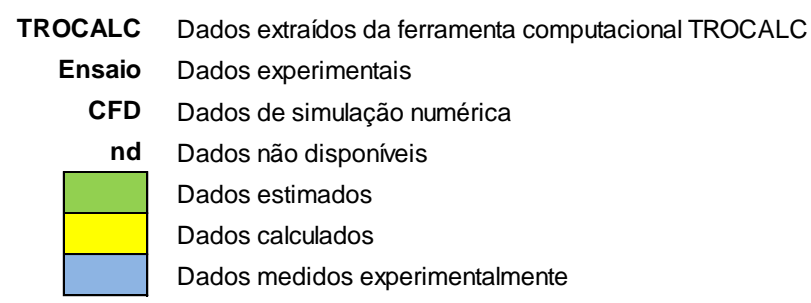

O caso mencionado como TROCALC-01 faz parte dos primeiros cálculos realizados durante o desenvolvimento da ferramenta computacional. Esses dados se referem à análise de desempenho do trocador de calor utilizado pelo veículo estudado.

O conjunto de resultados da análise numérica refere-se ao protótipo $A$ e dispõe-se somente dos dados relativos ao desempenho aerodinâmico, conforme exposto anteriormente. Foi possível avaliar os dados de vazão e diferencial de pressão no radiador.

O ensaio no 3 é parte do conjunto de resultados obtidos através dos testes realizados em laboratório. Foi escolhido esse conjunto para análise devido à 
semelhança de condições com dados disponíveis de temperatura e transferência de calor.

A vazão do líquido de arrefecimento, dado de maior incerteza durante esse desenvolvimento, foi calculada com base nos valores de temperatura e transferência de calor aferidos em testes e expandida para os demais cálculos.

Os demais dados referem-se aos cálculos realizados utilizando a ferramenta computacional em que foram utilizados os dados experimentais do ensaio $\mathrm{n}=3$ como informação de entrada.

Ao avaliar os dados de vazão, nota-se a primeira estimativa para os cálculos com o aplicativo TROCALC acima dos valores medidos em testes e daquele calculado pelo programa de CFD. Para os primeiros cálculos com a ferramenta computacional, foi considerada inicialmente a mesma velocidade do fluxo livre, $60 \mathrm{~km} / \mathrm{h}$, com a hipótese de isenção de perdas na entrada do duto. Os resultados obtidos inicialmente foram justamente a motivação para a realização de ensaios experimentais.

A vazão obtida no teste o 3 foi de $0,55 \mathrm{~kg} / \mathrm{s}$. Considerando a área do fluxo livre do trocador, esse valor representa a velocidade de $11,5 \mathrm{~m} / \mathrm{s}(\approx 41 \mathrm{~km} / \mathrm{h})$. Pela simulação em CFD, utilizando a velocidade do fluxo livre de $60 \mathrm{~km} / \mathrm{h}$, foi possível obter a vazão de $0,72 \mathrm{~kg} / \mathrm{s}$ utilizando um modelo do veículo simplificado. Logo, tais indicativos corroboram para que as vazões em testes e através dos resultados numéricos apresentem uma boa correlação com a condição real do veículo em pista.

Outro fato importante é com relação à condição inicial para estimar valores de vazão. A hipótese utilizada nos primeiros cálculos demonstrou-se uma simplificação de grande impacto para os cálculos finais, de modo a não oferecer resultados com boa relação com as condições de uso do veículo.

Para o arquivo TROCALC-02, todos os dados aferidos durante o experimento foram transferidos para a ferramenta computacional. Com isso, foi possível verificar que a ferramenta apresentou valor para a transferência de calor próximo ao valor de obtido em teste. A diferença de $50 \mathrm{~W}$ representa $0,6 \%$ do valor aferido. 
Foi então desenvolvido o arquivo TROCALC-03 para verificar os resultados dos cálculos da ferramenta computacional sem a inclusão dos dados de temperatura de saída dos dois fluidos, de forma que a própria ferramenta apresentasse estimativas com base na metodologia empregada. Foram obtidos valores de temperatura de saída dos fluidos e de transferência de calor abaixo dos valores verificados em teste. Nota-se que a ferramenta computacional é fortemente dependente dos valores de temperatura inseridos e não somente dos valores diferenciais.

Para os dados obtidos de perda de pressão pelo radiador, foi possível verificar que os dados calculados apresentaram uma boa correlação, tanto pelo CFD quanto pela ferramenta computacional com os casos TROCALC-02 e TROCALC-03, porém o valor obtido experimentalmente está relativamente alto perante os demais. Nesse caso, especificamente para a avaliação de perda de pressão, podem-se reavaliar as condições dos testes. Em discussões com especialistas em projeto e desenvolvimento de radiadores, verificou-se que são utilizadas bancadas específicas com condições de fluxo controladas a montante e a jusante do radiador, de forma a evitar interferências nas medições. No caso dos testes desenvolvidos, as condições de fluxo a jusante estavam direcionadas para 0 ambiente e pode ser 0 fator responsável por essa divergência.

\subsection{CONCLUSÕES}

A aplicação do aplicativo TROCALC ao projeto e à análise de desempenho de trocadores de calor compacto mostrou-se adequada na determinação dos dados de transferência de calor e perda de pressão, quando utilizada em conjunto de dados experimentais e de análise numérica. Em caso de comparação direta com dados experimentais, foi possível obter resultados com variações abaixo de $1 \%$. 
Os testes realizados em laboratório foram de grande contribuição para esse trabalho. Essa atividade não havia sido prevista no momento de elaboração do plano desse estudo, porém foi necessário para obter valores representativos da vazão de ar e representar a melhor condição para avaliar a geometria do núcleo do radiador existente, fazendo o uso da coifa com isolamento ao redor do mesmo.

As características aerodinâmicas do veiculo são diretamente afetadas pela disposição do sistema de troca de calor na carenagem. Uma análise detalhada sobre o acondicionamento do equipamento de rejeição e suas consequências é fundamental para obter $\mathrm{o}$ menor coeficiente de arrasto e combinada com a disposição ótima para a eficiência de troca de calor.

Com os resultados obtidos em testes laboratoriais e com as direções apresentadas com a análise de dinâmica dos fluidos computacional, foi possível verificar a facilidade de integração da ferramenta computacional com os demais meios de obtenção de dados. Através das primeiras estimativas desenvolvidas com essa ferramenta, foi possível direcionar e refinar os valores obtidos e apresentar uma série de possibilidades de análises e direcionamentos para o projeto do veículo. Conclui-se que o aplicativo TROCALC é uma ferramenta de apoio às análises e que não exclui a discussão técnica e a utilização dos métodos tradicionais para obtenção de dados.

O resultado obtido no teste ํo 3 apresenta 0 valor de transferência de calor de $q=7,70 \mathrm{~kW}$, considerando a condição de velocidade de $30 \mathrm{~km} / \mathrm{h}$, sob rotação de $5500 \mathrm{rpm}$. O valor obtido apresenta uma diferença de apenas $0,50 \mathrm{~kW}$ em relação à demanda do sistema de $8,20 \mathrm{~kW}$ sob a rotação aproximada de $8500 \mathrm{rpm}$, representando apenas $6 \%$ dessa condição. Pode-se confirmar que o trocador de calor desenvolvido originalmente para o quadriciclo está superdimensionado para aplicação no veículo da Fórmula SAE, em consideração ao uso que esse veículo se destina.

Para futuros desenvolvimento ou sugestões para novos estudos com base no presente trabalho, as oportunidades a seguir podem ser consideradas: 
- Estudar uma nova geometria do veículo considerando o duto divergenteconvergente, de modo que se obtenha uma carenagem completa em favor do escoamento para o sistema de arrefecimento. A implementação do duto sem a modificação das partes adjacentes do veículo pode influenciar negativamente no comportamento do escoamento no duto;

- Desenvolver um plano de testes para a medição da perda de pressão em avaliação isotérmica, da forma como foi mencionado anteriormente sobre a prática dos fabricantes de trocadores de calor;

- Fazer uso e avaliar a aplicação dos módulos de simulação de transferência de calor de programa de simulação numérica como o FLUENT ${ }^{\circledR}$ e contribuir com os resultados extraídos dos testes e da ferramenta computacional;

- Avaliar outras configurações de duto convergente-divergente, variando as dimensões de entrada e saída para o escoamento e avaliar a contribuição dessa variação em relação à vazão de ar obtido no trocador de calor;

- Da mesma forma como o tópico anterior, propõe-se estudar o posicionamento ou inclinação do trocador de calor e avaliar a contribuição dessas alterações para o aumento da vazão de ar;

- Implementar um banco de dados e/ou equações para as propriedades físicas do ar no aplicativo TROCALC. Essa melhoria pode evitar a inserção de dados errados e enganos com as diversas unidades;

- Estudar em detalhes a influência da recirculação encontrada a montante dos protótipos A, C e D no processo de troca de calor; 


\section{REFERÊNCIAS BIBLIOGRÁFICAS}

BAYRAKTAR, I.; BAYRAKTAR, T. Guidelines for CFD simulations of ground vehicle aerodynamics. SAE paper 2006-01-3544. Chicago: Society of Automobile Engineers, 2006. 9p.

BUSCARIOLO, F. F. Estudo de diferentes tipos de solo em túnel de vento através de simulação numérica. 2009. 151p. Dissertação (Mestrado) - Escola Politécnica, Universidade de São Paulo, 2009.

CARR, G. W. Road vehicle dynamics: Setting the Scene. [S.I.]: Royal Aeronautical Society, 1995.

CHARYULU, D. G.; SINGH, G.; SHARMA, J. K. Performance evaluation of a radiator in a diesel engine: A Case Study. Applied Thermal Engineering, 1999. 15p.

CHRISTOFFERSEN, L.; SÖDERBLOM, D.; LÖFDAHL, L. Improving the cooling airflow of an open wheeled race car. SAE paper 2008-01-2995. Concord: Society of Automobile Engineers, 2008. 15p.

CLAYWELL, M., HORKHEIMER, D. Improvement of intake restrictor performance for a Formula SAE race car through 1D \& coupled 1D/3D analysis methods. SAE paper n. 2006-01-3652. Dearborn: Society of Automobile Engineers, 2006. 26p.

COSTA, E. A.; PINTO, M. G. Cooling and airflow management development for trucks considering pass-by-noise. SAE paper 2002-01-2226. Paris: Society of Automobile Engineers, 2002. 8p. 
CROOK, R. F. 14 rules for improving engine cooling system capability in highperformance automobiles. NARSA (National Automotive Radiator Association). Disponível em

http://www.arrowheadradiator.com/14 rules for improving engine cooling system capability in high-performance automobiles.htm. Acesso em 12 out. 2010.

EMMELMANN, H. J., BERNEBURG, H., Aerodynamic drag and engine cooling conflicting goals. SAE paper 980399. [S.I.]: Society of Automobile Engineers, 1990. $7 p$.

FROLING, T.; JUECHTER, T. 2006 Chevrolet Corvette C6 Z06 aerodynamic development, SAE paper 2005-01-1943. Detroit: Society of Automobile Engineers, 2005, 8p.

FUKUI, J., et al., The development of small formula-style racing car in Osaka University Formula Racing Club. SAE paper n. 2007-32-0122. Osaka: Society of Automobile Engineers, 2007. 4p.

GATTEI, L.; ROSSI, R.; CARDILE, E. A numerical simulation tool for automotive cooling system design. SAE paper 2008-01-0398. Detroit: Society of Automobile Engineers, 2008. 12p.

HUCHO, W. H. Aerodynamics of road vehicles. $4^{a}$ Ed. Butterworths, 1987, 918p.

HUCHO, W. H., JANSSEN, L. J., EMMELMANN, H. J. The optimization of body details: A method for reducing the aerodynamic drag of road vehicles. SAE paper $n$. 760185. Detroit: Society of Automobile Engineers, 1976. 20p.

INCROPERA, F. P.; DEWITT, D. P. Fundamentos de transferência de calor e massa. Rio de Janeiro: Livros Técnicos e Científicos Editora S.A., 1998. 494p.

INMETRO. Vocabulário internacional de metrologia: Conceitos fundamentais e gerais e termos associados (VIM 2008). Rio de Janeiro, 2008, 92 p. 
IPEM (Brasil). Apresenta recurso para conversão de unidades. Disponível em: $<$ http://www.ipem.sp.gov.br/5mt/cv2/index.htm>. Acesso em: 21 de junho de 2010

JASINSKI, W. J., SELIG, M. S. Experimental study of open-wheel race-car front wings. SAE paper 983042. Chicago: Society of Automobile Engineers, 1998. 9p.

JAWAD, B. A., LONGNECKER, M. M. Aerodynamic evaluation on Formula SAE vehicles. SAE paper 2001-01-1270. Detroit: Society of Automobile Engineers, 2001. $9 p$.

JAWAD, B. A., LONGNECKER, M. M., TIMMER, J. S. The impact of aerodynamics on vehicle performance in a Formula SAE racing style vehicle. SAE paper $n$. 2001-01-2744. Detroit: Society of Automobile Engineers, 2001. 5p.

KAYS, W. M., LONDON, A. L. Compact heat exchangers. $3^{a}$ Ed. Stanford: McGraw-Hill, 1984. 336p.

$\mathrm{KOCH}$, F. W., HAUBNER, F. G. Cooling system development and optimization for DI engines. SAE paper 2000-01-0283. Detroit: Society of Automobile Engineers, 2000. 13p.

MARIANI, A. L. C. Desenvolvimento experimental de medidores de vazão tipo multífuro. 1995. 168p. Dissertação (Mestrado) - Escola Politécnica, Universidade de São Paulo, 1995.

MELLO, P. E. B. Análise computacional do desempenho de trocadores de calor compactos com aletas recortadas. 1998. 101p. Dissertação (Mestrado) - Escola Politécnica, Universidade de São Paulo, 1998.

MENOTTI, G. C., BARREIRO, J. A. Aerodinâmica aplicada a veículos comerciais: Otimização de peças de acabamento externo. VIII Congresso e Exposição Internacionais da Tecnologia e Mobilidade. SAE paper n. 1999-01-3012. 1999. 
MUNSON, B. R., YOUNG, D. F., OKIISHI, T. H. Fundamentos da mecânica dos fluidos. $2^{\circ}$ ed. São Paulo: Editora Edgard Blücher Ltda., 2007. 804p.

NG, E. Y., WATKINS, S., JOHNSON, P. W., MOLE, L. Use of a pressure-based technique for evaluating the aerodynamics of vehicle cooling system. SAE paper 2002-01-0712. Detroit: Society of Automobile Engineers, 2002. 14p.

PLINT, M., MARTYR, A. Engine testing: Theory and practice. $2^{\mathrm{a}}$ Ed. Woburn: Butterworth-Heinemann, 1999. 363p.

QUIM, N. Desenvolvimento de uma metodologia de simulação aplicada ao sistema de arrefecimento veicular. 2007. 170p. Dissertação (Mestrado) - Escola Politécnica, Universidade de São Paulo, 2007.

Society of Automobile Engineers - SAE. 2009 Formula SAE rules, Detroit: Society of Automobile Engineers, 2009. 96p.

Society of Automobile Engineers - SAE. Surface vehicle recommended practice, laboratory testing of vehicle and industrial heat exchangers of heat transfer and pressure drop performance, SAE J1994, Warrendale: Society of Automobile Engineers, 2008. 11p.

VERSTEEG, H. K.; MALALASEKERA, W. An introduction to computational fluid dynamics: The Finite Volume Method. $2^{\mathrm{a}}$ Ed. Pearson, 2007, 503p.

WHITE, P.; SMITH, J.; MURDOCH, I. Cooling system performance evaluation. SAE paper 980431. Detroit: Society of Automobile Engineers, 1998. 6p.

WICKERN, G.; WAGNER, A.; ZOERNER, C. Cooling drag of ground vehicles and its interaction with ground simulation. SAE paper 2006-01-0339. Detroit: Society of Automobile Engineers, 2006. 13p. 
Referências Complementares

AGATHANGELOU, B.; GASCOYNE, M. Aerodynamic design consideration of a Formula 1 racing car. SAE paper 980399. Detroit: Society of Automobile Engineers, 1998. $4 p$.

KATZ, J., Race car aerodynamics: Designing for speed, Bentley Publishers, 1995.

RADFORD, D. W., FITZHORN, P. A., STANGLMAIER, R. H., SAKURAI, H. Engineering the motorsport engineering. SAE paper 2006-01-3609. Dearborn: Society of Automobile Engineers, 2006. 12p.

STAFFORD, S. A. Heat exchanger simulation in wind tunnel models. SAE paper 983039. Dearborn: Society of Automobile Engineers, 1998. 7p.

TENNEKES, H.; LUMLEY, J. L. A first course in turbulence. MIT Press, Cambridge, MA, 1972. 


\section{APÊNDICE A - Procedimento de Testes para Medição de Troca de Calor e de Perda de Pressão em Radiadores de Sistema de Arrefecimento Veicular}

\section{Introdução}

Uma das atividades do presente estudo é a apresentação de uma ferramenta computacional para cálculos de troca de calor em sistema de arrefecimento veicular. Com o objetivo de comprovar os valores calculados pelo programa, é proposta a realização de testes experimentais. A seguir é delineado um breve procedimento para realização de teste estático em veículo e é proposto o uso de uma planilha para auxiliar o registro dos valores medidos e realizar os cálculos necessários para conclusão do experimento.

\section{Objetivo}

O objetivo desse procedimento é estabelecer um guia prático para a medição de temperatura, vazão de fluxo de ar e pressão através do trocador de calor do sistema de arrefecimento veicular

Os valores medidos são registrados em uma planilha computacional desenvolvida em programa Microsoft Excel ${ }^{\circledR}$, que contém as fórmulas para realizar os cálculos necessários e que possibilita a verificação da troca de calor realizada pelo sistema de arrefecimento. A planilha de cálculo é desenvolvida com base no trabalho de prática recomendada da SAE (SAE Recommended Practice).

Após os cálculos, é possível comparar o valor de troca de calor aferido experimentalmente com o valor fornecido pela ferramenta computacional proposta pelo presente trabalho. 


\section{Materiais e Métodos}

O trabalho que fundamenta esse procedimento é o relatório de prática recomendada SAE J1994 (cujo título original é Laboratory Testing of Vehicle and Industrial Heat Exchangers for Heat Transfer and Pressure Drop Performance). Esse trabalho determina um procedimento para realizar ensaios experimentais em trocadores de calor de veículos e de sistemas industriais. Com base nesse trabalho, a seguir são apresentadas em detalhes as recomendações para local e instrumentação requerida para proceder os testes.

Para desenvolver o teste, o ambiente, ou laboratório, deve ser adequado para dispor a unidade de teste (veículo) em funcionamento regular, e que seja possível manter o controle da temperatura do ambiente e dos fluidos. Os gases expelidos pelo sistema de escapamento do veículo devem ser direcionados para o ar livre, de forma a não influenciarem as medições e proporcionar um ambiente adequado para realizar os testes.

A instrumentação mínima necessária para desenvolver o teste proposto deve conter indicadores de temperatura (termopares ou termômetros), instrumentação para medição de pressão e vazão de ar (anemômetro de fio quente ou de micro-pás).

A geometria do trocador de calor (principais dimensões e dados do tipo de superfície e construção) deve ser conhecida, bem como dados do motor, como capacidade, potência e combustível utilizado.

A medição de temperatura, pressão e vazão do fluxo de ar é realizada a jusante e a montante do trocador de calor. Essa medição deve ocorrer tomando-se o lado conhecido como "frio" do sistema, que está relacionado com o fluxo de ar. Deve ser realizada também, para referência, a medição de temperatura ambiente.

O automóvel tem seu motor ligado para aquecimento do sistema. No momento em que o sistema de arrefecimento acionar a ventoinha, momento em que se inicia a transferência de massa de ar através do trocador de calor, é possível tomar os 
dados de temperatura, vazão e pressão em dois ou mais pontos a jusante e a montante do radiador.

\section{Resultados}

Para auxiliar a análise dos resultados obtidos em testes, é proposto o uso da planilha de cálculos apresentada a seguir (Tabela 13). Os dados são inseridos nos campos em verde (onde se lê "valores medidos") e a planilha apresenta os valores calculados nos campos em amarelo ("valores calculados").

Após a conclusão dos testes e do preenchimento da planilha proposta, é então possível realizar a comparação direta com os valores calculados teoricamente para o fluxo de calor trocado entre os fluidos do sistema de arrefecimento. 
Tabela 13 - Planilha de auxílio ao cálculo de troca de calor em testes de sistemas de arrefecimento veicular.

Dados do Projeto / Project data:

Número da peça / Part number:

Fabricante / Manufacture:

Data da avaliação / Test date:

Avaliado por / Tested by:

Avaliação $\mathrm{n}^{\circ}$ / Test number:

Tipo do núcleo / Core type:

Dimensões do núcleo / Core size:

Construção do núcleo / Core construction:

Dados de teste / Test Data

Grandeza / Criteria Valores medidos / Measured values

Vazão do fluxo de ar

Cooling gas flow rate

Ug/m

$\mathrm{kg} / \mathrm{min}$

Temperatura do fluxo de ar na entrada

Cooling gas inlet temperature

Temperatura do fluxo de ar na saída

Cooling gas outlet temperature

Pressão do fluxo de ar na entrada

Cooling gas inlet pressure

Pressão do fluxo de ar na saída

Cooling gas outlet pressure

Pressão atmosférica

Barometric pressure

Valores calculados / Calculated values

Diferença de temperaturas de entrada e saída do ar

Cooling gas temperature differential

Diferença de pressão de entrada e saída do ar

Cooling gas pressure differential

Temperatura média do ar

Average cooling gas temperature

Calor específico médio do ar

Average cooling gas specific heat

Transferência de calor em relação ao ar

Cooling side heat transfer $\left(q=m^{*} c p * \Delta T\right)$
${ }^{\circ} \mathrm{C}$

${ }^{\circ} \mathrm{C}$

$\mathrm{Pa}$

$\mathrm{Pa}$

$\mathrm{kPa}$

${ }^{\circ} \mathrm{C}$

${ }^{\circ} \mathrm{C}$

${ }^{\circ} \mathrm{C}$

$\mathrm{kJ} / \mathrm{kgK}$

W
$2 \quad 3 \quad 4$

\begin{tabular}{|l|l|l|l|l|}
\hline & 2 & 3 & 4 & 5 \\
\hline & & & & \\
\hline & & & & \\
\hline
\end{tabular}

Comentários / Remarks: 